\title{
Papers and Posters Presented at the 33rd Annual Meeting of the Psychonomic Society The Adams' Mark Hotel, St. Louis, Missouri November 13-15, 1992
}

\author{
ANIMAL LEARNING I \\ Rose Garden, Friday Morning, 8:00-9:30
}

Chaired by Jennifer J. Higa, Duke University

8:00-8:10 (1)

Latent Inhibition for Responding. ROGER M. TARPY, Bucknell University, DAVID J. PRYBOCK, Arizona State University, \& JEAN E. ROBERTS, Penn College-Rats were allowed, for various periods of time, to press a lever for which they received no consequence. They were then allowed to press to receive a food reward. The more animals pressed during the preexposure period, the lower the rate of subsequent learning. Such latent inhibition for responding appears to depend on total amount of prior exposure to unrewarded leverpressing and is comparable to conventional latent inhibition using stimuli in several interesting ways. 8:15-8:30 (2)

Latent Inhibition From Exposure to Compound Stimuli in Developing Rats. DAVID L. McKINZIE, Binghamton University, WEIJUNG CHEN, University of lowa, \& NORMAN E. SPEAR, Binghamton University (read by Norman E. Spear)-Latent inhibition in Pavlovian conditioning of $\mathbf{A}$ was greater in infant rats following prior exposure to a simultaneous stimulus compound $(A B)$ or a more intense version of $A$ than to $A$ alone or both $A$ and $B$ presented sequentially. These effects differ from those observed in adults and suggest an infantile disposition for configuring simultaneous compounds and encoding the net result amodally in terms of intensity.

$$
\text { 8:35-8:45 (3) }
$$

Anticipatory Contrast, Choice, and Devaluation. CHARLES FLAHERTY \& CYNTHIA COPPOTELLI, Rutgers University-Rats given brief, daily, sequential access to $0.15 \%$ saccharin followed by $32 \%$ sucrose consume less saccharin than rats given two access periods to the saccharin. Is this anticipatory contrast effect due to the devaluation of the initial saccharin solution because it precedes the preferred $32 \%$ sucrose? Data will be presented from choice tests (saccharin that predicts $32 \%$ sucrose versus saccharin that predicts saccharin) and from experiments in which the $32 \%$ sucrose is devalued after the development of anticipatory contrast.

\section{8:50-9:05 (4)}

Range Effects and Dimensional Contrast With Multidimensional Stimuli. JOHN M. HINSON \& LINDA R. TENNISON, Washington State University-Pigeons were trained to discriminate one- and twodimensional visual stimuli. In some cases, stimulus range was extended to assess changes in discrimination of unchanged stimulus values. Dimensional contrast was observed with both unidimensional and multidimensional stimuli. Range effects were also observed in both stimulus sets. Dimensional contrast and range effects in these studies can be explained in terms of changes in attentional allocation.

$$
\text { 9:10-9:25 (5) }
$$

Effects of Food on Rats' Efficient Search of a Radial Arm Maze. W. TIMBERLAKE, W. WHITE, \& K. BELL, Indiana UniversityTimberlake and White (1990) showed that deprived rats searched a radial arm maze efficiently in the absence of any food on the maze. The present studies examined the effects of up to four arms with food on rats' efficiency of search, indexed by number of novel arms chosen, repetition of food arms, and speed of search. The results indicate an important degree of independence between the determinants of efficient search and the ingestion of food.

\author{
PERCEPTION I \\ St. Louis Ballroom B, Friday Morning, 8:00-10:00 \\ Chaired by Christina A. Burbeck, University of North Carolina at Chapel Hill
}

8:00-8:10 (6)

Mental Rotation Occurs Prior to Response Selection. MARK VAN SELST \& PIERRE JOLICOEUR, University of Waterloo (read by Pierre Jolicoeur)-The effect of an orientation manipulation on a mirror/normal judgment concerning a letter was attentuated with increasing overlap in processing times for the mirror/normal judgment and a preceding judgment about whether a tone was a high tone or a low tone. The results are interpreted following Pashler (1992) to indicate that the locus of the orientation effect occurs prior to the response selection phase of information processing.

\section{8:15-8:30 (7)}

The Effect of Environmental Pitch on Apparent Slant. ARNOLD E. STOPER, CRAIG FRIES, \& ABIGAIL BAUTISTA, Califormia State University, Hayward-A rod was viewed in a movable chamber which could be varied in pitch. The apparent slant (pitch) of the rod was judged by manually setting an unseen slant board to be parallel to the viewed rod. A large effect of environmental (chamber) pitch was found, indicating that slant relative to the line of sight (optic slant) was not consciously available to the subjects even though it must have been used as one component of the judgment.

\section{8:35-8:50 (8)}

Form as Information About Scale: Perceiving the Size of Trees. GEOFFREY P. BINGHAM, Indiana University-Physical constraints produce variations in the shape of biological objects that correspond to their sizes. We investigated whether two such properties of tree form can be discriminated and used to evaluate tree height. Observers judged simulated tree silhouettes of constant image size. Comparison was made to judgments of real trees. Tree form conferred an absolute metric on ground texture gradients. The horizon ratio was shown to be ineffective as an alternative source of absolute scale.

8:55-9:10 (9)

Egocentric Spatial Localization and Summation Among Spatially Separated Lines. LEONARD MATIN \& WENXUN LI, Columbia University-Visually perceived eye level (VPEL) was measured in the presence of either one or two parallel pitched-from-vertical lines symmetrically positioned around the median plane in darkness. Eighty-four combinations of pitch, line length, and location were investigated. The slope of the VPEL/pitch function increased linearly with length in the $3^{\circ}-24^{\circ}$ range examined. Summation of influences between line segments horizontally separated by $50^{\circ}$ was as great or slightly greater than summation between coextensive line segments. 9:15-9:30 (10)

What Factors Affect Perceptual Interference? JOAN GAY SNODGRASS \& CHUN RONG LUO, New York University-Perceptual interference occurs when prior exposure to a target's partial features inhibit its later recognition. Two experiments explored basic parameters of the effect, including paradoxical effects of viewing time. An additional five experiments explored the question of whether interference occurs only for limited sets or whether these effects are mediated by performance level differences. We found that interference only occurred when performance attained some moderate level, in accordance with a connectionist model to be described. 


\section{9:35-9:55 (11)}

The Perception of Object Size is Independent of Object Distance. RALPH NORMAN HABER, University of Illinois at Chicago, \& CHARLES A. LEVIN, Baldwin Wallace College-Classic theories of size perception consider only distance cues (size-distance invariance hypothesis) and familiarity as determinants, intertwining size and distance perception. In our experiments, subjects' object-size judgments are independent of distance and dependent on familiarity only if all tokens of each of the objects have the same size. Distance judgments are independent of size, except when distance information is impaired, and then only for objects with size-invariant tokens.

\section{REPETITION/PRIMING EFFECTS I}

St. Louis Ballroom C, Friday Morning, 8:00-9:50

Chaired by Betty Ann Levy, McMaster University

8:00-8:20 (12)

On the Demise of Automaticity. MARIL YN CHAPNIK SMITH, University of Toronto, DEREK BESNER, University of Waterloo, \& HIROTO MIYOSHI, University of Toronto-The received view is that activation of a word's internal representation leads to an automatic spread of activation to related representations, even if subjects are unable to report the prime. The present experiments show that this account cannot be correct. The context in which the prime is presented determines whether semantic priming occurs.

\section{8:25-8:45 (13)}

Dissociative Mediated, Backward and Forward Priming for Lexical Decisions. JAMES H. NEELY \& JOSHUA SLOAT, SUNY at Albany-For lexical decisions, small, but statistically significant, mediated priming effects were unaffected by changes in either the relatedness proportion (RP), the probability that word primes and targets were related, or the nonword ratio (NWR), the probability that a target is a nonword when the prime and target are unrelated. Forward priming increased as RP increased but was not affected by the NWR. Backward priming occurred only if both the RP and NWR were high. These effects pose problems for current theories of priming.

$$
\text { 8:50-9:05 (14) }
$$

Retroactive Priming in a Serial Target Detection Task. IRA H. BERNSTEIN \& PAUL R. HAVIG, University of Texas at ArlingtonWe describe a task in which priming-like effects are largely retroactive rather than proactive, in contrast to more traditional priming effects. The task involves sequential reporting of letter strings in which a target letter has a .5 probability of appearing versus not appearing at each of four locations. Target stimuli at a given location are much more likely to evoke a target response at preceding as opposed to succeeding locations.

$$
\text { 9:10-9:25 (15) }
$$

Repetition Blindness Interacts Dramatically With Word Frequency. LARRY HOCHAUS \& JONI L. MIHURA, Oklahoma State University-Repetition blindness is the failure to identify repeated words when visually presented in rapid succession. Experiments 1 and 3 show the repetition blindness effect is limited to high-frequency words and shifts to facilitation when rare words are used. Experiment 2 shows repetition blindness is unaffected by number of meanings. The interaction of repetition blindness and frequency rules out several response bias explanations of repetition blindness and was predicted by MacKay's node network theory.

$$
\text { 9:30-9:45 (16) }
$$

Consonant String Frequency Affects Detection of Repeated Letters. LESTER E. KRUEGER, LEANN M. STADTLANDER, \& LAUREN SUE SEIFERT, Ohio State University-The presence versus absence of letter repetition was discriminated more rapidly and more accurately when the sequence of nonrepeated context letters in the consonant string had been presented more frequently. When the context pattern appeared more frequently with one response (repetition present/absent), it induced a bias toward that response. Transfer tests showed that these effects were restricted to the lettercase (lower/upper) used in training.

\section{LETTER/WORD PROCESSING I \\ St. Louis Ballroom D, Friday Morning, 8:00-9:55}

\author{
Chaired by Susan A. Duffy, Amherst College
}

\section{8:00-8:20 (17)}

Reading Exception Words and Pseudowords: Are Two Routes Really Necessary? DAVID C. PLAUT, JAMES L. MCCLELLAND, CarnegieMellon University, \& MARK S. SEIDENBERG, University of Southern Califormia (read by James L. McClelland)-Many theorists claim that applying linguistic transformations to novel items requires rules and that handling exceptions requires a lexicon. Connectionist models have challenged this "dual route" assumption but have not performed well enough with novel items. We trained three different models to read a corpus of 2,998 words. All learned the corpus, including the exceptions, and all read nonwords much better than previous models. We discuss the "dual route" assumption in light of the results.

\section{8:25-8:45 (18)}

What Eye Fixations Tell Us About Phonological Recoding During Reading. MEREDYTH DANEMAN, EYAL M. REINGOLD, University of Toronto, Erindale College, \& MURRAY STAINTON, York University-Evidence for phonological recoding during reading has depended on paradigms requiring subjects to perform a secondary task (e.g., lexical decision, meaningfulness judgments) while reading. Our subjects simply read text for comprehension, and their eye movements were monitored for disruptions when encountering homophonic versus nonhomophonic errors (He wore blew/blow jeans). Homophones were no less disruptive when initially encountered, but they were faster to repair. We discuss implications for the temporal course of phonological access.

\section{8:50-9:00 (19)}

Use of Phonological Codes During Word Fixations in Reading. ALBRECHT INHOFF \& RICHARD TOPOLSKI, SUNY at BinghamtonEye movement measurements during passage reading showed similar viewing times on regular and irregular target words. Targets in Experiment 2 were pseudohomophones (brane) and visually similar nonwords (brame), contextually compatible (brain) and incompatible words (home). Initial viewing times for compatible words and pseudohomophones did not differ but were elevated in the remaining conditions. Pseudohomophones were refixated and required similar gaze times as similar nonwords. Use of phonological codes may thus occur during initial lexical analysis.

\section{9:05-9:25 (20)}

Priming From Ignored Information in Reading: Qualitative Differences Between Orthography, Phonology, and Semantics. DEREK BESNER, University of Waterloo, \& MARLENE BEHRMANN, Rotman Research Institute and University of Toronto-We report a series of experiments in which readers must ignore part of a display in order to respond correctly (e.g., name the underlined portion in FARM vs. PHARM vs. GARM). Additional experiments show that semantic as well as orthographic and phonological knowledge from the whole word influences performance. The data require an account in which multiple knowledge levels are concurrently active, but manifest their effects in qualitatively different ways.

\section{9:30-9:50 (21)}

Naming in a Shallow Orthography is Mainly Prelexical: Evidence From Hebrew. RAM FROST, Hebrew University-The use of prelexical and lexical phonology was examined in pointed (shallow) and in unpointed (deep) Hebrew orthography. Larger frequency and semantic priming effects were found in naming unpointed rather than pointed print. When the presentation of vowel marks was delayed, subjects were inclined to wait for the vowels to appear even though the words could be named unequivocally using lexical phonology. These results suggest that prelexical phonology is the default strategy for the reader in shallow orthographies. 


\section{HUMAN LEARNING/MEMORY I \\ Promenade C, Friday Morning, 8:00-10:05}

Chaired by Suzanne B. Lovett, Bowdoin College

8:00-8:15 (22)

de Groot Recalled: Reconstructive Recall of the Scientific Literature. KIM J. VICENTE, University of Toronto, \& WILLIAM F. BREWER, University of Illinois (read by William F. Brewer)-We have discovered that the classic study of expertise in memory for chess positions by de Groot (1946) is frequently distorted in secondary texts. Analysis of these distortions suggests that they are examples of schema-based reconstructive recall. Two memory experiments, one using research psychologists and one using undergraduates, replicate the distortions frequently found in the published literature and thus support the reconstructive memory account of the errors in the secondary texts.

$$
\text { 8:20-8:35 (23) }
$$

Very Long-Term Encoding Specificity. RUTH S. DAY, Duke University -The encoding specificity principle demonstrates that memory is excellent when cues presented during acquisition and recall are the same. This research suggests that the principle is even more powerful than previously thought-its effects can last for years and the forgetting function resembles those found for more semantic (as opposed to episodic) tasks. Implications for general theories of memory are discussed.

$$
\text { 8:40-8:55 (24) }
$$

Modeling Time-of-Week Memory. STEEN F. LARSEN, University of Aarhus, \& CHARLES P. THOMPSON, Kansas State University (sponsored by Charles $P$. Thompson)-Knowledge about time of week in dating autobiographical events produces a scalloped absolute error distribution. This study shows that the shape of the distribution remains invariant over retention intervals up to 14 months. However, the shape changes with type of event (news vs. autobiographical). The data are fitted with a model which integrates the time-of-week information available to the subject with a factor of random guessing.

$$
\text { 9:00-9:20 (25) }
$$

Relation of Recall Output Time and Accuracy in STM. BARBARA ANNE DOSHER \& JIAN-JIANG MA, Columbia University-Short-term memory span for digits, letters, and words was measured by keypress recall. Across materials, $50 \%$ accuracy corresponded to about $6 \mathrm{sec}$ in recall duration (first to final response)-approximately triple Baddeley's (1986) span limit of $2 \mathrm{sec}$ in pronunciation time. Recall duration (often quadratic with list length) was a slightly better predictor of span than pronunciation time (linear with list length). A model of decay during recall is discussed.

\section{9:25-9:45 (26)}

Theories of Associative Priming. TIMOTHY P. McNAMARA, Van derbilt University-Associative priming is usually attributed to the spread of activation or to the construction of compound retrieval cues. We assess the relative abilities of these theories to account for priming in the absence of association (including "nonmediated priming"), the relationship between free association and priming, priming that spans an intervening item, and the effects of different types of primes (e.g., words vs. nonwords).

\section{9:50-10:00 (27)}

A Modality Effect at Early List Positions. ALLISON R. MARKS \& ROBERT G. CROWDER, Yale University (read by Robert G. Crowder)-Three experiments indicated that presentation modality affected free recall of early list items in the distractor paradigm. When arithmetic distractors were presented silently after each target memory word, visually presented stimuli were remembered better than vocalized stimuli. These results were consistent with a modification of Neath and Crowder's (1990) extended version of the Ratio Rule, a temporal-distinctiveness model of serial-position effects. A fourth experiment tested and generally supported this model.

\section{PSYCHOLINGUISTICS I \\ Promenade D, Friday Morning, 8:00-9:45}

\section{Chaired by Janet L. McDonald, Louisiana State University}

\section{8:00-8:15 (28)}

Heredity, Maturation, and Proficiency in Sentence Comprehension. DAVID J. TOWNSEND, Montclair State College, THOMAS G. BEVER University of Rochester, \& CAROLINE CARRITHERS, Rutgers University-Computational models attribute proficient comprehension to the overall efficiency of working memory, while genetic models emphasize the independence of linguistic computations. In three experiments, we compared right-handed subjects who differed in comprehension skill, familial handedness background, and age. The results favored computational predictions for children and genetic predictions for adults. We discuss various interpretations of these age differences and develop a model that integrates computational and genetic factors in the acquisition of linguistic proficiency.

\section{8:20-8:40 (29)}

Rules or Connections? The Past Tense Revisited. MARK S. SEIDENBERG, University of Southerm California, \& KIM DAUGHERTY, Hughes Aircraft Company and University of Southern California-A seemingly minor aspect of language-the past tense of verbs-has generated considerable debate over the role of connectionist models in explaining language. We describe a simple back-propagation network that learns regular and irregular past tenses with good generalization, and simulates data from experiments on past tense generation. The same principles govern this model as the Seidenberg and McClelland pronunciation model, suggesting a common underlying basis for the two types of knowledge.

\section{8:45-9:00 (30)}

Controlling Number Agreement on Verbs and Anaphors. KATHRYN BOCK, University of Illinois, KATHLEEN M. EBERHARD, Michigan State University, \& J. COOPER CUTTING, University of Illinois-English speakers must track the number of the sentence subject to carry out verb agreement and anaphor agreement. These different kinds of agreement may call on different kinds of number information, either conceptual or grammatical. To examine this, we varied the features of spurious number controllers in production tasks that elicited agreement errors on verbs and tag pronouns. The results suggested that speakers are more likely to use conceptual number for anaphors than for verbs.

\section{9:05-9:20 (31)}

Disorientation Affects Mixed-Case More Than UPPERCASE Words. KEVIN JORDAN \& LAREE A. HUNTSMAN, San Jose State University-Disoriented words produce longer lexical decision times than do upright words. This effect is often attributed to the need for mental rotation prior to further processing. Since this phenomenon has been reported only for uppercase words, we hypothesized that a mixed-case format would provide observers with cues to the location of the beginning of disoriented words for subsequent processing; no mental rotation would be required. Contrary to this expectation, disoriented mixed-case words produced longer lexical decision times than uppercase words.

\section{9:25-9:40 (32)}

What Causes Repetition Deafness? A Test of Seven Hypotheses. DONALD G. MACKAY \& MICHELLE MILLER, UCLA-Why is immediate recall more difficult for repeated than unrepeated words in computer-compressed speech? Experimental results reported here indicate that repetition deafness does not reflect response bias, cognitive capacity, criterion shifts, perceptual fusion of repeated words, a refractory period phenomenon, or any theoretical process that is inhibitory in nature. Rather, repetition deafness reflects a binding problem resulting from the extra time required to form two connections from the single node that represents repeated words. 
ANIMAL LEARNING II

Rose Garden, Friday Morning, 9:40-11:45

Chaired by David R. Thomas, University of Colorado at Boulder

9:40-10:00 (33)

Rescaling the Peak Force of Operant Beam Presses in Rats. JASPER BRENER, ANDREW SLIFKIN, \& SUZANNE H. MITCHELL, SUNY at Stony Brook-The peak force (PF) of isometric beam presses is the product of the rate of force augmentation $(\mathrm{dF} / \mathrm{dT})$ and the duration of force augmentation (Tpf). Experiments show that both factors contribute to raising peak response force when reinforcement contingencies demand higher PFs. Decreases in the probability of reinforcement elicit transient increases in Tpf but do not influence dF/dT. However, differential reinforcement of higher PFs results in long-term elevations of $\mathrm{dF} / \mathrm{dT}$ but does not influence Tpf.

\section{0:05-10:15 (34)}

Vasopressin and Telemetered Physiological Responses. HELEN M. MURPHY \& CYRILLA H. WIDEMAN, John Carroll UniversityTelemetered activity and core body temperature were recorded daily in vasopressin-containing (LE) and vasopressin-deficient (DI) rats under ad-lib and food-restricted conditions. Although circadian rhythms of activity and body temperature were similar in DI and LE rats during the ad-lib condition, the food-restricted condition produced marked differences, with DI animals showing an increase in activity and a decrease in body temperature. Vasopressin appears to play a modulatory role in foodrestriction stress.

\section{0:20-10:40 (35)}

Experience With Uncontrollable Aversive Events Is Exhausting THOMAS R. MINOR, UCLA-Behavioral and pharmacological data will be presented which suggest that intense, chronic fear during inescapable shock in the "learned helplessness" paradigm eventually compromises brain energy metabolism in rats. Rapid hydrolysis of ATP under these circumstances increases brain adenasine, which potently inhibits neural transmission and causes behavioral symptoms of conservationwithdrawal in helpless animals.

$$
\text { 10:45-11:00 (36) }
$$

The Biological Function of Pavlovian Conditioning: Long-Term Advantages of Winning Territorial Contests. KAREN L. HOLLIS, MICHELLE J. DUMAS, PAULA FACKELMAN, \& PIYUSHA SINGH, Mount Holyoke College-Previous work with blue gourami fish has shown that Pavlovian conditioning of aggressive behavior enhances the ability of males to defend their territories in signaled contests. Recent studies show that this advantage of signaling may persist long beyond the signaled encounter; subsequent territorial contests are affected greatly by a male's history of winning or losing. These results are discussed in light of well-known neuroendocrinological changes associated with winning and losing aggressive contests.

\section{1:05-11:20 (37)}

Pavlovian Sexual Conditioning: Omission Contingency Tests. LAWRENCE L. CRAWFORD \& MICHAEL DOMJAN, University of Texas at Austin (read by Michael Domjan)-Male Japanese quail learned to approach a light that was paired with visual exposure to a female quail in a Pavlovian conditioning procedure. The addition of an omission contingency for the approach response did not yield lower levels of responding than a yoked control procedure either in acquisition or in the maintenance of the conditioned behavior. The results suggest that sexual approach conditioning is mediated primarily by Pavlovian rather than instrumental contingencies.

\section{1:25-11:40 (38)}

Matching Behavior in Self-Stimulating Rats: Computational Implications. TERRENCE A. MARK \& C. R. GALLISTEL, UCLA (read by C. R. Gallistel)-Rats allocate their time between two self-stimulation levers in accord with the relative abundance of reward, where relative reward abundance is the product of the subjective magnitude of individual rewards and the number of rewards obtained per unit time. The time-allocation ratio tracks relative reward abundance on a time scale on the order of one interreward interval; hence, matching cannot be correctly calculated from session totals.

\section{PERCEPTION II \\ St. Louis Ballroom B, Friday Morning, 10:10-12:00}

Chaired by Paula Goolkasian, University of North Carolina at Charlotte

10:10-10:30 (39)

Visual-Motor Effects of Prolonged Exposure to $2 \mathrm{~g}$ in the Human Centrifuge. ROBERT B. WELCH, MALCOLM M. COHEN, \& CHARLES W. DEROSHIA, NASA-Ames Research Center-Exposure to $2 \mathrm{~g}$ ( $\mathrm{Z}$ axis) for approximately $27 \mathrm{~min}$ in a human centrifuge induced the "elevator illusion" (apparent elevation of a visual target), which gradually declined in magnitude over the course of the exposure period. Underreaching for an unseen target occurred at the outset of hypergravity. These errors were quickly overcome by means of adaptation and were followed by a transient negative aftereffect in $1 \mathrm{~g}$. The effects of errorcorrective visual feedback during target-pointing were examined.

10:35-10:55 (40)

Further Tests of Feature-Module Architectures for Color and Form. MICHAEL KUBOVY \& DALE COHEN, University of Virginia-Gestalt detection (= RSVP + grouping): a target texture that has a boundary, is embedded in a sequence of scrambled distractor textures. A boundary is defined by color, form, or both. When both, the two boundaries may coincide. The subject reports the location of one boundary. Last year, we presented data for targets $>167$ msec: detection of dual-feature coincident boundary is better than probability summation of individual boundaries. This year, we report on briefer target durations.

\section{1:00-11:15 (41)}

Processing Multidimensional Stimuli. LAWRENCE E. MARKS, John B. Pierce Laboratory and Yale University-Sensory/perceptual systems process stimuli contextually, relative to other recently presented stimuli: Even brief stimulus exposures can produce marked changes in response (loudness, brightness, taste intensity, vibration intensity) that are specific to the make-up of the stimulus (its sound frequency, wavelength, chemical composition, vibration frequency). Such qualityspecific, "adaptation"-like effects, which are revealed when stimuli vary multidimensionally, are general characteristics of perceptual processing; they probably represent central adjustments in sensitivity.

11:20-11:40 (42)

Texture Segregation. JACOB BECK \& WILL GOODWIN, University of Oregon-Experiments will be reported on how (1) perceived texture segregation depends on the interchange of light and dark values in a discrepant quadrant and (2) how the background intensity affects the perceived texture segregation of isoluminant squares differing in hue arranged in striped and checked patterns. There is increasing evidence that texture segregation depends on differences in the outputs of spatialfrequency channels. The implications of the experimental results for such theories will be considered.

$$
\text { 11:45-11:55 (43) }
$$

Perceived Area: Within Shape and Across Shape Discriminations. CHRISTINA A. BURBECK \& DAN ARIELY, University of North Carolina at Chapel Hill-Area discrimination thresholds for same-shape comparisons with circles or squares were lower than the comparable length or height thresholds, whereas length thresholds for a cross (two length samples) were raised. Area judgments between unlike shapes and for sums of multiple objects were substantially elevated. Thus, although observers can accurately discriminate between like objects on the basis of area (not just length), they do not appear to have an accurate abstract representation of area.

\section{REPETITION/PRIMING EFFECTS II}

St. Louis Ballroom C, Friday Morning, 10:00-12:15

Chaired by Marilyn C. Smith, University of Toronto

10:00-10:20 (44)

Strategic Versus Automatic Influences of Memory: Attention, Awareness, and Control. LARRY L. JACOBY, McMaster University-Rather than identifying different processes with different tasks, as is done when interpreting task dissociations between performance 
on implicit and explicit tests, the experiments that are to be reported made use of a process dissociation procedure to separate the withintask contributions of strategic and automatic influences of memory. Factors such as dividing attention during the study presentation of items reduce later ability to engage in strategic or consciously controlled use of memory, but leave automatic or unconscious influences invariant.

\section{0:25-10:45 (45)}

Transfer of Fluency Across Repetitions and Across Texts. BETTY ANN LEVY, McMaster University-A series of studies indicate that the text representation that mediates more fluent reading across repetitions is an "episodic" record containing information about text and lexical properties of the passage. Transfer is not mediated by abstract word representations. Similarly, the memorial record from one text will facilitate the reading of a different text, if the messages are related, but not if only a large number of words are shared by the two texts.

\section{0:50-11:10 (46)}

Implicit Memory for Speaker's Voice: Intonation and Fundamental Frequency. BARBARA A. CHURCH \& DANIEL L. SCHACTER, Harvard University (read by Daniel L. Schacter)-Previous research has shown that priming of spoken words on an auditory stem completion task is reduced when speaker's gender is changed between study and test. We examined whether similar effects occur within a single voice, and found that priming on auditory identification and completion tasks was reduced by study/test changes in voice intonation or fundamental frequency. Additional studies suggest that a cortically based perceptual subsystem plays a role in voice-specific priming.

\section{1:15-11:30 (47)}

Interference Versus Facilitation as Measures of Implicit Remembering. COLIN M. MACLEOD, University of Toronto, Scarborough Campus-Three experiments examined word-naming facilitation and colornaming interference as latency measures of implicit remembering. Prior study always facilitated naming a studied word aloud, even with long studytest intervals. However, color-naming interference was identical for studied and unstudied words, even when color naming immediately followed study of the irrelevant word. Priming is very operation-specific: When attention is directed to the same stimulus in a different way at study and test, priming may not appear on that test.

\section{1:35-11:50 (48)}

The Simon Then Garfunkel Effect: Semantic Priming and the Modularity of Mind. GILLIAN RHODES, University of Canterbury, ALAN PARKIN, Sussex University, \& TANYA TREMEWAN, University of Canterbury - The central claim of modularity (Fodor 1983, 1985 ) is that perceptual input analyzers are encapsulated from central knowledge and expectancies. We addressed three questions that are relevant to assessing this claim: (1) Does semantic priming affect sensitivity? (2) Does sensitivity change when priming cannot be mediated by direct, associative, within-module links? (3) Are the sensitivity changes genuine perceptual effects? Our results indicate a positive answer to all three questions and so challenge modularity.

\section{1:55-12:10 (49)}

Cross-Language Semantic Priming: Evidence for Independent Lexical and Conceptual Contributions. JUDITH F. KROLL, Mount Holyoke College, ALEXANDRA SHOLL, JEANETTE ALTARRIBA, University of Massachusetts-Amherst, CHRISTINE LUPPINO, LISA MOYNIHAN, \& CAROLINE SANDERS, Mount Holyoke College-Lexical decision is typically primed by a variety of semantic/associative relations whereas naming is primed only by the presence of highly associated words. We used this dissociation to examine lexical and conceptual contributions to cross-language priming. For a group of relatively fluent English-Spanish bilinguals, category relations produced priming only within the first language. In contrast, highly associated antonyms produced both withinand across-language priming. The implications for models of bilingual memory representation will be discussed.

\section{3-D/MOVEMENT PERCEPTION I \\ St. Louis Ballroom D, Friday Morning, 10:05-12:20}

Chaired by Mary K. Kaiser, NASA-Ames Research Center

10:05-10:15 (50)

Depth Perception of Stereoscopically Presented Virtual Objects Interacting With Real Background Patterns. STEPHEN R. ELLIS, NASA-Ames Research Center and University of California, Berkeley, \& URS J. BUCHER, NASA-Ames Research Center (read by Urs J. Bucher)-The influence of physically presented background stimuli on the perceived depth of spatially extended, stereoscopic virtual images has been studied using a head-mounted virtual environment display. This display allows presentation of physically unrealizable stimulus combinations. Interposition of a physical background at the perceived depth of the virtual image causes it to appear closer to the observer. Two alternative explanations for the phenomena appealing to either oculomotor processes or Gestalt organizational principles have been investigated. 10:20-10:35 (51)

The Dimensional Distribution of Stereoscopic Depth Mechanisms: Answers and Questions. CHRISTOPHER W. TYLER, SmithKettlewell Institute-Mechanisms of binocular combination for stereoscopic depth reconstruction may be distributed through three types of stimulus dimension: retinal space, binocular disparity, and spatial tuning. A combination of previous and new evidence indicates multiple binocular mechanisms along each of these dimensions. Do these represent a single set of mechanisms with covariant properties, limited to the main diagonal or a subplane of the three dimensions, or are the mechanisms distributed independently throughout this 3-D space?

10:40-10:55 (52)

The Stereo Aperture Problem and Anisotropies in Stereo Depth Thresholds. ELIZABETH THORPE DAVIS, ROBERT A. KING, \& ALANA ANOSKEY, Georgia Institute of Technology-The receptive field profiles of left and right monocular inputs can affect stereoacuity. If retinal disparity is encoded by differences in spatial phase of monocular inputs, a "stereo aperture problem" occurs. That is, only disparities perpendicular to the pattern's orientation are encoded. This problem does not occur for spatial position encoding of disparity. Results for vertical and oblique patterns suggest spatial phase encoding. Results for horizontal patterns, however, suggest spatial position encoding.

11:00-11:15 (53)

3-D Determinants of Object Perception Under Occlusion. JOHN MONTEROSSO, University of Pennsylvania, \& PHILIP J. KELLMAN, Swarthmore College (read by Philip J. Kellman)-Binocular disparity, observer-contingent motion, and 3-D positioning of real objects were used separately to study 3-D unit formation under occlusion. Subjects rated perceived connectivity of two visible surfaces, one above the other, separated by a horizontal occluder. Visible parts varied in relative rotations around the $\mathrm{X}$ and $\mathrm{Y}$ axes, and $\mathrm{Z}$ translation (egocentric distance). Most results were compatible with a straightforward generalization to 3-D of the boundary interpolation model proposed by Kellman and Shipley (1991).

\section{1:20-11:35 (54)}

Perceiving the Slope of Natural Terrains. DENNIS R. PROFFITT \& MUKUL BHALLA, University of Virginia-The perceived inclination of hills is extremely distorted. What anyone would call a very steep hill-the steepest mountain ascent in the Tour DuPont bicycle rate-is no more than $9^{\circ}$. Assessments were made using verbal, visual, and tactile dependent measures of perceived inclination in outdoor contexts, stereo head-mounted virtual realities, and stereo computer terminal displays. In general, small inclines are greatly overestimated, and all unnaturally steep inclines appear to be nearly vertical.

\section{1:40-11:55 (55)}

Priming of Structural Representations of Three-Dimensional Objects. LYNN A. COOPER, Columbia University, \& DANIEL L. 
SCHACTER, Harvard University-Subjects studied realistic, depth-cued renderings of abstract, three-dimensional (3-D) objects. Memory for the objects was subsequently probed via either an implicit (determining the symmetry/asymmetry of individual objects) or an explicit (old/new recognition) test. Robust priming was exhibited for symmetric objects, following study conditions that emphasized the objects' 3-D structure. Effects of both encoding manipulations and study-to-test transformations of object attributes on priming and recognition are described.

\section{2:00-12:15 (56)}

Stereoacuity and Pulfrich Effect Magnitude. HARUTUNE H. MIKAELIAN \& SHARON STRATTON, University of New Brunswick-Pulfrich effect (PE) magnitude, using foveal vision, was correlated with stereoacuity (random dot stereograms). As reported by Thompson and Wood at ARVO (1991), no reliable correlations were found. Peripheral viewing generated significantly larger PE magnitude, although again no reliable correlations between stereoacuity and PE magnitude were observed. Thus, although some subjects could not use retinal disparity to perceive depth (in random dot stereograms), temporally induced equivalent disparity appears to be effective in producing vivid depth percept.

\section{REASONING}

Promenade C, Friday Morning, 10:15-12:25

Chaired by Tom Trabasso, University of Chicago

\section{0:15-10:25 (57)}

Covariation and Necessity on a Reasoning Task. JOHN B. BEST, Eastern Illinois University-The logical deduction game Mastermind was used to investigate the use of a covariation heuristic in reasoning. Subjects were presented with single hypotheses and chose one of four follow-up hypothesis/feedback pairings. When asked to make all possible logical deductions from the resultant two-hypothesis/feedback grouping, subjects concluded that colors that had been held constant across the two hypotheses must be included in the code regardless of both the feedback and the color's actual logical status.

\section{0:30-10:45 (58)}

Both Pragmatic and Structural Constraints Guide Analogical Mapping. BARBARA A. SPELLMAN \& KEITH J. HOLYOAK, UCLA (read by Keith J. Holyoak)-Theories of analogical mapping make differing claims concerning whether mapping is influenced by pragmatic as well as structural constraints. We constructed analogs that mapped ambiguously, and manipulated subjects' beliefs about the importance of specific objects and relations in source and target analogs by asking subjects directed questions. Subjects' subsequent mappings were guided by pragmatic demands, which could partially offset opposing structural and semantic pressures. Results indicate that the influence of pragmatics could not be attributed solely to subjects ignoring unemphasized information.

\section{0:50-11:05 (59)}

The Relationship Between Comprehension Ability and Metacomprehension. RUTH H. MAKI, North Dakota State University-The relationships between comprehension ability and subjects' abilities both to predict their performance over text material and to assess their levels of performance after the tests were examined. The Nelson-Denny comprehension test and Gersbacher, Garner, and Faust's (1990) Multi-Media Comprehension Battery were used to measure comprehension ability. Although there was no evidence that comprehension ability related to the ability to predict, positive correlations were found between posttest assessments and comprehension ability.

$$
\text { 11:10-11:30 (60) }
$$

The Rashomon Phenomenon: Understanding Memory Differences for the Same Event. NANCY L. STEIN, MARIA LIWAG, \& DANIEL WEBSTER, University of Chicago-When two people remember an event where one person has experienced an emotional reaction, what types of theories best describe the structural and content properties of each representation? What theory best describes and predicts the commonalities and differences in the two representations? A study will be presented where parents and children recall emotional events in which children have experienced specific emotions while parents have been observers or participant/observers of the emotional event.

\section{1:35-11:55 (61)}

How Do People Judge Whether a Regularity is Causal? YUNNWEN LIEN \& PATRICIA W. CHENG, UCLA (read by Patricia W. Cheng)-Some regularities are causal (e.g., touching a red-hot poker and burning one's hand); others are not (e.g., the ringing of an alarm clock that coincides with sunrise). Whereas causal regularities support inference, accidental regularities do not. Our experiment tests the role of coherence in differentiating causal from noncausal regularities. Coherence was operationalized in terms of consistency across regularities at different levels of abstraction. Coherent regularities were judged more causal than incoherent ones.

$$
\text { 12:00-12:20 (62) }
$$

Responding Correctly to Invalid Syllogism Problems: The Four Fundamental Facts. MARVIN LEVINE \& MICHAEL CASSIDY, SUNY at Stony Brook-In syllogism research, large numbers of problems are presented, each of which consists of two premises. The subject, told of the possible conclusions along with the alternative "There is No Valid Conclusion" (NVC), selects for each problem one of the alternative answers. When do subjects select NVC? From seven published studies, four facts appear that relate NVC responding to the premise forms and figures and to the experimental procedures. A simple heuristic is suggested that may underlie these facts.

\section{NEURAL NETWORK MODELS}

Promenade D, Friday Morning, 9:55-12:05

Chaired by Walter Schneider, University of Pittsburgh

9:55-10:15 (63)

Real World Scientific Inferences May Require Confirmation Bias. SUSAN T. CHITWOOD \& RYAN D. TWENEY, Bowling Green State University (read by Ryan D. Tweney)-Most manifestations of confirmation bias have been identified as cognitive failures. We modeled Michael Faraday's experimentation by using a neural network to simulate the conduct and results of a series of experiments taken from his diary. While networks were able to learn to predict nearly all of the experimental outcomes, they were unable to learn long sequences of mixed confirmatory and disconfirmatory results. Perhaps real world inferential contexts are in general computationally intractable, unless "filtered" by theoretical expectations or confirmatory heuristics.

\section{0:20-10:35 (64)}

Escape and Avoidance Revisited: A Neural Network Approach. NESTOR A. SCHMAJUK \& DAVID URRY, Northwestern University-A neural network describes escape and avoidance by integrating classical conditioning processes (warning stimuli [WS] and responses $[R]$ become associated with the presence or absence of a shock unconditioned stimuli [US]), and operant conditioning processes (WS-R associations develop when $R$ predicts the absence of the US). The intensity of the avoidance response depends on the combined strengths of WS-US and WS-R associations. The model correctly describes numerous experimental results in real time.

\section{0:40-10:55 (65)}

A Model of Naming in Alzheimer's Disease: Unitary or Multiple Impairments? LYNETTE J. TIPPETT \& MARTHA J. FARAH, Carnegie-Mellon University (read by Martha J. Farah)-Previous research suggests three different functional loci of impairment in the naming deficit of Alzheimer's disease: visual/perceptual, semantic, and lexical. We present a neural network model, which, by virtue of its distributed and interactive nature, accounts for all three types of evidence with a single locus of damage-namely, semantic memory. Specifically, after semantic damage, it shows sensitivity to "lexical" frequency, vulnerability to "visual" degradation, and confusions among exemplars of the same "semantic" category.

$$
\text { 11:00-11:15 (66) }
$$

Base-Rate Neglect and Interference: Success Versus Failure of Neural Nets. STEPHAN LEWANDOWSKY, University of OklahomaThe error-driven learning of neural networks contributes to their suc- 
cesses as well as failures. For example, the linear network of Gluck and Bower (1988) successfully predicted base-rate neglect in a medical diagnosis task. On the other hand, the same model suffers from catastrophic interference in certain situations (Lewandowsky, 1991). Several studies jointly investigated base-rate neglect and interference using a standard A-B/A-C paradigm. With increasing interference, base-rate neglect was found to disappear more gradually than predicted by the network.

\section{1:20-11:35 (67)}

Computational Model of Novel Popout. WILLIAM A. JOHNSTON, KEVIN J. HAWLEY, \& JAMES M. FARNHAM, University of UtahObjects in familiar arrays are seen better than objects in novel arrays, but novel objects pop out from familiar arrays. A two-tiered network model of this phenomenon incorporates two key assumptions: suppression of bottom-up processing from first to second tier of objects that match expectation, and a consequent release from lateral inhibition at the first tier of objects that do not match expectation.

$$
\text { 11:40-12:00 (68) }
$$

Psimulated Psychophysics and Dolphin Echolocation Recognition. HERBERT L. ROITBLAT, University of Hawaii, PATRICK W. B. MOORE, NRaD/NCCOSC, Hawaii, DAVID A. HELWEG, University of Hawaii, \& PAUL E. NACHTIGALL, NRaD/NCCOSC, Hawaii-Echoes were recorded while a dolphin performed a delayed matching-to-sample task. The dolphin's matching performance was compared with the ability of a neural network to recognize the same targets. The current model incorporates information about dolphin hearing to simulate cochlear and eighth nerve responsivity. The simulated psychophysical properties of the model will also be reported.

\section{ASSOCIATIVE LEARNING: ANIMAL} Rose Garden, Friday Afternoon, 1:00-3:30

\section{Chaired by Michael Domjan, University of Texas at Austin}

\section{1:00-1:15 (69)}

Differences in the Associative Structures of Serial and Simultaneous Negative Features. STEVE C. HALLAM, NICHOLAS J. GRAHAME, ROBERT C. BARNET, \& RALPH R. MILLER, SUNY at Binghamton (read by Ralph R. Miller)-Four experiments used a blocking paradigm to assess the similarity of associative structures that result from serial $(A \rightarrow U S / X \rightarrow A-)$ and simultaneous $(A \rightarrow U S / X A-)$ feature-negative training. Simultaneously trained negative features (i.e., Pavlovian conditioned inhibitors) blocked novel simultaneous negative features, and serially trained negative features (i.e., negative occasion setters) blocked novel serial negative features. However, simultaneous conditioned inhibitors did not block serial negative occasion setters or vice versa. This suggests that conditioned inhibition and negative occasion setting reflect different associative mechanisms.

$$
\text { 1:20-1:30 (70) }
$$

Reinforcer Devaluation Effects in Chain Schedules. BEN A. WILLIAMS, University of California, San Diego-Pigeons were trained on two alternating three-link chain schedules. The terminal-link stimulus of one of the chains was devalued by separate extinction training. When both chains were again presented, there was little effect of the devaluation procedure on initial-link responding, contrary to the effects of reinforcer devaluation in simple conditioning and second-order conditioning in autoshaping procedures.

\section{1:35-1:45 (71)}

Partial Reinforcement Eliminates the Massed Shock Deficit. DOUGLAS A. WILLIAMS \& ELENA TINIO, University of Winnipeg-Contexts associated with shocks spaced $3 \mathrm{sec}$ apart evoke little defensive freezing in rats even though most theories predict high levels. Our data suggest that contextual freezing is low because the context is continuously reinforced. Two bouts of 5 footshocks in a single session produced substantial freezing in a 3-sec group. Resistance to extinction was greater than groups receiving one bout of 10 shocks $(60 \mathrm{sec}$ throughout or $3 \mathrm{sec}$ early or late in the session).

$$
\text { 1:50-2:05 (72) }
$$

Adjustment to Partial Reinforcement and Role of the Primordium Hippocampi in the Instrumental Performance of Toads (Bufo arena- rum). MAURICIO R. PAPINI, Texas Christian University, RUBEN N MUZIO, \& ENRIQUE T. SEGURA, Instituto de Biologia y Medicina Experimental-Experiments on partial reinforcement (PR) with toads, in which reward magnitude, amount of acquisition training, N-R transitions, and response effort were varied, indicated that PR impairs acquisition but does not produce the PR extinction effect. Ablation of the primordium hippocampi has no effect on acquisition but increases persistence during extinction after both continuous reinforcement and PR. This research is discussed in relation to comparative, developmental, and neurobiological studies of PR in vertebrates.

\section{2:10-2:25 (73)}

Learning in Honeybees as a Function of Reward Probability. PATRICIA A. COUVILLON, MONIKA E. FISCHER, \& M. E. BIT TERMAN, University of Hawaii-Honeybees were trained individually to choose between two targets differing in odor, one providing sucrose and the other water. In 9 problems, two odors were used and the reward ratio was varied systematically over a wide range. In a 10 th problem, three odors were used in an ambiguous-cue $(\mathrm{A}+/ \mathrm{B}-, \mathrm{B}+/ \mathrm{C}-)$ design. The results were predicted quantitatively and accurately from a simple theory developed in previous work on simultaneous discrimination in honeybees.

\section{2:30-2:45 (74)}

Outcome Devaluation in an Instrumental Biconditional Discrimination. RUTH M. COLWILL, Brown University-Experiments with rats used the outcome devaluation technique to examine instrumental biconditional discrimination learning. Subjects were trained to make one response in one stimulus and a different response in another stimulus. Correct responses earned either the same or a different outcome; in correct responses were never reinforced. Then, one outcome was devalued and discriminative performance was assessed in extinction. Regardless of training conditions, responding was modified by a change in the value of its outcome.

$$
\text { 2:50-3:05 (75) }
$$

Context-Specificity of Target Versus Feature Inhibition in a Feature-Negative Discrimination. MARK E. BOUTON \& JAMES B. NELSON, University of Vermont-In feature-negative discriminations, animals respond to a target stimulus when it is presented alone but not when it is presented in compound with a feature stimulus. In several experiments, responding to the compound increased when we tested it outside the original apparatus context. This effect was due to a loss of inhibition to the target more than inhibition to the feature. Animals may learn that a target is "inhibitable" in a particular context in this paradigm.

$$
\text { 3:10-3:25 (76) }
$$

Chronic Learned Helplessness: Two Pavlovian Therapy Procedures. PHILIP J. BERSH, MICHAEL F. STROMBERG, WAYNE G. WHITEHOUSE, Temple University, \& JOSEPH R. TROISI, II, St. Anselm College-After five sessions of light-signaled inescapable shocks, rats were exposed for five sessions to the training context (C), explicitly unpaired lights and shocks (EUP), or the truly random control (TRC) procedure. Group TRC showed significantly less shock-escape impairment than Group C in a shuttlebox test. Group EUP also performed better than Group $\mathrm{C}$, with the difference almost significant.

\section{SOCIAL-PERSONALITY PROCESSES}

\section{St. Louis Ballroom B, Friday Afternoon, 1:00-2:25}

\section{Chaired by Sandra L. Schneider, University of South Florida}

\section{1:00-1:10 (77)}

Sex Differences in Attitudes Toward Romantic Love Among College Students. RICHARD S. CIMBALO \& DEORA O. NOVELL, Daemen College-Prentice, Briggs, and Bradley (1983), using factor analysis, describe three major dimensions of romantic love among college students (traditional, sexual, routine) and four minor dimensions (marriage/family, drugs, aberrant sex, religion). A rating scale was administered to 112 college students to examine possible sex differences. Females rated traditional and marriage/family dimensions, and males rated the aberrant sex dimension as significantly more romantic. The results imply a romantic "double standard," and theoretical implications are considered. 


\section{1:15-1:25 (78)}

The "Silent Scream": Arousal, Defensiveness, and Changes in Abortion Attitudes. CARLYLE J. DEVOE, McDonnell-Douglas Corporation, \& JAMES D. EVANS, Lindenwood College (read by James D. Evans)-In a randomized Solomon four-group design, college students viewed either an antiabortion tape, "The Silent Scream," or an equally arousing control tape concerning traffic accidents. Significant antiabortion attitude change occurred only in the abortion-tape condition. Amount of change was positively correlated with level of emotional arousal and negatively correlated with defensiveness. Semipartial correlations suggested that the level of emotional arousal was the key link between defensiveness and less attitude change.

$$
\text { 1:30-1:45 (79) }
$$

Context Effects on Judgments of Multidimensional Similarity. DOUGLAS H. WEDELL \& JAMES S. ROBERTS, University of South Carolina-Judged similarity among emotion words was assessed using sorting and pairwise rating tasks. Context was manipulated by adding words that increased the frequency of different emotion categories and thereby the density of stimuli in that region of the emotion space. Significant effects of context were observed for the sorting task and were represented by an emergent dimension in multidimensional scaling solutions. Context effects were greatly attenuated for the pairwise rating task.

$$
\text { 1:50-2:05 (80) }
$$

Reliability and Validity of the Quality of Motivation Questionnaire. R. CHRIS MARTIN, RAMA ESHELBRENNER, \& BRAD RUTKOWSKI, University of Missouri-Kansas City-The Quality of Motivation Questionnaire is a 310 true/false item instrument which produces 38 scales measuring sources of motivation, adaptive and maladaptive skills, and self-esteem. Test/retest with 100 subjects ( 50 males, $50 \mathrm{fe}$ males) produced significant (as high as .88) correlations on all scales. Concurrent and predictive validity tests showed the instrument useful in industry for managers.

$$
\text { 2:10-2:20 (81) }
$$

Proofreading Ability as a Function of Personality Type. B. MICHAEL THORNE \& CONSTANCE CLAIRE GORDY, Mississippi State University-Personality type (as determined by the Myers-Briggs Type Indicator) and proofreading ability were studied in 195 undergraduates. On the proofreading task, females performed better than males, intuitive types performed better than sensing types, feeling types did better than thinking types, and there were no differences between introverts and extraverts or between judging and perceiving types. The difference between feeling types and thinking types was primarily due to the sex difference in proofreading ability.

\section{TOUCH}

St. Louis Ballroom C, Friday Afternoon, 1:00-3:10

\section{Chaired by Robert B. Welch, NASA-Ames Research Center}

$$
\text { 1:00-1:10 (82) }
$$

A Tactile Movement Aftereffect. MARK HOLLINS, University of North Carolina at Chapel Hill-A tactile movement aftereffect (Thalman, 1922) was produced by having subjects place their hand on a ridged, rotating drum. The aftereffect was comparable whether the stationary test stimulus was the drum itself, or a terrycloth cylinder, but weaker if the hand was not in contact with any surface. Aftereffect duration and vividness increased with adapting duration (30 sec-3 min). Subjects disagreed regarding the direction of the aftereffect, a result sug gesting more than one process.

$$
\text { 1:15-1:25 (83) }
$$

The Perception of Symmetric and Asymmetric Patterns by Touch and Vision. SOLEDAD BALLESTEROS \& JOSÉ MANUEL REALES, Universidad Nacional de Educación a Distancia-Symmetry is a very salient property for the visual system but is it also important for the haptic system? In a series of experiments we investigate the perception of symmetric and asymmetric patterns presented haptically. Results indicate that performance with asymmetric patterns is higher than with symmetric ones under several materials and exploration-time conditions. This finding is compared to previous results obtained when the same patterns were presented visually.
1:30-1:40 (84)

Where's the Dominance? WAYNE A. HERSHBERGER, Northern Illinois University, \& GIOVANNI F. MISCEO, Benedictine CollegeForty-eight subjects judged the size of various standard squares by selecting an equivalent stimulus from a set of comparison squares. They viewed each standard square through a negative meniscus lens $(50 \%$ reduction) while grasping the square through a cloth preventing sight of their hand. Then they selected an equivalent comparison square, half doing so visually, half haptically. The latter group evinced "haptic dominance" as much as the former group evinced "visual dominance." 1:45-2:00 (85)

Effect of Hand Position on Perception of Tactile Stimuli. MAR THA A. RINKER \& JAMES C. CRAIG, Indiana University (read by James C. Craig)-Subjects have difficulty identifying a tactile target stimulus when a different stimulus, a nontarget, is presented at a nearby site. The present study examined how the position of the hand in space affects the perception of similarity between target and nontarget stimuli. As the fingers are moved from the horizontal to the vertical position, the direction of pattern motion across the target site (the thumb) is altered relative to the nontarget site (the index finger).

$$
\text { 2:05-2:20 (86) }
$$

Haptic "Looming." PATRICK A. CABE, Pembroke State University-A cord with weights at each end is suspended by two horizontally separated hooks. The cord passes around an observer's finger midway between, and below the level of, the hooks. As the finger moves vertically, angular change between cord segments and changing tension components both specify impending collinearity of finger and hooks. Individuals are seen to use tension rather than angular change information in making judgments of impending collinearity. The analogy to optical looming is drawn.

\section{2:25-2:40 (87)}

Size-Distance Invariance Hypothesis in Haptic Perception. DRAGANA BARAC-CIKOJA \& MICHAEL T. TURVEY, CESPA, University of Connecticut (sponsored by Laurie B. Feldman)-Haptically perceiving the size of gap by probing with a hand-held rod was examined in five experiments. Size of an occluded gap was reported by adjusting a visible gap. Variables manipulated were the following: gap size, gap distance along the rod, number of arm segments involved in probing, haptic angle at the contact, and inertial properties of the rod. Equivalent manipulations of probe and body parameters differed in their effects on haptic size perception.

$$
\text { 2:45-3:05 (88) }
$$

Orthogonal Redundant Information About 3-D Objects: Constraints on Haptic Dimensional Integration. SUSAN J. LEDERMAN, Queen's University, ROBERTA L. KLATZKY, University of California, Santa Barbara, \& CATHARINE REED, Carnegie-Mellon University-Two complementary experimental paradigms, "redundancy withdrawal" and "orthogonal insertion," were used to assess the extent of dimensional integration in a speeded classification task when dimensions (texture, shape, hardness) could be extracted haptically from the same local patch. Results indicated bidirectional dimensional integration between texture and shape and unidirectional integration when hardness was the targeted dimension. We attribute the asymmetry to the difficulty of hardness discriminations. The extent to which dimensional integration was not volitional is also considered.

\section{SYMPOSIUM I: \\ CONNECTIONIST MODELS AND COGNITIVE THEORY St. Louis Ballroom D, Friday Afternoon, 1:00-3:30}

Chaired by Mark S. Seidenberg, University of Southern California

$$
\text { 1:00-1:20 (89) }
$$

Introductory Remarks. MARK S. SEIDENBERG, University of Southern California-Connectionist models have come to play an important role in thinking about perception, cognition, and learning. Yet the role of such models in explaining behavior is not at all obvious and has been the subject of considerable debate. Can models of considerable complexity contribute to the identification of general principles of cognition? Or is connectionism inherently atheoretical, a massive exer- 
cise in nonlinear regression? Has the first generation of connectionist research led to new insights, or merely provided a new way of implementing preexisting theories? Symposium participants will provide a variety of answers in attempting to achieve a stable equilibrium state, avoiding local minima.

\section{1:25-1:45 (90)}

The Theory Behind Connectionist Models: The Role of Processing Architecture and Training Environment in Determining Aspects of Overt Performance. JAMES L. McCLELLAND, Carnegie-Mellon University-Connectionist theory is developing hand in hand with connectionist models of specific cognitive tasks. The theory allows us to see how behaviors characteristic of human performance can arise from architectural properties of the underlying processing system or from the structure of the ensemble of examples on which the processing system is trained. Examples will illustrate the roles of both theory and modeling in addressing basic issues about the nature of the human informationprocessing system.

$$
\text { 1:50-2:10 (91) }
$$

Neuropsychology, Connectionism, and Cognitive Theory. MARTHA J. FARAH, University of Pennsylvania-In the most common use of neuropsychological data to constrain cognitive theory, a selective impairment in ability $\boldsymbol{X}$ implies a component of the cognitive architecture dedicated to $X$. This assumes that, after damage to one component, the functioning of the remaining components is unaffected. Connectionism is a theoretical tool for understanding more complex and realistic relations between the cognitive architecture, functional lesion, and manifest behavior. Connectionist reinterpretations of several neuropsychological impairments will be described.

$$
\text { 2:15-2:35 (92) }
$$

Levels of Description in Connectionist Theorizing. MICHAEL MCCLOSKEY, Johns Hopkins University-In this talk, I contribute to the confusion surrounding the following questions: Is the vocabulary of units, connections, weights, activation rules, and the like, sufficient for the formulation of connectionist cognitive theories? That is, can a connectionist theory be stated entirely at this level of description? If not, what level(s) of description should supplement (or replace) the units and connections level? In more general terms, what concepts are doing explanatory work in connectionist theorizing?

\section{2:40-3:00 (93)}

Connectionism and Reasoning. KEITH J. HOLYOAK, UCLAThe application of connectionist models to high-level reasoning affords both challenges and opportunities. The challenges arise from the need to represent systematic relational structure. The opportunities include accounting for gestalt-like phenomena in terms of "soft" constraint satisfaction, explaining working-memory limitations that constrain reasoning with "mental models," and accounting for the role of dynamic binding in commonsense reasoning.

$$
\text { 3:05-3:25 (94) }
$$

Discussion. WALTER KINTSCH, University of Colorado.

$$
\begin{gathered}
\text { LATERALITY } \\
\text { Promenade C, Friday Afternoon, 1:00-2:45 } \\
\text { Chaired by Robert Solso, University of Nevada, Reno }
\end{gathered}
$$

1:00-1:20 (95)

The Role of the Right Hemisphere in Intellectual Giftedness. MICHAEL W. O'BOYLE, CAMILLA P. BENBOW, \& JOEL ALEXANDER, Iowa State University-Three experiments were conducted to investigate the possibility that enchanced involvement of the right hemisphere $(\mathrm{RH})$ during basic information processing is related to extreme intellectual giftedness. Data from precocious and average-ability youths performing a dichotic listening for syllables task, a free-vision chimeric face task, and a noun/verb determination task (the latter two having corresponding EEG measurements), all suggest that the ability to access and coordinate $\mathrm{RH}$ processing resources are characteristics of the gifted brain.

$$
\text { 1:25-1:35 (96) }
$$

The Absence of Older Left-Handers: Differential Mortality or Social-Historical Trend? STANLEY COREN, University of British
Columbia-The scarcity of older left-handers suggests that sinistrals have shorter lifespans. An alternate interpretation is that older left-handers were switched to right-handedness. To separate historical trend from differential mortality, two samples (age 8-100 years, $N=1,960$ and $N=8,526$ ) were measured, separated by a 12 -year interval. Both samples showed fewer older left-handers. There was no significant increase in the proportion of left-handers over the 12-year period, supporting the differential mortality hypothesis rather than a historical trend.

\section{1:40-1:55 (97)}

Visual Pattern Processing That Is Unconscious and Localized Within Left and Right Hemispheres. LLOYD L. AVANT \& ALICE A. THIEMAN, lowa State University-Two experiments presented good and poor Garner dot patterns to LVF versus RVF or to upper versus lower visual field. Duration judgments for paired $10-\mathrm{msec}$ presentations were differentially influenced by LVF versus RVF inputs but not by upper versus lower field inputs. A third experiment showed presence/ absence detection of the patterns to be at chance level. These results show prerecognition visual processing that is localized within the left and right hemispheres.

\section{2:00-2:15 (98)}

Orthogonal Lateralized Processes Have Orthogonal Attentional Resources. DAVID B. BOLES \& MARK B. LAW, Rensselaer Polytechnic Institute-Factor analysis has revealed a number of hemispheric processes that are largely orthogonal across subjects. Do these have equally orthogonal attentional resources associated with them? Dualtask methodology is brought to bear on the problem. Experiment 1 finds evidence of multiple resources but does not distinguish between processspecific and hemisphere-undifferentiated capacity. Experiment 2 clarifies the outcome in favor of process-specific resources. These results point to an expanded multiple-resource model of attention.

$$
\text { 2:20-2:40 (99) }
$$

Reversal of Meaning Suppression for Ambiguous Words: Time Course and Laterality Effects. CHRISTINE CHIARELLO, Syracuse University, LORIE RICHARDS, University of Kansas Medical School, \& LISA MAXFIELD, Syracuse University-Homograph primes were shown twice. Second presentation targets could be related to the same meaning as the first homograph-prime pair or an alternate meaning. As reported last year, RVF target pronunciations were slowed when a new meaning was instantiated (130-msec SOA). Further experiments obtained reversed effects $(100$-msec SOA): repeating the same meaning slowed responses, but presenting a new meaning speeded them. We attribute this disambiguation failure to inhibition of weakly activated codes.

\section{CATEGORIZATION}

Promenade D, Friday Afternoon, 1:00-4:30

\section{Chaired by Stephan Lewandowsky, University of Oklahoma}

\section{1:00-1:15 (100)}

Inductive Inferences by Preschoolers and Level of Category Label. ELIZABETH F. SHIPLEY, University of Pennsylvania-Three-yearolds taught a property of a depicted animal were asked if depicted animals from the same subordinate category, the same basic-level category (different subordinate category), or a different basic-level category possessed the property. Three conditions were used for all stimuli: (1) subordinate, (2) basic-level, or (3) superordinate labels. More inductive inferences occurred with basic-level than subordinate labels. The superordinate label "animal" was interpreted as "kind of animal." The results are interpreted using Goodman's account of induction.

$$
\text { 1:20-1:35 (101) }
$$

The Nature of Structured Imagination. THOMAS B. WARD, Texas A\&M University-When individuals imagine and generate novel instances of a category, their creations are highly structured. Two experiments demonstrate that this structuring is often based on the retrieval of specific instances of the category, but that task constraints can lead individuals to rely more on broader knowledge structures. The results support (1) a mixed model of category representation and (2) the idea that similar structures and processes underlie creative and noncreative aspects of cognition. 
1:40-1:55 (102)

Perceptual Manifestations of an Analytic Structure: Interactions with Categorization Processes. GLENN REGEHR \& LEE R. BROOKS, McMaster University (read by Lee R. Brooks)-Following practice applying a perfect classification rule, subjects showed a strong similarity-to-old-items effect, depending on the perceptual characteristics of the training items. Two types of perceptual variation were contrasted: feature individuation (whether features occur in identical form in different items), and holistic individuation (whether an item's features cohere into an individuated whole). The presence of individuated features was not sufficient to produce exemplar-based transfer if the item's holistic individuality was altered. 2:00-2:15 (103)

Categorization of Conjunctively Defined Fuzzy Sets of Visual Stimuli. JAMES A. HAMPTON, City University, London-When people make categorization judgments about conjunctions of fuzzy categories (e.g., SPORTS WHICH ARE ALSO GAMES), they sometimes fail to apply a strict intersective rule for defining the conjunction, and instead base conjunctive membership on a compensation between degrees of membership in each constituent set. Two new experiments investigate this phenomenon in the case of more perceptual categories (cartoon faces and colored letters), in an attempt to discover the generality of nonintersective conjunctions.

\section{2:20-2:35 (104)}

Incidentally, the General is Particularly Determined: An EpisodicProcessing Account of Implicit Learning. BRUCE W. A. WHITTLESEA \& MICHAEL D. DORKEN, Simon Fraser University-Current accounts of implicit learning emphasize unconscious abstraction of general structure. Contrary to such accounts, we demonstrate that subjects achieve no deep structural sensitivity when stimuli are truly incidental. When stimuli are processed for different purposes, subjects variously acquire knowledge about particular events, or about the deep structure of particular items or the domain in general. We conclude that memory performs whatever operations are functional in satisfying current demands, and accidentally becomes sensitive to underlying structure.

$$
\text { 2:40-2:55 (105) }
$$

Modeling Primary and Secondary Generalization in Concept Learning. ANDRÉ VANDIERENDONCK, University of GhentPrimary generalization is said to occur when a new exemplar is assigned to a particular category because of its similarity to one or more exemplars stored in memory. Experimental evidence is presented showing that under some conditions, categorization also depends on other, secondary, sources of information (e.g., rules, abstractions, etc.). Furthermore, this paper presents a frame of reference for modeling primary and secondary generalization, together with supporting experimental evidence.

\section{3:00-3:20 (106)}

Rule-Plus-Exception Model of Classification Learning. ROBERT M. NOSOFSKY, Indiana University-A rule-plus-exception model of classification learning is formalized and tested. According to the model, people attempt to learn categories by forming simple rules and then storing occasional exceptions to those rules. Complete exemplars are virtually never stored. The model accounts for fundamental category learning phenomena such as prototype effects, effects of specific exemplars, sensitivity to correlated features, and the difficulty of learning different types of classification problems.

$$
\text { 3:25-3:40 (107) }
$$

Automaticity and Transfer in Skilled Performance: How InstanceSpecific is Category Learning? WOO-SEOC HANN \& THOMAS H. CARR, Michigan State University (read by Thomas H. Carr)-In acquired automaticity, what defines a "stimulus"-the identity of each instance, or its category? We find the degree of instance specificity versus category-wide transfer in a letter classification task depends on the variability among instances during both training and transfer. Greater instance specificity occurs when instance variability is less, and asymptotic training performance is faster under these conditions. Category-wide transfer occurs with more instance variability but at the cost of slower asymptotic training performance.
3:45-4:00 (108)

Rigidity, Malleability, Object Kind, and Object Naming. BARBARA LANDAU, University of California, Irvine, MICHAEL LEYTON, Rutgers University, CASSANDRA MOORE, \& BETH LYNCH, Columbia University -We found massive effects of certain shape-related properties in 3-year-olds' and adults' extension of a novel object's name. Line-drawn objects with straight edges and sharp corners elicited virtually no generalization to shape changes, consistent with the "shape bias" (Landau, Smith, \& Jones, 1988). In contrast, objects with curved edges, curved/wrinkled edges, or curved/wrinkled edges plus "eyes" elicited increasingly broad generalization to shape changes. Properties of shape as well as those more obviously diagnostic of category (eyes) can suggest different object kinds.

\section{4:05-4:25 (109)}

Extrapolation: The Sine Qua Non of Abstraction. JEROME BUSEMEYER, ED DELOSH, SANGSUP CHOI, \& MARK MCDANIEL, Purdue University-To extrapolate properly from past experience, the learner must abstract a rule that is capable of producing new responses outside the range of that past experience. We report the results obtained from a functional learning task where we found impressive extrapolation performance for linear, quadratic, and exponential functions. These results prove to be difficult to explain by purely associative adaptive network models of learning, and they point to the need to develop rule learning models.

\section{BEHAVIORAL PHARMACOLOGY}

Rose Garden, Friday Afternoon, 3:40-5:30

Chaired by Lewis M. Barker, Baylor University

3:40-3:50 (110)

Individual Differences in Amphetamine-Induced Place Conditioning. LINDA PARKER, Wilfrid Laurier University - In Phase 1, rats were divided into high responders and low responders on the basis of their rate of activity while in a novel chamber. In Phase 2, they were given four place-conditioning cycles with $d$-amphetamine serving as the US drug. Only the Phase 1 high responders developed a preference for the amphetamine-paired chamber in Phase 2. These results support recent reports (e.g., Deminiere et al., 1989; Piazza et al., 1989) that noveltyinduced activity predicts the ability of amphetamine to serve as a reinforcer in the drug self-administration paradigm.

$$
\text { 3:55-4:10 (111) }
$$

Repeated Sessions of Intruder Defeat Accentuate Withdrawal From Morphine in Rats. JON L. WILLIAMS, JONATHAN M. JUST, \& CHARLES M. FARMER, Kenyon College-Rats exposed to four sessions of attack and defeat as colony intruders, by dominant male conspecifics, showed greater morphine withdrawal $24 \mathrm{~h}$ later than rats given one or no sessions of defeat. Withdrawal testing involved giving subjects a 5-mg injection of morphine sulfate followed by a 5-mg naloxone challenge. The impact that repeated defeat subsequently had on precipitated withdrawal was also found to be significantly blocked when subjects were given naltrexone prior to the defeat sessions.

$$
\text { 4:15-4:35 (112) }
$$

Pavlovian Conditioning and Tolerance to the Anorectic Effect of CCK. TINA GOODISON \& SHEPARD SIEGEL, McMaster University (read by Shepard Siegel)-Experiments were conducted to evaluate the contribution of conditioning to tolerance to the anorectic effect of cholecystokinin (CCK). The results indicated that (1) tolerance is "contingent" (the rat must eat in conjunction with drug administration for anorectic tolerance to develop), (2) tolerance is displayed only in the context of environmental cues previously associated with CCK, (3) CCK-tolerant rats overeat when presented with cues previously associated with the peptide, and (4) CCK tolerance displays "latent inhibition."

$$
\text { 4:40-4:50 (113) }
$$

Train/Test Drug-State Change Disrupts Avoidance but not Escape Responding. CYNTHIA J. HEINZEN \& DENNIS C. WRIGHT, University of Missouri-Columbia (read by Dennis C. Wright)-Rats were 
one-way avoidance trained while drugged $(15 \mathrm{mg} / \mathrm{kg}$ pentobarbital) and tested nondrugged. To assess "reminder" effects from Test Trial 1, the reminder was separated from Test Trials 2-10 by $1 \mathrm{~min}, 1 \mathrm{~h}$, or $24 \mathrm{~h}$. Groups showed equivalent train/test decreases in avoidance responding. While avoidance responding was drug-state dependent, efficient escape responding was not. Escape latencies on nonavoidance trials decreased significantly across training days, but there was no train/test increase in escape latencies.

\section{4:55-5:10 (114)}

Inescapable Shock Treatment, Dexamethasone, and Punishmentand Open-Field Testing: A Role for ACTH? D. CHRIS ANDERSON, University of Notre Dame-Inescapable shock treatments (ST) were evaluated in three studies. Experiment 1 involved punishment (PUN) and Experiments 2 and 3 open-field (OF) testing. Dexamethasone (DEX) was given subcutaneously (Experiment 1 ) or via double cannula to the median eminence of the hypothalamus (Experiments 2 and 3) prior to ST, testing, or both. Similar injection procedures were applied to non-ST controls. ST and DEX noninteractively affected PUN learning (Experiment 1), while both interactively influenced OF performances (Experiments 2 and 3). Implications for the role of aversive test stimuli and ACTH memory-retrieval theory are discussed.

\section{5:15-5:25 (115)}

The Effects of Midazolam on Potentiated Startle and Freezing Behavior. JACQUELYN CRANNEY, University of New South WalesForty-eight male Wistar rats were assigned to four groups: midazolammidazolam, midazolam-saline, saline-saline, and midazolam-midazolam. Drug administration was switched for two groups after 2 days of a 7-day schedule of daily presentations of ten 100-msec, 115-dB, whitenoise stimuli (60-sec VI). Midazolam interfered with the acquisition, and possibly the expression, of conditioned fear, as indexed by freezing behavior and potentiated startle.

\section{DEVELOPMENTAL/AGING PROCESSES}

St. Louis Ballroom B, Friday Afternoon, 2:35-5:40

\section{Chaired by William J. Hoyer, Syracuse University}

\section{2:35-2:55 (116)}

Two Strikes Against You: Individual Differences in Early Literacy. FREDERICK J. MORRISON, ELIZABETH H. MCMAHON, University of North Carolina at Greensboro, \& GARY L. WILLIAMSON, Greensboro Public Schools-In a longitudinal investigation of growth of literacy skills, we examined individual differences (e.g., across social class and race) at the beginning of kindergarten, end of kindergarten, and end of first grade. Major, reliable individual differences in early reading, math, language, and cultural literacy skills were found at the start of the kindergarten year. Degree of progress made by different racial or socioeconomic groups over the next years was virtually identical. 3:00-3:20 (117)

The Effect of Suggestibility on Children's Recognition Memory. KATRINA DELAMOTHE \& JOHN E. TAPLIN, University of New South Wales (read by John E. Taplin)-Misleading postevent information is shown to impair story-based picture recognition memory in 5and 10-year-old children. This suggestibility effect did not interact with either age or manipulations targeted at trace strength for the original information. Artifactual possibilities were controlled using McCloskey and Zaragoza's modified test procedure, and certain other potential causes such as differential memory trace strength also seem doubtful, leaving source monitoring failure as a likely explanation for the effect obtained.

$$
\text { 3:25-3:45 (118) }
$$

Intrusions in Alzheimer's Disease in Immediate and Delayed Memory Tasks. SUSAN KARP MANNING, JOAN GREENHUT-WERTZ, \& JOAN A. MACKELL, Hunter College - CUNY and New York University Medical Center-Immediate serial recall of subjects with Alzheimer's disease (AD) was compared with that of young and elderly normal subjects using the suffix paradigm and the same six letters in repeated random orders. This was followed by delayed recall and recognition tasks for these stimuli. Unlike normal subjects, AD subjects recalled never-presented letters in all tasks and were unable to suppress the suffix. These intrusions suggest specific deficits in AD.

\section{3:50-4:10 (119)}

The Development of Autosuggestibility in Memory. CHARLES J. BRAINERD, University of Arizona-Results are summarized from studies of a potentially common form of childhood memory distortion: autosuggestibility. The basic phenomenon, which is predicted by fuzzytrace theory, occurs when children's memories for informational inputs to problems that produce highly inaccurate reasoning are reconfigured in the direction of such reasoning. The results show that this type of distortion is a regular concomitant of illogical reasoning in childhood, and that it decreases steadily with development. Interestingly, these distortions do not seem to be directly caused by illogical reasoning itself Rather, they appear to arise from mutually inconsistent codings of background inputs prior to reasoning.

$$
\text { 4:15-4:35 (120) }
$$

Objects and Relations in Young Children's Use of a Scale Model. JUDY DELOACHE, DON MARZOLF, DAVID UTTAL, \& JILL SCHREIBER, University of Illinois at Urbana-Champaign-Several experiments have investigated very young children's understanding of scale models. After watching a miniature toy being hidden somewhere in a scale model of a room, 3-year-old children are able to find a larger toy hidden in the corresponding place in the room. Do children succeed by understanding the overall symbolic relation between the model and room, or do they simply perform a series of object-object matches? Three experiments will be presented showing the crucial role of relational structure in using a model. These data argue that awareness of the overall model-room correspondence underlies success in the model task.

$$
\text { 4:40-5:00 (121) }
$$

What Type of Speed Mediates Adult Age Differences in What Type of Cognition? TIMOTHY A. SALTHOUSE, Georgia Institute of Technology-Previous research has revealed that statistical control of measures of perceptual speed greatly attenuates the adult age differences across a wide range of cognitive variables. This project, involving a total of 246 adults between 18 and 84 years of age, was designed to distinguish the influence of motor speed from perceptual-cognitive speed, and to determine the interrelations among age, a task-independent measure of processing speed, study time, decision time, and decision accuracy.

$$
\text { 5:05-5:15 (122) }
$$

What is Unique About Age in Age-Related General Slowing? DAVID A. BALOTA \& F. RICHARD FERRARO, Washington University-Response latencies of healthy aged individuals can be nicely predicted by the response latencies of younger adults and by some general slowing factor. We report results from a series of 12 experiments that included 199 conditions, and investigate this relationship both across age groups and within age groups. The results indicate that the same type of function exists within age groups as between age groups. Thus, age is just one of a number of factors that may produce this relationship. 5:20-5:35 (123)

Developmental Changes in the Visual Control of Posture. BENNETT I. BERTENTHAL, DINA L. BAI, \& JAMES L. ROSE, University of Virginia-A moving-room paradigm was used to study visuomotor coupling in human infants between 5 and 13 months of age. Frequency and amplitude of the wall movements were systematically varied; sway frequency, magnitude of postural displacement, and measures of motor development were used as dependent variables. The results revealed frequency entrainment of postural sway, but only following the onset of independent sitting. Strength of this entrainment did not vary with amplitude of displacement, but did vary with the velocity of the visual stimulation.

\section{INFORMATION PROCESSING \\ St. Louis Ballroom C, Friday Afternoon, 3:20-5:35 \\ Chaired by Saul Sternberg, University of Pennsylvania}

3:20-3:35 (124)

Methods for Dealing With Reaction Time Outliers. ROGER RATCLIFF, Northwestern University-First, the power of different methods of minimizing the effects of outliers (cutoffs, transformations, etc.) 
on ANOVA is examined as a function of shifts or spreads in the RT distribution. Second, the effects of cutoffs and outliers on different measures of location, spread, and shape, and the variability of these measures is examined. Third, the advantages of fitting an explicit model to recover means and standard deviations from distributions with outliers are discussed.

\section{3:40-4:00 (125)}

Scheduling Processes Using Working Memory. RICHARD SCHWEICKERT, ADDIE DUTTA, SANGSUP CHOI, \& ROBERT W. PROCTOR, Purdue University-Memory search and mental arithmetic both use working memory. Response times in a dual task indicate these processes do not use working memory at the same time. A PERT network analysis indicates that both working-memory processes preceded both responses. Further, the order in which the processes were executed was changed by changing the instructions about which response to give first. Facilitation and inhibition due to properties shared by the dual stimuli are discussed.

$$
\text { 4:05-4:20 (126) }
$$

A Test of an Activation Notion of Working Memory. JUDY CANTOR, Carnegie-Mellon University, \& RANDALL W. ENGLE, University of South Carolina (read by Randall W. Engle)-Two experiments tested the relationship between LTM activation and working-memory capacity. In Experiment 1, subjects learned sentences varying in number of related concepts or fan size. Speeded verification showed that low-span subjects produced larger fan effects than high-span subjects. Experiment 2 used thematically related sentences of varying fan size. Only high-span subjects produced the negative fan effects indicating the learning of a mental model. These results support a "general capacity model."

\section{4:25-4:35 (127)}

Circadian Arousal Effects on the Efficiency of Working Memory. TOM PETROS, BILL BECKWITH, TODD HALLIN, MAUREEN WINGER, \& WADE MITCHELL, University of North Dakota-The influence of morningness-eveningness and time of day on workingmemory operations was examined in college subjects. No effects were observed on any measure of memory span while the rate of scanning working memory for digits was faster across time of day. The importance of circadian influences on working-memory operations will be discussed. 4:40-4:50 (128)

Information Overload and Degraded Memory Probes. DAVID BURROWS, Skidmore College-Subjects were presented with continuously expanding memory lists. In a standard recognition condition, subjects determined whether a probe word was a memory list member. In the degraded condition, the initial letter of each probe word was deleted. Accuracy in the two conditions did not differ. RTs in the degraded condition were approximately $500 \mathrm{msec}$ slower. These and other data suggest that the locus of overload effects is in the time required to process information.

\section{4:55-5:05 (129)}

Temporal Oscillations and the Time Quantum in Human Perceptual Decisions. STANISLAS DEHAENE, INSERM and CNRS, Paris (sponsored by Jacques Mehler)-A time quantum was identified in several feature and conjunction detection tasks in the visual and auditory modalities. Histograms of 1,600 RTs from a single individual were multimodal with a regular pattern of peaks and troughs, indicating that responses could only be emitted at regularly recurring time intervals following stimulus presentation. On average, perceptual decisions were reached after 4-7 discrete processing steps, each taking the same "quantum" duration proportional to task difficulty.

\section{5:10-5:30 (130)}

A Theory of Congruity Effects: The Case of Garner's Paradigm. DANIEL HOLENDER, Free University of Brussels-This is a followup of the theory of congruity effects I presented last year. It is now extended to account for Garner's effects. It is argued that these effects do not arise earlier in processing than Stroop and Stroop-like effects. They all stem from interactions taking place at the response initiation stage of processing. Later stages of response execution may also be involved. It is also argued that congruity effects are mediated consciously.

\section{AUDITORY PROCESSES}

St. Louis Ballroom D, Friday Afternoon, 3:40-5:40

\section{Chaired by Cynthia H. Null, NASA-Ames Research Center}

\section{3:40-3:55 (131)}

Auditory Streaming by European Starlings. RICHARD F. BRAATEN, University of Denver, \& STEWART H. HULSE, Johns Hopkins University (read by Stewart H. Hulse)-European starlings were trained to discriminate between two repeating serial sound patterns:

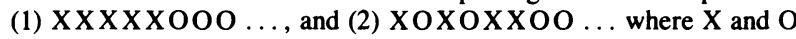
each represent a unique spectral structure. Among other things, the starlings could still maintain the discrimination on the basis of either the X-element or the Y-element subpatterns by themselves. These results, along with suitable controls, indicate that starlings heard the $X$ and $O$ patterns as segregated auditory streams. To our knowledge, this is the first report of auditory streaming in nonhuman animals.

4:00-4:20 (132)

Can Songbirds Categorize Songs Using Frequency Ratio (Relative Pitch)? RON WEISMAN \& MILA NJEGOVAN, Queen's University-In nature, songbirds can produce and recognize the highly constant frequency ratio between adjacent notes (relative pitch) in conspecific song. Here was adapted an experimental design from the study of concept learning to determine whether songbirds can categorize songs on the basis of the frequency ratio in operant discrimination experiments. Specifically, we contrasted pseudocategory discrimination of positive songs unrelated in relative pitch to category discrimination of positive songs at a common frequency ratio.

$$
\text { 4:25-4:40 (133) }
$$

Pictures at an Exhibition. JUSTINE SERGENT, Montreal Neurological Institute-During this Mussorgsky-like promenade presentation, PET pictures will be exhibited that illustrate variations of cerebral activation in 10 professional pianists performing musical sight-reading, playing the piano, and listening to their performance. The experimental tasks were designed after Maurice Ravel's pattern of preserved and impaired musical skills following brain damage. The results indicate that the neural network underlying the reading of musical notations and their translation into movement patterns on a keyboard is parallel to, but distinct from, that subserving corresponding verbal tasks.

$$
\text { 4:45-4:55 (134) }
$$

Effect of Form and Higher Level Structures on Melodic Expectancies. CAROL L. KRUMHANSL, Cornell University, \& EUGENE NARMOUR, University of Pennsylvania-The implication-realization model (Narmour, 1990) specifies principles governing melodic expectancies. Experimental support has been found for the model by varying local (note-to-note) melodic structures. The model holds that expectancies are also influenced by implications of higher level melodic structures and by similarity of musical form. The experiments to be reported test the effects of these variables on judged closure and the degree to which melodic continuations are expected.

\section{5:00-5:15 (135)}

Expertise and Age Differences in Perception and Memory for Melodies. ANDREA R. HALPERN, Bucknell University, JAMES C. BARTLETT, \& W. JAY DOWLING, University of Texas at Dallas-We tested young-adult and elderly musicians and nonmusicians to determine if agerelated decrements in perception and memory for melodies are moderated by musical structure and expertise. Age-related decrements in a perception task were smaller among musicians than nonmusicians, but this interaction did not occur in a memory task. Performance in the perception task was higher for tonal than atonal melodies in all groups. Thus, expertise but not structure conferred some advantage in ameliorating age-related deficits.

\section{5:20-5:35 (136)}

Range of Planning in Skilled Music Performance. CAROLINE PALMER \& CARLA VAN DE SANDE, Ohio State University-We investigated two influences on the range of planning in music performance: serial distance and structural content. Pianists performed music in which the serial distance and phrase structure relationships among musical 
events were varied. Both errors and timing measures indicated interactive effects of distance and structure on performance, implicating both in the partitioning of musical sequences during planning.

PICTURE MEMORY/PROCESSING

Promenade C, Friday Afternoon, 2:55-5:30

Chaired by Aura Hanna, NASA-Ames Research Center

$$
\text { 2:55-3:10 (137) }
$$

Evidence for an Amodal Picture-Word Processing Model From a Bilingual Drawing-Writing Task. PAUL C. AMRHEIN, RAMON SANCHEZ, BARBARA KIM, University of New Mexico, \& JOHN THEIOS, University of Wisconsin-Spanish-English bilinguals wrote or drew presented or corresponding English words, Spanish words, or pictures. Relative to drawing/writing onset latencies for within-language/ mode trials (e.g., write Spanish word given Spanish word/draw picture given picture), latency increments for corresponding cross-language/mode trials (e.g., write Spanish word given English word/write Spanish word given picture) were equivalent across production conditions. Results indicate separate memory stores for English words, Spanish words, and pictures, each having equivalent amodal conceptual store access.

$$
\text { 3:15-3:30 (138) }
$$

Context Effects in Scene Perception. ALEXANDER POLLATSEK, LINDA L. LAGASSE, GARY E. RANEY, \& KEITH RAYNER, University of Massachusetts-Subjects viewed scenes and named a target object that was "wiggled" to draw attention. The target object was either consistent or inconsistent with either the initially fixated object and/or the rest of the scene. Naming times were speeded by the consistency of the background but actually slowed by the consistency of the initially fixated object, indicating that scene consistency effects are not explainable by "object-to-object priming."

$$
\text { 3:35-3:45 (139) }
$$

False Recognition of Group Members Continues Over Repeated Acquisition Trials. JAMES J. JENKINS, JANE A. NOLL, University of South Florida, \& J. TERRELL TUTEN, Culver-Stockton College-Several investigators have shown that subsets of related geometric patterns can produce recognition of nonpresented items if the acquisition items have the properties of a group generator. Such "stimulus set generalization" must compete with otherwise excellent specific memory. We varied the number of presentations of the acquisition set (one, three, five, seven, and nine presentations) asking whether repetition strengthened the role of specific memory. Stimulus set generalization remained impressively strong.

$$
\text { 3:50-4:05 (140) }
$$

Boundary Extension: Traces of a Perceptual Schema. HELENE INTRAUB, JENNIFER L. BODAMER, \& EDWARD WILLEY, University of Delaware-Viewers' picture memory is usually distorted; they remember information that was not in the picture, but is likely to have existed just outside its boundaries. Experiment 1 shows that this occurs even when viewers receive prior knowledge of (1) the type of tests and (2) the phenomenon itself. Experiment 2 replicates it following long and brief $(250 \mathrm{msec})$ presentations. Results suggest that picture perception includes activation of a perceptual schema that becomes incorporated in the pictorial representation in memory.

$$
\text { 4:10-4:25 (141) }
$$

Bearings in Mental Maps. KARL F. WENDER \& MONIKA WAGENER, University of Trier-Mental representations of spatial relations were investigated by judgments of spatial directions (bearings) between locations within a configuration. A method similar to nonmetric multidimensional scaling is presented to reconstruct a previously learned configuration from directional judgments. The usefulness is demonstrated using data from an experiment in which subjects learned the map of a fictive city. A second experiment tested the perception of directional judgments under various conditions.

$$
\text { 4:30-4:45 (142) }
$$

Gestalt Self-Organizing Forces in Visual Memory. LEWIS O. HARVEY, JR., University of Colorado, ANNE IGEL, University of Regensburg, \& ERIC K. SCHMIDT, University of Colorado-The errors made in reproducing the location of simple visual stimuli presented within a frame are not random: They are greatly influenced by the shape of the frame. The theoretical forces generating these patterns of errors may be represented by dynamic potential fields and may be computed using decomposition methods based on vector calculus. The fields are not changed by viewing distance but are severely weakened by memory loading.

\section{4:50-5:05 (143)}

High-Level Shape Recognition Without an Inferior Temporal Lobe. IRVING BIEDERMAN, University of Southern California, PETER C. GERHARDSTEIN, ERIC E. COOPER, \& CHARLES A. NELSON, University of Minnesota-Individuals with unilateral inferior temporal lobectomies performed two tasks with briefly presented lateralized line drawings: (1) naming and name priming, and (2) judging whether two objects, presented sequentially with an intervening mask, were the same or different in shape, disregarding differences in orientation up to $60^{\circ}$ in depth. In either task, the disadvantage of presenting an image to the lobectomized hemisphere, either initially or in a second priming block, was negligible.

$$
\text { 5:10-5:25 (144) }
$$

Categorical Versus Identity Information in Faces. ALICE J. O'TOOLE, University of Texas at Dallas, KENNETH A. DEFFENBACHER, University of Nebraska at Omaha, HERVÉ ABDI, \& DOMINIQUE VALENTIN, University of Texas at Dallas (read by Kenneth A. Deffenbacher)-Individual faces can be represented as a weighted combination of eigenvectors extracted from an autoassociative matrix of many faces. We test the usefulness of different eigenvector ranges for face recognition and categorization by sex. Eigenvectors with larger eigenvalues contain categorization information. We demonstrate that adding the first two eigenvectors produces a masculine face, whereas subtracting the second eigenvector from the first produces a feminine face. Recognition is better using eigenvectors with smaller eigenvalues.

\section{SPEECH PERCEPTION}

Promenade D, Friday Afternoon, 4:40-5:40

Chaired by Laurie B. Feldman, SUNY at Albany and Haskins Laboratories

$$
\text { 4:40-4:55 (145) }
$$

On the Independence of Phonetic and Auditory Perception. ROBERT E. REMEZ, JENNIFER S. PARDO, Barnard College, \& PHILIP E. RUBIN, Haskins Laboratories-Do the resources of auditory form perception contribute to speech recognition? Our new tests examine a case in which phonetic attention impaired the resolution of auditory form. Although "preemptiveness"' of the speech mode has been observed at low power, and in cases of poor auditory performance, this new instance using sinewave words elicits high performance levels. We use this new measure to assess the relative likelihood that preemptiveness occurs pre- or postperceptually.

5:00-5:15 (146)

Prerecognition Processing of Spoken Nonwords Affects Subsequent Word Recognition. WILLIAM P. WALLACE \& MARK T. STEWART, University of Nevada-Spoken words and nonwords were presented for lexical decision across five successive "gates" (initial $1 / 5$ th, initial 2/3ths, etc.) followed by a recognition test. Each word had two nonword derivations created by replacing an early or late phoneme (e.g., telegram: delegram, telegrad). Late, compared with early nonwords, averaged later gates $(4.46$ vs. 3.62$)$ for correct lexical decisions and resulted in higher false-positive recognition rates $(.52$ vs. .20) to base words.

\section{5:20-5:35 (147)}

Delayed Activation in Auditory Word Recognition: AcousticPhonetic Similarity and Phoneme Class. CYNTHIA M. CONNINE, DAWN G. BLASKO, \& DEBRA TITONE, SUNY at BinghamtonPreviously, we reported that base words are not activated by phonetically dissimilar nonwords (NUMBER-KUMBER) in a cross-modal priming paradigm. We replicated this result and extended it to show that phonetically dissimilar nonwords do activate words with sufficient delay $(350 \mathrm{msec})$. Stimuli where nonwords were created by altering a vowel showed similar results. The findings suggest that activation from lexical neighbors combines with degree of acoustic-phonetic match to modulate lexical access. 


\section{POSTER SESSION I \\ St. Louis Ballroom E, Friday Evening, 5:45-7:15}

(148)

Observational Learning of Fishing Behavior in Bushbabies (Otolemur garnettii). J. P. WARD \& S. L. WATSON, Memphis State University-Thirty-eight bushbabies (Otolemur garnettii) were exposed to either active, passive, or no models and subsequently assessed for acquisition of fishing behavior. Results indicated that model type influenced latency to approach fishbowls and duration of interaction with them. Interestingly, lineage (i.e., whether the animals' parents fished), rather than model type, significantly predicted actual fishing behavior. Discussion centers around implications for modeling studies and the importance of heredity and/or mother-infant interactions on future behavior.

(149)

US Preexposure Strengthens Taste Aversions at Short Retention Intervals. W. ROBERT BATSELL, JR. \& MICHAEL R. BEST, Southern Methodist University (presented by Michael R. Best)-Saccharin aversions are weaker when tested 1 day after conditioning than 5 days later. This outcome is partially attributable to the novelty of the conditioning episode. When US preexposure is delivered to reduce novelty, no effects are seen at a 5-day retention interval. However, at a 1-day interval, this manipulation appears to strengthen the aversion relative to controls. These findings will be discussed in relation to retention interval effects and US preexposure effects.

(150)

A Laboratory Simulation of Social Foraging in Pigeons. DAVID E. HOGAN, AMY T. WOESTE, \& NGOZI O. KANU, Northern Kentucky University-Follower pigeons were reinforced for pecking a key that was either adjacent or nonadjacent to a key pecked by a leader bird (a concurrent choice procedure). A preference for the adjacent key was found to be correlated (1) directly with the speed of pecking by the leader bird during the trial and (2) inversely with increases in reinforcement duration for nonadjacent choices (nonadjacent choices produced either 2,4 , or 8 times more food than did adjacent choices).

(151)

Visual Asymmetry Patterns During Mental Rotation: Effects of Age and Spatial Ability Level. STEPHANIE M. CLANCY, Southern Illinois University-Carbondale-Young (18-22 years) and older adults (60-75 years) varying in spatial ability were administered a computerized mental rotation task under lateralized viewing conditions. Subjects were required to discriminate figures selected from the Vanderplas and Garvin (1959) standardized set of random shapes that were rotated from a standard orientation and presented at approximately $3^{\circ}$ of visual angle of fixation. The Vandenberg and Kuse Mental Rotations Test was administered to assess spatial ability level. Main effects and interactions involving age (young vs. old), spatial ability level (high, medium, low), degree of rotation, visual field (LVF vs. RVF), and response type (same vs. different) were observed for both the reaction time and percent correct data. The pattern of results indicates that spatial ability level significantly influences age differences in asymmetry patterns during a mental rotation task.

Factors Affecting Performance in a Lateralized Embedded Figures Task. DANIEL VOYER \& BLAINE D. CHISHOLM, St. Francis Xavier University-A lateralized embedded figures task (EFT) was used to investigate the relation between gender, familial left-handedness, solution strategy, and laterality. Right-handed subjects showed a right hemisphere advantage (RHA) on the EFT. However, this RHA was stronger in males with familial left-handedness and females without familial lefthandedness. Solution strategy was a significant predictor of overall performance, but did not predict laterality effects. These findings are discussed in terms of their implications for future research on the lateralization of spatial functions.

\section{(153)}

Individual Differences in Foveal Local/Global Processing: Role of Interhemispheric Interaction. STEPHEN CHRISTMAN, University of Toledo-Individual differences in the processing of local/global information under conditions of foveal versus lateralized presentation of input were examined. Although left- and right-handers did not differ in direction or extent of hemispheric lateralization for local/global processing, left-handers exhibited both greater interference and greater integration between local and global levels in foveal processing. The results highlight the role of the interaction between left and right hemisphere processes in central vision.

\section{(154)}

Differential Hemispheric Bias for Prototype Abstraction Processes. ROBERT SOLSO \& PATRICK AMENT, University of Nevada, RenoThe focus of this study is an investigation of the potential differential capabilities of the cerebral hemispheres to abstract information and to store it as a prototype representation. Subjects were presented with a set of exemplars (abstract patterns or numbers) derived from a prototype stimulus. This was followed by a recognition phase in which old, new, and prototype stimuli were presented. Results indicate a left visual field advantage for the abstraction of the geometric pattern prototype.

(155)

Long-Term Consequences of Closed-Head Injuries. MARC MARSCHARK, LYNDA RICHTSMEIER, University of North Carolina at Greensboro, \& HERBERT CROVITZ, Duke University-Long-term effects of minor to moderate closed-head injuries (CHI) were examined in samples of university students with and without histories of $\mathrm{CHI}(N=$ 303). Cognitive tests assessed verbal and nonverbal memory as well as visuospatial and verbal fluencies. Affective-emotional variables also were examined. Results indicated no reliable differences among groups on any cognitive measures. Across replications, however, $\mathrm{CHI}$ students significantly and consistently reported more emotional distress and dysfunction than did two control groups.

(156)

The Psychological Reality of the Body Schema: A Test With Normal Subjects. CATHERINE L. REED \& MARTHA J. FARAH, University of Pennsylvania-Neuropsychological dissociations suggest the existence of a "body schema," a representation of the spatial relations among body parts, not used for other spatial stimuli. Two experiments verify the psychological reality of the body schema. In Experiment 1, proprioceptive information concerning one's own body position influences visual perception of others' body positions. In Experiment 2, this effect is shown to be specific to the perception of bodies, as opposed to other complex three-dimensional forms.

(157)

Deficits in Visual Attention Following Parietal Damage: Object Based or Space Based? ROBERT EGLY, University of Califormia, Davis, JONATHON S. DRIVER, University of Cambridge, \& ROBERT D. RAFAL, University of California, Davis-When parietal patients attend to an object, they have difficulty disengaging to attend to a contralesional stimulus. Theories dispute whether attention is object-based or space-based. We examined whether the disengage deficit applies to objects or to space per se by requiring an attentional shift which was constant in distance and acuity, but we manipulated whether patients had to disengage from one object to attend to another. The data indicate both object-based and space-based mechanisms.

$$
\text { (158) }
$$

Toward an Image Similarity Metric. FRANK M. MARCHAK, JACOB D. GOLDSTEIN, TASC, \& JON L. DESMOND, U.S. Army Labcom-A metric is described that captures the visual similarity of images of natural scenes, based on measures that characterize orientation, number and magnitude of edges, scaling of texture elements, distribution of elements, and hue/brightness. These measures include contrast, fractal dimension, correlation distance, hue, and intensity. A vector description is constructed on the basis of these measures, and a standard distance metric is used to describe the degree of difference between the images.

\section{(159)}

Anomalous Trichromats Show Luminance Additivity. CHARLES B. WOODS, KEITH D. WHITE, \& ANDREA WALCZAK, University of Florida-Luminance additivity fails in color-normal observers, giving evidence of their color-opponent processing. We measured thresholds for $6^{\circ} 546 \mathrm{~nm}, 632 \mathrm{~nm}$, and $546 \mathrm{~nm}+632 \mathrm{~nm}$ increments made to $12^{\circ}$ backgrounds in anomalous trichromats who have moderate to small 
Rayleigh match ranges (good color discrimination). The adapting backgrounds were $2850 \mathrm{~K}$ white or monochromatic $(546 \mathrm{~nm}$ or $632 \mathrm{~nm})$. Unlike normals, these anomalous observers show luminance additivity, and thus no evidence of color opponency in these detection tasks, despite possessing good color discrimination

(160)

A Neural Architecture for Visual Search. WILLIAM ROSS \& ENNIO MINGOLLA, Boston University (presented by Ennio Mingolla)-A model of early visual processes performs search by parallel object segmentation or grouping and serial object recognition. The model explains parallel conjunctive searches as recursive applications of mechanisms that help separate figure from ground. Although related to feature integration theory and guided visual search, the model differs in treating search as one application of more general object separation and recognition mechanisms. Simulations of the model account for important recent data, both qualitatively and quantitatively.

(161)

Necessary Conditions for Speeded Visuomotor Adaptation. BRUCE BRIDGEMAN, SULEKHA ANAND, University of California, Santa Cruz, KAITLIN E. BROWMAN, University of Michigan, \& ROBERT B. WELCH, NASA-Ames Research Center-In adaptive generalization (Welch, Bridgeman, Anand, \& Browman, 1991), subjects adapt to two opposite prismatic displacements of the visual field and improve their rate of adaptation after 12 alternating 30-trial exposures. We demonstrate here that 5 exposures are not sufficient to establish adaptive generalization. In a second experiment, subjects did not improve in the rate of adaptation even after 15 exposures of 18 trials each, nor could they transfer visuomotor adaptation to the hand not used in training. These results help to define the conditions necessary for adaptive generalization. (162)

Discrimination of Filled and Empty Short-Time Intervals. SIMON GRONDIN, Laurentian University-The extent to which the signal types influence the discrimination of short-time intervals remains an open question. Two experiments are presented to compare the discrimination of filled and empty intervals in both auditory and visual modalities. In Experiment 1 , where intervals are about 250 -msec, the discrimination is superior with empty intervals in both modalities. In Experiment 2, with intervals lasting about $50 \mathrm{msec}$, empty intervals show superior performances with visual signals only. The results are discussed in terms of timing mechanisms.

\section{(163)}

Subjective Tilt Illusion in Dot Localization. DAVID J. BRYANT \& ILAVENIL SUBBIAH, Northeastern University-Diagonal lines appear tilted away from axes of symmetry. In three experiments, subjects estimated the location of a dot relative to orthogonal axes. Responses were biased away from axes of symmetry. Provision of instructions to estimate location on each axis separately eliminates the effect, suggesting that subjects normally judge location relative to the origin of the two axes, creating a subjective line that appears tilted away from axes of symmetry.

Rotation in Depth of Linear Arrays of Points Systematically Influences Egocentric Localization. WENXUN LI \& LEONARD MATIN, Columbia University-Two $64^{\circ}$ long vertical arrays of equally spaced visible points in a frontoparallel plane were symmetrically positioned around the median plane ( $25^{\circ}$ eccentricity) in darkness. Visually perceived eye level (VPEL) was measured at 63 combinations of array pitch ( 7 values) and number of points (NOP, 9 values). The slope of the VPEL/pitch function was linear and increased with NOP along a negatively accelerated exponential. For NOP $=25$, the slope reached the value measured for two continuous $64^{\circ}$ lines.

$$
\text { (165) }
$$

The Basketball Hoop Illusion. MICHAEL K. MCBEATH, NASAAmes Research Center-Observers were found to typically underestimate the diameter of a basketball hoop relative to that of a basketball by $20 \%$ or more. The illusion occurs in other sports with balls and holes, and is independent of exposure to the sport. Findings support that distortion is due to observers confounding linear extent of an object with projected area. Observers appear to routinely make large systematic er- rors in judgments concerning sizes of familiar, closely viewed, threedimensional objects.

(166)

Distractor Location and its Effect on Target Processing. PAULA GOOLKASIAN, University of North Carolina at Charlotte-The location of a letter distractor was manipulated to study its effect on performance in a Stroop-like task. In the first study, distractors appeared in a known foveal or peripheral location, while in the second study there was uncertainty regarding the location of the distractor. Foveal distractors consistently disrupted target processing while peripheral distractors influenced target processing in a more selective way that depended upon the relatedness of the stimuli and the target location.

\section{(167)}

The Whole Advantage in Object and Part Comparisons. CORLENE ANKRUM, Washington State University at Vancouver, \& JOHN PALMER, University of Washington-In same-different tasks, observers perform better on comparisons of two whole objects than on comparisons of a whole object and a part (Ankrum \& Palmer, 1991). The present study investigates four hypotheses for this whole advantage. These hypotheses attribute the effect to invalid parsing by the observer, emergent features present only in whole objects, or advantages for whole objects in encoding or retrieval. Of these, only the retrieval hypothesis can account for all the findings.

\section{(168)}

Sequence Comparison Methods Can Be Used to Study Speech Perception. LYNNE E. BERNSTEIN, Gallaudet University, \& MARILYN E. DEMOREST, University of Maryland Baltimore CountySubjects lipread isolated sentences. Responses were phonemically transcribed and computationally aligned (phoneme-by-phoneme) with transcribed stimulus sentences. The method employs a perceptual distance metric and an algorithm for minimizing the total estimated perceptual distance between stimulus and response. Study of randomly selected versus true stimulus-response alignments shows measures such as phonemes correct and substitution uncertainty are sensitive to the nature of sentence pairs. True alignments reveal perceptual effects such as misaligned word boundaries.

\section{(169)}

Influence of Internal Phonetic Category Structure in On-Line Speech Processing. SARAH C. WAYLAND \& JOANNE L. MILLER, Northeastern University-Recent research shows that phonetic categories have internal structure, in that listeners judge some members within a category as more prototypical than others. In the present investigation, which used an on-line syllable monitoring task, we found that prototypicality judgments are correlated with monitoring speed: the more prototypical the stimulus, the more quickly it is identified. We take this finding as evidence that internal category structure plays a role in on-line speech processing.

Locus of the Lexical Shift in Ganong's Phoneme Identification Paradigm. MARK A. PITT, Ohio State University-In the Ganong paradigm, subjects tend to identify an ambiguous token-initial phoneme so that the utterance forms a word, not a nonword. This finding has been interpreted as evidence of lexical knowledge facilitating phonemic processing. An alternative interpretation attributes the lexical shift to postperceptual response bias. Two experiments examined these alternatives by analyzing identification data using signal detection theory analysis methods. Results suggest that the shift is due partially to changes in perceptual sensitivity.

Eye Movements in Chess: Perceptual Differences Between Experts and Novices. EYAL M. REINGOLD, University of Toronto, Erindale College, \& NEIL CHARNESS, University of Waterloo-The perceptual component of chess skill was investigated by recording eye movements of experts and novices during a "check detection" task. Results indicated that with increased skill there was less sensitivity to the number of distractors, the presence or absence of a Knight, and the impact of substituting the traditional chess symbols with letters (e.g., $\mathrm{K}$ for King). Similarly, eye movements during choose-a-move and position recognition tasks demonstrated experts' superiority in perceptual analysis. 


\section{(172)}

Analogical Transfer: From Diagrammatic Pictures to Real-World Problems. ZHE CHEN, University of Kentucky-In four studies, subjects viewed a sequence of diagrammatic pictures, interpreted their conceptual meanings, and then attempted to solve a real-world problem using the conceptual information from the pictures. The results indicate that stimuli features such as object concreteness, surface attribute similarity, causal relations, and procedural detailedness affect the cognitive components involved in analogical transfer: extracting the conceptual information, noticing and mapping the analogous relations, and executing the solutions in solving the target problem.

Problem Solving by Novice Macintosh Users. JENNIFER L. DYCK, University of Central Florida-Naive computer users completed one of four instructional conditions: no instruction, mouse/icon, file manipulation, or MacTour. Subjects then solved mouse/icon, file manipulation, and transfer tasks. File manipulation tasks took longer to complete and were completed less frequently than mouse/icon tasks. Additionally, for nonpracticed tasks, subjects were more likely to use the strategy of label-following, a tendency to choose menu items that share one or more terms with the task description.

(174)

Across-Domain Transfer From Program Debugging to Electronic Troubleshooting. ADRIENNE Y. LEE \& NANCY PENNINGTON, University of Colorado, Boulder (presented by Nancy Pennington)Transfer across domains was investigated by having experienced subjects (extensive programming but no electronics) and inexperienced subjects (no programming or electronics) debug programs and troubleshoot circuits. Four levels of diagnostic skill were identified. Few inexperienced subjects displayed high strategy levels in either domain; however, all experienced subjects diplayed high levels on most problems. Results suggest that general diagnostic skills spontaneously transfer across domains with extensive practice in one domain; but these skills are not universal.

Problem-, Process-, and Self-Oriented Verbalizations and Their Relation to Problem Solving Performance. LINDA S. BUYER, University of Notre Dame, BERNADETTE BERARDI-COLETTA, University of Illinois at Chicago, \& PAMELA THORPE, University of Notre Dame-Chi et al. (1989) have demonstrated that "Good" problem solvers generated many more verbalizations and proportionally more self-explanations than "Poor" solvers while studying worked-out examples of mechanics problems. Our subjects verbalized while trying to solve arrangement, transformation, and inducing structure problems. Contrary to Chi et al., our solvers generated fewer verbalizations than nonsolvers. Solvers produced proportionally more process-oriented statements while nonsolvers produced proportionally more self-oriented statements. Solvers and nonsolvers did not differ in proportion of problemoriented statements produced.

\section{(176)}

Reasoning About Curvilinear Motion: Using Principles or Analogy. RICHARD CATRAMBONE, Georgia Institute of Technology, JOHN JONIDES, University of Michigan, \& CAREN M. JONES, Stanford University-People often predict a curved path for an object exiting a curved tube, presumably because of faulty intuitions about physics. Yet, if people remember a familiar situation, such as water exiting a twisted garden hose, they correctly predict a straight path for the object. A second study disconfirmed a hypothesis suggested by subject protocols, specifically, that the hose implied greater speeds and therefore straighter paths for the object.

\section{(177)}

Evidence for Scripts for Everyday Motor Activities. TERRY R. GREENE, SUSAN E. HOUSTON, CANDACE C. REINSMITH, \& EDWARD S. REED, Franklin \& Marshall College-The hypothesis that everyday motor activities are guided by scripts was tested. Subjects physically shadowed an individual brushing his teeth. The individual's motor sequence either matched or grossly mismatched the subject's normal sequence. As evidenced by latencies and facial expressions, ability to shadow was facilitated in the matched condition and adversely affected in the mismatched condition, thus supporting the hypothesis. (178)

Detailed Recognition Memory for Pictures and Stories Presented Separately and Simultaneously. VIRGINIA A. DIEHL, Western Illinois University - Two experiments examined how recognition memory for auditorily presented stories and picture details is influenced by (1) the extent to which the picture is coherent and (2) the simultaneous presentation of a picture and story. Greater coherence had a detrimental effect on memory for picture detail. In addition, the results suggested that when visual task demands were high (i.e., when the picture was least coherent), a bias toward visual information (picture) processing occurred.

(179)

"Earwitness" Voice Recognition: Accuracy and Impact on Jurors. LORI R. VAN WALLENDAEL, AMY SURACE, MELISSA BROWN, \& DEBBIE HALL, University of North Carolina at Charlotte-Two hundred subjects listened to a taped sales pitch. After one of three delay intervals, subjects were unexpectedly asked to identify the "salesperson's" voice from a five-voice lineup. Delay interval had a significant effect on accuracy. Confidence was unrelated to accuracy. In a second study, mock jurors were asked to render verdicts regarding trial summaries that included an earwitness identification. Variables that affected juror verdicts were not the same as those that had affected witness accuracy.

\section{(180)}

Spatial Information Obtained From Simulated Travel is not Equally Available. DALE S. KLOPFER, GARY B. REID, Bowling Green State University, \& RAY MARCELO, Wright-Patterson Air Force Base-Levine et al. (1982) reported that spatial information obtained when subjects traverse paths while blindfolded is simultaneously and equally available. We had subjects press buttons to traverse computerdisplayed paths that were seen as connected corridors. Subjects were then placed at various path locations and pointed to other path locations. We found that pointing accuracy and latency varied across pointing tasks, suggesting that spatial information obtained in this manner is not equally available.

\section{(181)}

Cognitive Representation of Motion: Possible Effects of "Representational Friction.” TIMOTHY L. HUBBARD, Eastern Oregon State College-Influences of implied friction on remembered location of targets undergoing horizontal apparent motion are examined. When targets do not contact a surface, remembered location is displaced forward in the direction of motion and downward below the path of motion. When targets crash through a barrier or slide along the upper boundary of a surface, forward displacement decreases and downward displacement increases. Results support the hypothesis that mental representations of motion contain an analog to friction.

\section{(182)}

Central Display Location Does Not Reduce Inefficiency in Monitoring for Automation Failures. INDRAMANI L. SINGH, Banaras Hindu University, India, ROBERT MOLLOY, \& RAJA PARASURAMAN, Catholic University of America (sponsored by Raja Parasuraman)Detecting a failure in the automatic control of a flight task is poor when automation reliability is constant over time-an effect known as automation-induced "complacency." We examined whether central location of the automated task would prevent complacency during flightsimulation performance. Monitoring for automation failure was inefficient when automation reliability was constant but not when it varied over time. Thus automation-induced complacency cannot be prevented by central location of the automated task.

(183)

The Effect of Repeated Responses on Response Time. DANIEL B. WILLINGHAM, University of Virginia, \& BRIAN J. PRENDERGAST, Williams College-Subjects performed a two-choice response time task with no warning (NoWarning), with a warning regarding where the GO signal would appear (WarningWatch), or with a warning that subjects responded to (WarningPush). As expected, RTs were faster in WarningWatch than in NoWarning; RTs were still faster in WarningPush. 
The results are discussed in terms of the possible locus of the effect and in terms of its relationship to sequential effects in continuous RT tasks.

Motor Programming of Keystrokes Under Varying Response Conditions. PATRICIA A. MULLINS, Catholic University of AmericaReaction time to begin typing a prespecified number of keystrokes increases as the length of the sequence increases when alternating index fingers are used but not when the same index finger types repetitively. However, with an interference task, responses produced by repetitive single index fingers also demonstrate an increased reaction time effect. These findings are discussed in the context of claims that motor programming underlies movement execution as an organizational strategy to control serial order.

\section{(185)}

Observational Learning and Characteristics of Motor Reproduction. YEOU-TEH LIU \& LES G. CARLTON, University of Illinois, UIUC (presented by Les G. Carlton)-The characteristics of movement reproduction from observational learning were examined. Delayed and concurrent imitation strategies were used to examine the spatial and temporal characteristics of movement reproduction. Learning occurred with both imitation strategies. Movements produced from the delayed imitation strategy followed the natural intrinsic dynamics of the movement system. For the concurrent imitation strategy, however, a nonstable coordination mode emerged in early stages of imitation.

\section{(186)}

Joint Angle Determinants in Aimed Arm Movements With Excess Degrees of Freedom. CHARLES E. WRIGHT \& REBECCA STATES, Columbia University-Horizontal arm movements of a seated subject are resolved into angles at five joints. Although a strong influence, the two-dimensional position of the target alone does not determine final joint configuration. Other determinants that we explore include: the relative location of the starting position, the arm configuration at the starting position, recent configurations at the target, and jointangle preference gradients. Unlike studies of Brüwer and Cruse, our experiments control and manipulate speed and accuracy task constraints (187)

Orthogonal S-R Compatibility: Influence of Hand Eccentricity. DANIEL J. WEEKS, Lakehead University, \& ROBERT W. PROCTOR, Purdue University-Micheals (1989) reported that orthogonal S-R compatibility effects for responses made at left and right eccentricities from the body midline were mediated by the identity and spatial eccentricity of the responding hand. However, hand and response locations were confounded in that study. The confound was removed in the present experiment thereby demonstrating that the compatibility effects reported by Micheals are attributable to spatial eccentricity and not limb identity.

(188)

The Relationship Between Reaction Time and Response Organization. IAN M. FRANKS, MARION KETELAARS, \& PAUL NAGELKERKE, University of British Columbia-An experiment by Henry and Rogers (1960) showed that subjects spent more time preparing a complex response than they did a simple finger lift. Since that time researchers have had equivocal findings investigating this phenomenon. However, the definitions of movement complexity have been confined to gross behavioral levels of analysis, that is, number of movement reversals, number of tapping movements, and so forth. Several experiments are described herein that show simple reaction time is related to changes in the organization of the response, organization being defined in terms of the acceleration traces and the pattern of EMG recordings associated with the movement.

(189)

Recognizing Subjectivity in Fictional Narrative: The Role of Subjective Elements. GAIL A. BRUDER, SUNY at Buffalo, \& JANYCE M. WIEBE, University of Toronto-Eight passages from fiction were selected to test part of Wiebe's (1990) algorithm for recognizing subjective sentences. For each passage, subjects read either the original or an experimental version with subjective elements removed from one sentence. Following each passage, one objective and one subjective statement tested the interpretation of that sentence. As predicted by the al- gorithm, subjects' test statement agreement ratings showed more tendency toward subjective interpretations with original than with experimental versions

\section{(190)}

Egocentric Perspective in Conversational Descriptions of a Complex Display. MICHAEL F. SCHOBER, New School for Social ResearchSpeakers described locations of geometric shapes on a complex display for a partner whose vantage point was the same, $90^{\circ}$ off, or $180^{\circ}$ off. The partners were either imaginary or other subjects who gave feedback in conversation. Speakers with imaginary addressees usually took their partner's perspective. Speakers with actual partners were more likely to speak egocentrically, and they said less. Other aspects of the descriptions varied at the different vantage point offsets.

(191)

Relationship Between Importance Ratings and Recall for Procedural Texts. CAROL BERGFELD MILLS, Goucher College, VIRGINIA A. DIEHL, Western Illinois University, DEBORAH P. BIRKMIRE, US Army Human Engineering Laboratory, \& LIEN-CHONG MON, University of Maryland-Correlations were performed between importance ratings and recall for eight different procedural texts. Two units of analysis were used-idea units and propositions. With propositions, correlations tended to be larger than for idea units, but correlations were not as large as in previous research with narrative texts.

The Role of Logical Connectives in the Processing of Coherent Discourse. JOHN D. MURRAY, University of Florida-Reading time and cued-recall were measured as subjects read coherent sentence pairs reflecting additive, causal, and adversative relationships. An appropriate connective was placed between the sentences for half of the subjects and omitted for the remaining subjects. The absence of a connective only affected reading time for the adversative pairs and memory for the causal pairs. The roles of the connective and the intersentential relationship on the maintenance of local coherence are discussed.

(193)

Hearing the Sarcasm: The Illusory Transparency of Intention With Spoken Messages. BOAZ KEYSAR, University of Chicago-Subjects listened to answering-machine messages ("Thanks a lot for the helpful hint") and judged their intended and perceived meanings. Privileged information led them to believe that the speaker was either sincere or sarcastic. Though they knew that the addressee had no access to the information, they thought that sarcasm would be perceived when it was intended. Both judgment and latency measures reveal this egocentric bias, generalizing the phenomenon from written to spoken modality. (194)

How Long Does It Take to Activate an Inference? JOSEPH P. MAGLIANO, WILLIAM B. BAGGETT, \& ARTHUR C. GRAESSER, Memphis State University-We investigated whether causal antecedent, causal consequence, superordinate goal, and subordinate goal inferences are generated on-line during comprehension and also determined the time course of their activation. The study incorporated a lexical decision task and manipulated inference category, the rate of word presentation in a rapid serial visual presentation (RSVP) format, and the delay between the last word in a sentence and the test word in a stimulus onset asynchrony (SOA) interval.

The Forms and Functions of Figurative Language. RICHARD $M$. ROBERTS, National Center for Health Statistics, \& ROGER J. KREUZ, Memphis State University (presented by Roger J. Kreuz)-Speech act theory emphasizes the goals and intentions that underlie figurative language. However, these goals have never been completely specified. We developed a goal taxonomy for eight figures of speech: hyperbole, idioms, indirect requests, irony, understatement, metaphor, rhetorical questions, and simile. We verified the taxonomy by asking professors of English to provide similarity ratings for these eight figures. Their expert ratings of similarity correlated significantly with novices' intuitions about how the figures are used.

$$
\text { (196) }
$$

Naming and Lexical Decision Provide a Window Into Syntactic and Semantic Processes. JULIE E. BOLAND, Ohio State University- 
Sentence processing research has long needed a direct methodological probe capable of distinguishing between initial syntactic and semantic representations. A series of experiments tested and supported the hypothesis that cross-model naming is selectively sensitive to syntactic representations whereas lexical decision is sensitive to both syntactic and semantic representations. This paradigm could provide critical information concerning the flow of information through the sentence processing system. Suggestive results and experimental parameters are discussed.

\section{(197)}

Advance Planning of Phonological Segments in Language Production. ROBERT R. PETERSON, Indiana University, \& CURT BURGESS, University of California, Riverside-Planning of segmental information was investigated using a "modified" memory search task. Subjects prepared short utterances, and had to determine whether a target word was part of the sequence. Distractors shared either onset or coda segments with a word in the utterance. Based on interference observed for these distractors, it appears planning of codas is limited in range, while onset preparation is less sensitive to serial distance. Further, intonational structure appears to modulate phonological encoding.

\section{(198)}

Cues to the Comprehension of Anaphoric Pronouns. JEAN E. NEWMAN, University of New Mexico-The relative importance of (verb) semantics, word order, and focus (passivisation) to the interpretation of ambiguous pronouns in auditorily presented sentences was assessed with both an "on-line" naming task and a sentence-final comprehension task (verification). Semantic cues are most important but interact with word order, indicating a default preference for the most recently mentioned noun rather than a "perspective-taking"' strategy, even for passive sentences.

\section{(199)}

Pigs Don't Fly: Cues in First- Versus Second-Language Reading. CHERYL FRENCK-MESTRE, JOEL PYNTE, Université de Provence, \& JYOTSNA VAID, Texas $A \& M$ University (sponsored by Steven M. Smith)-Two experiments aimed at evidencing strategy differences in first- versus second-language reading. Experiment 1 compared the strategic use of animacy in both languages for syntactically complex sentences. Experiment 2 examined whether the detection of syntactic errors would differ between the two languages, especially where nonsyntactic cues could be used to compute sentence meaning. Results are discussed relative to the suggestion that good and poor readers differ in their use of syntax.

\section{(200)}

Can Plagiarism Occur Inadvertently? PATRICIA L. TENPENNY, Loyola University of Chicago-Brown and Murphy (JEP:LMC, 1989) suggested that plagiarism may occur inadvertently if one has implicit memory for an item without explicit memory. Their experiments employed items from common categories. However, charges of plagiarism challenge the claim that one's work is truly novel, not just novel in a particular context. The present experiment varied whether known exemplars (e.g., cat) or novel exemplars (e.g., yalpmer) were produced. Inadvertent plagiarism occurred only for known exemplars.

(201)

The Advantage of First Mention in Spanish. MANUEL CARREIRAS, Universidad de La Laguna, MORTON ANN GERNSBACHER, University of Wisconsin - Madison, \& VICTOR VILLAGOOD, University of Oregon-The advantage of first mention, which is readers' faster access to participants mentioned first in a sentence, has been observed only in English. Because Spanish allows patientfronting, without using the passive voice, Spanish sentences can isolate the advantage of first mention from an advantage of syntactic subject. Three experiments demonstrated that the advantage of first mention occurs in Spanish, for both first-mentioned participants and first-mentioned inanimates (in sentences containing two inanimates).

$$
\text { (202) }
$$

Interaction of Thematic and Lexical Information in Parsing: $A$ Connectionist Account. CURT BURGESS, University of California, Riverside, DEBORAH M. SHAIBE, Louisiana State University, MING LI, Syracuse University, \& ROBERT R. PETERSON, Indiana Univer-
sity-A series of simulation experiments demonstrates that the probability of a syntactic garden path is determined by the convergence of thematic, lexical, and grammatical information. Specifically, the thematic fit of agents and patients, morphological verb bias, and processing of the disambiguating preposition with the ambiguous verb can account for garden-path behavior exhibited by human subjects. Simulation results fit well with data from two existing experiments (Burgess et al. 1990, 31 st Annual Meeting of the Psychonomic Society, New Orleans).

Mechanisms Underlying Priming on Word- and NonwordFragment Completion. BRADFORD H. CHALLIS, MARY JACIW, \& CHRISTINE E. PIVETTA, University of Toronto-Subjects studied words (NUTMEG), regular nonwords (CHOCEL), and irregular nonwords (BNEFKR) under conditions designed to control perceptual and lexical processing. At test, subjects completed word (-U-M-G) and nonword fragments (CH-CEL, B-EFKR; say the first letter that comes to mind). The results imply that perceptual, lexical, and perhaps conceptual processes may play a role in priming for word fragments, whereas only perceptual processes underlie priming for regular nonwords. No priming occurred for irregular nonwords.

(204)

Repetition Priming for Newly Formed and Pre-Existing Associations. YONATHAN GOSHEN-GOTTSTEIN \& MORRIS MOSCOVITCH, University of Toronto, Erindale College (presented by Morris Moscovitch)-Five studies explored the ability to form word associations in implicit memory. In a lexical decision task for pairs that had no preexisting association, repetition priming effects were found for intact but not recombined pairs. Repetition effects were greater for pairs comprised of low-frequency rather than high-frequency words. Comparable repetition effects for pairs with preexisting associations were found using a speeded semantic relatedness task. Changing modalities between study and test virtually eliminated all repetition priming effects.

(205)

Implicit Memory for "Novel" Words: The Role of Prior Knowledge. JENNIFER DORFMAN, University of Arizona-Four experiments investigated the role of componential information in implicit memory for "novel" words. Word judgments were biased by prior presentation of novel words formed out of morphemes and syllables but not pseudosyllables, an effect dissociable from explicit memory. These results are interpreted in terms of the activation and integration of componential information and as evidence against the role of new (e.g., perceptual) representations in priming of novel information.

(206)

Increasing Word Length of Repeated Word Does Not Eliminate Repetition Blindness. STEPHEN A. WURST \& EDWARD MILLET, SUNY at Oswego-Distinctiveness of a repeated word was manipulated in an RSVP task to study repetition blindness (Kanwisher). All words in each sentence were five letters or less, except for the repeated word of eight letters or more. Repetition blindness still occurred with these items. The differences between the inability to detect repetitions in this task and previous research where repetitions are accurately detected (Wurst) will be discussed.

\section{(207)}

Towards a Distinctive Model of Serial Position Effects in Recognition. IAN NEATH, Purdue University-Digitized photographs of snowflakes were presented for a recognition judgment after varying retention intervals. While overall accuracy and discrimination remained constant, as the retention interval increased, primacy increased from chance to reliably better than chance, but recency decreased to chance levels, replicating Wright et al. (1985). A variation of Murdock's (1960) distinctiveness model accounted for the changing primacy and recency effects. Similar patterns were observed for both between- and withinsubjects designs.

\section{(208)}

Context Effects on Digit Recall. JEROME FRIEMAN, RODNEY VOGL, NANCY ELDER, \& ALLISON FOX, Kansas State University-The effects of retrieval cues on digit recall were investigated in two experiments. Each trial consisted of the serial presentation of 12 digits followed by a recall test. Some or all of the other digits were pre- 
sented on test trials. The obtained serial position curves flattened when the other 11 digits were presented during testing.

(209)

Cued Recall Hypermnesia: A Test of Multiple Retrieval Cue Hypothesis. HOWARD L. WHITEMAN, HAJIME OTANI, \& VICKIE OWENS, Central Michigan University (presented by Hajime Otani)The hypothesis that cued recall hypermnesia is based on the availability of multiple retrieval cues that relate target items together was examined. Subjects studied a list of $\mathbf{3 6}$ word pairs by either generating two additional cues, generating one additional cue, or copying the cue that was provided. The categorical nature of the list was also manipulated. The results showed that in both categorized and uncategorized lists, multiple retrieval cues produced greater hypermnesic effects.

Further Dissociations Between "Remember" and "Know" Judgments in Recognition Memory. SUPARNA RAJARAM \& H. BRANCH COSLETT, Temple University School of Medicine - In a recognition memory task where subjects made "Remember" (to items recollected vividly) or "Know" (to items recognized on some other basis) judgments, "Remember" responses increased with greater perceptual overlap between study and test items (e.g., picture-picture vs. word-picture; same vs. different picture size) while "Know" responses increased in the crossformat conditions These results are inconsistent with the notion that " $\mathrm{Re}$ member" and "Know" responses are affected by conceptual and perceptual manipulations, respectively.

\section{(211)}

Tracking Relative Reinforcement Rate Reversals. LEON R. DREYFUS, DANIEL KOLKER, Vassar College, \& D. ALAN STUBBS, University of Maine-Pigeons were exposed to concurrent schedules in which each session included an unsignaled shift in the distribution of reinforcers. The temporal location and duration of these reversals in relative reinforcement rate were varied systematically over sessions. Time allocation followed relative reinforcement rate more closely at higher overall rates of reinforcement and with longer reversal durations. Tracking also depended on the temporal location of the reversal period.

(212)

Sensory Preconditioning in a Flavor Learning Paradigm. RON MEHIEL \& WILLIAM WILSON, Shippensburg University-Three experiments compared the efficacy of flavor-taste and flavor-calorie associations to foster sensory preconditioning in rats. Calories were a more potent US than was sweetness. Calories and sweetness together did not produce stronger sensory preconditioning than calories alone. Differences in sensory properties of conditioning and testing solutions produced negative contrast in tests for sensory preconditioning, but not positive contrast.

\section{(213)}

Rhythmic Influences on Harmonic Expectancy. MARK A. SCHMUCKLER, University of Toronto, Scarborough Campus, \& MARILYN BOLTZ, Haverford College-A series of experiments examined the role of rhythmic context on harmonic expectancy formation and processing. On the basis of reaction time and rating scale measures, expectancies for a final chord (preceded by three context chords) varied as a function of the harmonic identity of the final chord, the rhythm of the context chords, and the timing of the final chord relative to a steady pulse. These results suggest the necessity of temporal weighting factors in models of harmonic processing.

Explicit and Implicit Memory for Song Lyrics. WANDA T. WALLACE \& MATTHEW D. SCHULKIND, Duke University-How many times have you sung along with a popular song without having thought about its semantic content? An experiment, using both explicit and implicit tasks, assessed memory for a novel song. Under incidental learning instructions, subjects appear to process songs for their surface, rhyth- mic, poetic, phonemic, and perhaps emotional content much more than for their semantic content, whereas the same words when spoken, rather than sung, appear to encourage greater semantic processing.

$$
\text { (215) }
$$

Recall of Musical Cadences. LEON MILLER, University of Illinois, Chicago-Sensitivity to musical sequential structure was investigated in two groups of pianists who demonstrated noncontextual pitch-naming ability. Nondisabled and disabled musicians were asked to listen to and then reproduce chord sequences of varied cadential structure and length. Recall accuracy increased with more conventional chord grouping and was associated with greater "chunking" in recall. These effects were evident in both groups, although subtle differences in sensitivity were suggested in individual protocols.

Reducing "Catastrophic" Interference Through Weight Modulation. JAY C. RUECKL, Harvard University-Many of the attractive properties of connectionist networks stem from their use of superimpositional memory storage. However, superimpositional memory can also result in excessive amounts of retroactive and proactive interference. Results are presented showing that interference can be reduced through the use of item-specific weight modulation in conjunction with standard weight-modification learning algorithms.

Evolution of Consciousness. NG TAI-KEE, South China Normal University (sponsored by Cynthia $\mathrm{H}$. Null)-There are two important ways in which consciousness has evolved: (1) The human body is formed out of DNA, RNA, and protein; and (2) some Lvei link or trace can pass through the brain, hypothalamus, pituitary gland, endocrine system, immune system, and the system that determines biochemical metabolism, and can more or less affect reproductive cells, chromosomes, and genes. Lvei plays a special role and can be considered a consciousness in itself. When $t=0$, these two aspects of the evolution of consciousness will be united as a circle, with Lvei as a connective point.

(218)

Depressed Mood and Stimulus Preference. MARY TRAHAN, Randolph-Macon College-Mood induction was used to produce sad and neutral mood groups. Subjects were told they would write fictional paragraphs and selected 15 sentences from a set of $\mathbf{3 0}$ (half positive, half negative) to use as paragraph openers. Sad subjects chose significantly more negative opening sentences than neutral subjects did. Thus, stimulus choice reflected mood-congruent tendencies. Subjects who reported longer episodes of depression also chose more negative sentences than those with briefer depressions.

Cognitive Resources and the Acquisition of Spatial Knowledge. GARY L. ALLEN, University of South Carolina-The requirement to perform a concurrent task during a simulated route learning exercise significantly reduced subjects' accuracy on subsequent scene recognition and distance estimation tasks in comparison with subjects who performed no concurrent task. Performance on a map verification task was poor and was not affected by the concurrent task. Other results suggested that map alignment may be an important variable in the map verification task. Findings suggest that even basic recognition-based aspects of learning spatial layout are dependent on the dedication of cognitive resources.

Research Support From the National Science Foundation. FRED STOLLNITZ, JOSEPH YOUNG, \& N. JOHN CASTELLAN, JR., $\mathrm{Na-}$ tional Science Foundation.

Research Support From the Air Force Office of Scientific Research. JOHN F. TANGNEY, Air Force Office of Scientific Research. 
HUMAN PERFORMANCE

Rose Garden, Saturday Morning, 8:00-9:40

Chaired by Tom Petros, University of North Dakota

8:00-8:15 (222)

Does Acquisition of Skill Always Require Drill? PATRICIA BAGGETT, University of Michigan, \& ANDRZEJ EHRENFEUCHT, University of Colorado-Learning to perform paper-and-pencil arithmetic operations requires years of practice. But now calculators are being introduced in elementary school mathematics. Does learning to use them also require drill? Children in six second-grade classes used calculators several times a week during math lessons, but there were no drill and practice sessions. They were then tested for their skill in adding numbers with decimal points. Results indicate that children can acquire skills in using calculators without drill.

\section{8:20-8:35 (223)}

Pleasure as a Sign of Efficacy of Intellectual Activity. MICHEL CABANAC \& JAMES EVERETT, Laval University-Previous work has shown that sensory pleasure is the key to optimal physiological behaviors. The present study explored the hypothesis according to which pleasure would also be the key to optimal intellectual activity. Ten subjects played video golf on a Macintosh computer. After each hole, they were invited to rate their pleasure or displeasure on a magnitude estimation scale. Their ratings of pleasure correlated negatively with the difference in par minus their performance, that is, the better the performance, the more pleasure reported. This result would indicate that pleasure is aroused by the same mechanisms and follows the same laws in physical and intellectual tasks.

\section{8:40-8:55 (224)}

Imagined Rotation Rates Vary Widely in a Smooth Linear Gradient With Axis Direction. LAWRENCE PARSONS, University of Texas at Austin-Rate of imagining an object rotate about its principal axis varies widely with axis direction in a precise linear gradient, increasing as the axis approaches line of sight and decreasing as it approaches vertical. The perspective from which an object is imagined to rotate greatly and linearly affects the slope and intercept of its RT orientation function. Controlling perspective effects, slope, and intercept times trade off precisely for different rotation axes, consistent with our model.

\section{9:00-9:15 (225)}

What Stimulus-Response-Effector Relations are Learned in Choice-Reaction Tasks? ROBERT W. PROCTOR \& ADDIE DUTTA, Purdue University-Three experiments examined practice with different stimulus-response assignments and hand placements. Experiment 1 showed that spatial mapping remains the primary determinant of performance across three sessions and determines the degree of transfer to other conditions. The other experiments showed that alternation between conditions during practice interferes if the spatial mapping varies but not if it is constant. The benefits of practice in all experiments apparently reflected more efficient translation between spatial stimulus and response codes.

\section{9:20-9:35 (226)}

Maintenance of High-Level Skill in Pianists: The Role of Practice. RALF TH. KRAMPE, Max-Planck Institute for Human Development and Education (sponsored by K. Anders Ericsson)-Forty-eight pianists differing in age and skill level were compared on a variety of tasks ranging from simple finger tapping to intentional variation of performance in musical interpretation. Elderly experts had maintained the same level of skill as young experts, but showed age-related decline in far transfer tasks similar to elderly controls. Current practice level and especially practice during the last 10 years were predictive of performance after control for age and skill level.
ANIMAL COGNITION I

\author{
St. Louis Ballroom B, Saturday Morning, 8:00-10:05
}

Chaired by C. R. Gallistel, UCLA

8:00-8:15 (227)

Similarity Judgments of Facial Stimuli by Rhesus Monkeys. KARYL B. SWARTZ, Lehman College of CUNY, JOHN GIBBON, New York State Psychiatric Institute and Columbia University, \& H. S. TERRACE, Columbia University-A same-different task was used to study rhesus monkeys' perceptions of photographs of faces of monkeys and humans. Error rates on different trials were subjected to a multidimensional scaling analysis. The results suggested that the subjects' judgments were made according to species categories, that is, humans were classified with humans and monkeys were classified with monkeys. These findings have implications for theories of the biological and perceptual bases of species identity.

8:20-8:35 (228)

Human and Monkey Memory for Upright and Inverted Faces of Human and Nonhuman Primates. MARIA T. PHELPS, WILLIAM A. ROBERTS, University of Western Ontario, \& ANTHONY A. WRIGHT, Health Science Center at Houston (read by William A. Roberts)-People, squirrel monkeys, and rhesus monkeys were tested for working memory and reference memory of upright and inverted human and nonhuman primate faces. Working memory was tested using delayed matching, and reference memory was tested using two-choice simultaneous discrimination learning. Both people and monkeys showed clearly better retention of upright than inverted human faces but a less pronounced difference between upright and inverted monkey faces.

$$
\text { 8:40-9:00 (229) }
$$

Proficient Performance of a Conjunctive, Recursive Task by a Parrot. IRENE M. PEPPERBERG, University of Arizona-Comprehension abilities of a Grey parrot, Alex, were tested on conjunctive tasks. Each trial used 7 items chosen from 100 objects of various shapes, colors, and materials, and Alex had to label an instance of one category of an object that was uniquely defined by the conjunction of two other categories (e.g., "What color is the [object defined by shape and material]?). Other objects exemplified one, but not both, defining categories. Alex's accuracy was $76.5 \%$.

\section{9:05-9:20 (230)}

Recording Monkey Speech: The First "Playback" Experiments. DOUGLAS K. CANDLAND, Bucknell University-Richard Lynch Garner in 1895 used the then-new phonograph to record monkey sounds, then played the sounds to monkeys in U.S. zoos in the hope of uncoding monkey language. As the results were promising, the Smithsonian and New York Zoological Society provided funds for an expedition to Gabon, where Garner lived in a cage and did playback experiments to assess the language of chimpanzees and gorillas. This presentation reports the results.

$$
\text { 9:25-9:40 (231) }
$$

Proportional Discrimination in Rats: Further Evidence of Numerical Competence. HANK DAVIS \& AMANDA PARRIAG, University of Guelph-Although there is considerable evidence of numerical competence in many animal species, there has been little attention paid to whether nonhumans possess a sense of proportionality. In the present study, rats were trained to dig for food in locations that corresponded to $25 \%, 50 \%, 75 \%$, and $100 \%$ of the length of an enclosure. Following training, the absolute length of the enclosure was altered to test whether foraging behavior was responsive to proportional, rather than absolute distance cues. Our results suggest that rats are capable of discriminating proportionality, thus extending evidence of numerical competence in this species.

$$
\text { 9:45-10:00 (232) }
$$

Birds' Discrimination of Numerosity Changes With Dot Displays. JACKY EMMERTON, Purdue University-Pigeons were trained in a 
series of relative numerosity discriminations with simultaneously presented dot arrays. Once they reached a $70 \%$ correct training criterion, the numerosity difference between arrays was either increased or decreased on intermixed test trials. The results add support to findings that birds can differentiate the abstract property of relative number. Discrimination accuracy was modulated by the display density, suggesting that the birds used a serial scanning strategy to process the stimuli.

\section{PATTERN RECOGNITION}

St. Louis Ballroom C, Saturday Morning, 8:00-9:25

\section{Chaired by Howard C. Hughes, Dartmouth College}

8:00-8:20 (233)

Global-To-Local Change Over the Time Course of Object Recognition. THOMAS SANOCKI, University of South Florida-Primes and target objects were presented briefly, producing integration, and then masked. Identification accuracy was measured. Primes contained either global or local target features, and were presented before or after the target. When presented early in processing, global features facilitated identification more than local features, whereas later in processing, local features facilitated more than global features. Recognition may begin with the activation of a global representation, which then facilitates later encoding of local features.

$$
\text { 8:25-8:40 (234) }
$$

Levels of Stimulus Structure Versus Levels of Properties. RUTH KIMCHI, University of Haifa-The present research investigated the relative salience of level of pattern structure (global/local) and level of property (higher order/lower order) for the perceptual system. Subjects classified hierarchical patterns constructed by an orthogonal combination of level of pattern structure and level of property. Level of pattern structure and level of property interacted so that classification at the local level was inferior to classification at the global level only when it involved lower order properties.

\section{8:45-9:00 (235)}

A Context-Produced Increase in Visibility: Types of Stimuli. DONALD L. KING, HESTER HICKS, \& PAMELA D. BROWN, Howard University-Context + target and context stimuli were discriminated between, as were target and blank stimuli, using two different procedures. The context + target stimuli were a square and all the possible two-line (e.g., right angle) and three-line (e.g., bracket) stimuli with the square's top line as the target. The results indicate that the contexts of the square and three-line stimuli increased the visibility of the target more than did the contexts of the two-line stimuli.

$$
\text { 9:05-9:20 (236) }
$$

Piece-by-Piece Rotation of Visual Image Pairs. JANICE E. MURRAY, University of Otago, MICHAEL C. CORBALLIS, University of Auckland, \& JUNE CAMPSALL, Carleton University-Subjects in three experiments made reflection decisions on two-element displays rotated as a unit, where both elements were normal, both reflected, or one normal and one reflected. The estimated rate of mental rotation was half that estimated from a task involving single elements. Additional results suggest that dependence of rate of rotation on number of elements is a consequence of piecemeal rather than slower-but-holistic rotation of more complex stimuli to the upright.

\section{ATTENTION I}

\section{St. Louis Ballroom D, Saturday Morning, 8:00-9:45}

\section{Chaired by Robert S. McCann, Sterling Software}

\section{8:00-8:15 (237)}

Negative Priming in Target Localization. W. TRAMMELL NEILL, LESLIE A. VALDES, \& KATHLEEN M. TERRY, Adelphi University-In a target localization task, subjects responded to a target " $O$ '" while ignoring a distractor " $X$." Responses were slowed to probe targets at the recent distractor location. This negative priming effect (1) decays over time, (2) persists over intervening trials, (3) generalizes to relative location, (4) occurs without a distractor on the probe trial, and (5) does not occur for ignored target locations. Implications for the ories of negative priming and "inhibition of return" are discussed. 8:20-8:35 (238)

How Often is Fine, but Don't Ask Where. CLAUDE G. ČECH, University of Southwestern Louisiana-Incidental learning in frequency memory experiments is sometimes operationalized as knowing whether later memory tests will require frequency estimation. A better approach manipulates knowing whether there will be any subsequent memory tests. The current studies impose a more rigorous requirement: whether an item is in the experiment-imposed attentional focus. Given a memory task (intentional learning) and repetition of some list items in a subsequent debriefing (incidental learning), can subjects distinguish list from debriefing frequency?

$$
\text { 8:40-8:50 (239) }
$$

The Time Course of Attention Resource Allocation to Uncued Locations. MARYLOU CHEAL, DON R. LYON, University of Dayton Research Institute, \& LAWRENCE R. GOTTLOB, University of Dayton Research Institute and Arizona State University-The time course of precuing effects at the cued location has been studied widely, but the precise time course of resource allocation to uncued locations is as yet unknown. Data from our laboratory provide time courses for both the effects of central and peripheral cues. At uncued locations, there was no increase in accuracy with cue lead-time for either cue type, but accuracy was higher with a central cue than with a peripheral cue.

$$
\text { 8:55-9:15 (240) }
$$

Simultaneous Attentive and Automatic Processing of Visually Presented Characters. RICHARD SHIFFRIN, ASHER COHEN, \& MICHAEL FRAGASSI, Indiana University-To what degree do we process visual information outside the current focus of attention? We extended a task devised by Eriksen, Webb, and Fournier (1990), in which two consecutive locations are cued. Before attention moves to the target location, the information in that location is made consistent or inconsistent. We obtained evidence for two processes occurring at the same time, one reflecting processing from an attended location, and one reflecting automatic processing from nonattended locations.

$$
\text { 9:20-9:40 (241) }
$$

Testing Attentional and Motor Explanations of Inhibition of Return. HO-WAN KWAK \& HOWARD EGETH, Johns Hopkins University (read by Howard Egeth)-Inhibition of return refers to a slowing of reaction time when a target is preceded by a noninformative cue in the same spatial location. Experiments tested motor and attentional explanations of the effect; both were disconfirmed. Inhibition of return thus seems to be a simple consequence of stimulation. However, it cannot be explained in terms of low-level masking or adaptation effects.

\section{LETTER/WORD PROCESSING II}

Promenade C, Saturday Morning, 8:00-9:40

Chaired by Meredyth Daneman, University of Toronto, Erindale College

\section{8:00-8:15 (242)}

Event-Related Brain Potential Evidence of Lexical and Message Level Priming in Sentences. GARY E. RANEY, University of Massachusetts at Amherst, IRA FISCHLER, University of Florida, \& MARIUS HARDONK, State University of Utrecht (read by Ira Fischler)-The N400 component of the ERP was used to measure priming for target words presented in sentences or as part of a continuous word list. Target words were preceded by congruent or neutral contexts. Within sentences, priming increased as the contexts were made more congruent with the target words. For word lists, priming only occurred in the maximally congruent conditions. The results are described as evidence for both intralexical and message level priming.

$$
\text { 8:20-8:35 (243) }
$$

Whole Word Pattern Disruption in Lexical Decisions. GREGORY O. STONE, Arizona State University-The case alternation manipulation (e.g., WoRd) was generalized to the concept of pattern disruption (i.e., whole word patterns are disrupted, but individual letters are unaffected). When several pattern disruption manipulations were crossed with other 
factors in a lexical decision task, the same qualitative pattern of results occurred for each. However, the magnitude of effects varied consistently with type of disruption. Implications for theories of lexical access will be discussed.

\section{8:40-8:55 (244)}

Evidence for a Three-Way Horse Race During Word Recognition. PHILIP A. ALLEN \& TIMOTHY A. WEBER, Cleveland State University-We conducted four lexical decision experiments that manipulated letter case and color coding. Experiment 1 compared lexical decisions for letter sequences color coded as a function of syllable to letter sequences presented in a single color. Experiment 2 compared lexical decisions for syllable-consistent versus syllable-inconsistent color coding. Experiment 3 mixed case and color coding by syllable (i.e., half the trials were presented in lowercase with syllable-consistent and syllable-inconsistent color coding, and half the trials were presented in mixed-case letters with syllable-consistent and syllable-inconsistent color coding). Finally, Experiment 4 consisted of a lexical decision task that used all monochrome presentation but presented letter sequences in either lowercase letters (e.g., "hello"), mixed-case by syllable (e.g., "HELlo"), or mixed case by letters (e.g., "hElLo"). The results from these four experiments indicate that subjects form parallel independent word-level, syllable-level, and letter-level codes of a word during word recognition. 9:00-9:15 (245)

Flexible Coding in Visual Word Recognition. KENNETH PUGH, Haskins Laboratories, KARL REXER, University of Connecticut, \& LEONARD KATZ, Haskins Laboratories (read by Leonard Katz)Nonword context was varied in four lexical decision experiments so as to include a relatively low proportion of pseudohomophones (PH condition), or no pseudohomophones (NPH condition). Subjects in the PH condition responded faster and more accurately than subjects in the NPH condition. By several measures of phonological processing, subjects in the NPH condition showed greater sensitivity to phonological information than subjects in the PH condition. Implications for dual-route theories are discussed.

$$
\text { 9:20-9:35 (246) }
$$

The WORD Without the T-Scope. WILLIAM PRINZMETAL, University of California, Berkeley, \& BETH SILVERS, California School of Professional Psychology-Word-superiority effect (WSE) and worddetection experiments were conducted without using a brief exposure. We discovered that (1) the word-letter and word-nonword differences are caused by different factors that are typically confounded, (2) the word-letter difference is due to the relative difficulty of finding a single letter in a mask, and (3) a mask is necessary for a word-detection effect, but for a previously unsuspected reason. Implications for subliminal perception research will be discussed.

\section{HUMAN LEARNING/MEMORY II}

Promenade D, Saturday Morning, 8:00-9:40

\section{Chaired by William F. Brewer, University of Illinois}

\section{8:00-8:10 (247)}

Mirror Effect in Frequency Discrimination. ROBERT L. GREENE \& ANJALI THAPAR, Case Western Reserve University-In recognition, stimulus variables that increase hits tend to decrease false alarms (the mirror effect). Experiments reported here look for an analogous effect when subjects are given a list of repeated items and then have to make judgments of frequency. The situations under which the mirror effect is found in frequency discrimination have implications for accounts of the phenomenon.

8:15-8:30 (248)

Tests of the Mirror and List Strength Effects for Item and Associative Recognition. WILLIAM E. HOCKLEY, Wilfrid Laurier University-Associative recognition memory for random pairs of words and single item recognition were compared with respect to the mirror effect (Glanzer \& Adams, 1985, 1990) and the list strength effect (Ratcliff, Clark, \& Shiffrin, 1990). The pattern of results does not support the view that associative recognition involves a recall process (e.g., Clark,

1992). Rather, the results are consistent with the view that item and associative recognition are based on similar retrieval and decision processes. 8:35-8:50 (249)

Decision Processes in Recognition Memory: The Case of Multiple Target Distributions. ELLIOT HIRSHMAN \& DAWN TREMBATH, University of North Carolina-Chapel Hill-Recent studies of the liststrength effect in recognition memory have focused on the effect of strong items on memory for weak items when both types of items are presented in mixed lists. We consider how subjects discriminate old items from new items in these mixed lists from the perspective of signal detection theory. We hypothesize that subjects compute a mixed distribution for old items that represents both strong and weak items. This hypothesis generates predictions about response bias in mixed and pure lists that are confirmed in several experiments.

\section{8:55-9:15 (250)}

Converging Evidence for Two Processes in Recognition Memory. DOUGLAS L. HINTZMAN, University of Oregon-Several lines of evidence from our laboratory converge on the conclusion that recognition memory involves at least two processes: a fast, relatively undifferentiated assessment of familiarity and a slower, recall-like process. This evidence comes from experiments in which subjects must reject, as new, test items that are very similar to the target items. The evidence includes: bimodal frequency-judgment distributions, biphasic retrieval-dynamics functions, and differential effects of repetition and instructions.

9:20-9:35 (251)

The Role of Item-Specific and Relational Processing in Recognition and Recall. FRANCIS S. BELLEZZA, Ohio University-R. R. Hunt and $\mathrm{G}$. $\mathrm{O}$. Einstein have proposed that item-specific processing based on distinctive features of words is necessary for optimal recognition performance and that relational processing based on common word features is necessary as well for optimal free recall. Some experimental results are presented which seem to be exceptions to these rules.

INGESTIVE BEHAVIOR

Rose Garden, Saturday Morning, 9:50-11:30

\section{Chaired by Helen M. Murphy, John Carroll University}

\section{9:50-10:05 (252)}

Flavors Tasted During Recovery From Alcohol Intoxication are Preferred. LEWIS M. BARKER, Baylor University-Preference for coffee (CS) was conditioned by repeatedly allowing rats to drink this flavor during recovery from i.p. injections of ethanol (US). Rats concurrently conditioned to avoid saccharin and to prefer coffee (saccharin $\rightarrow$ ethanol $\rightarrow$ coffee pairings) showed significantly higher coffee preferences than did rats conditioned only to prefer coffee (ethanol $\rightarrow$ coffee pairings). Despite lengthy saccharin-to-coffee time intervals, in concurrent conditioning saccharin apparently acts as an excitor: coffee preferences decreased after saccharin aversion was extinguished. 10:10-10:30 (253)

Potentiation of Aversion to Visual Cues Following Taste-Toxicosis Pairing. JOSEPH J. FRANCHINA, CHERYL Y. PENN, DAVID WRIGHT, JAMES LANTER, \& LAURA E. HOUGH, Virginia TechTo evaluate within-compound versus synergistic-compound explanations of potentiation effects to visual cues, we had chicks drink a colorful flavored solution, red vinegar; $6 \mathrm{~h}$ later, they received a pairing of the uncolored flavor, clear vinegar, with toxicosis. Testing with the original color, red, in unflavored water yielded reliable potentiation effects, as measured by approach and consummatory response latencies and total intake. Results supported the within-compound view. Control studies investigated the bases for interelement transfer.

10:35-10:45 (254)

Relationship Between Dissociation and Eating Disorders in AfricanAmerican Women. ELLEN F. ROSEN, College of William \& Mary, \& LINDA C. PETTY, Hampton University-Dissociation is separation of sensation, affect, perception, and/or behavior. Extreme levels may result from early traumatic experiences. Dissociation may be associated with eating disorders. Eating disorders are less prevalent among African- 
American women, and therefore dissociation also ought to be lower. Yet, because of social prejudice, African-Americans are often exposed to early trauma. This study investigates the relationship between dissociation and eating disorders in African-American college women. 10:50-11:00 (255)

Analysis of Mechanisms Underlying Slow Reacquisition of an Extinguished Conditioned Taste Aversion. TODD R. SCHACHTMAN, JULIE A. HART, \& MELANIE MCEWEN, University of MissouriExperiments obtained slow reacquisition of an extinguished conditioned taste aversion, providing extensive extinction was administered prior to the reconditioning trials. These results conflict with previous claims that slow reacquisition does not occur with taste aversions. Additional experiments found that slow reacquisition remained following treatments that attempted to enhance associability of the CS prior to reconditioning. The findings are consistent with the view that slow reacquisition is due to poor retrievability of the CS-US association.

\section{1:05-11:25 (256)}

Individual Differences in Taste and Emotionality are Linked. NANCY K. DESS, Occidental College-In a prior study, stress reduced the avidness with which rats drank saccharin; results suggested increased sensitivity to saccharin's aversive taste properties. A lone, naive, male rat who was averse to saccharin prompted a selective breeding project on whether individual differences in sensitivity to saccharin's aversive taste in the absence of experimental stress (1) have a genetic component and (2) are linked to affective processes more generally. Three generations provided clear answers: "Yes." The former finding replicates other work with rodents and humans, but the latter is new.

\section{NEUROPSYCHOLOGY}

St. Louis Ballroom B, Saturday Morning, 10:15-11:25

Chaired by Marc Marschark, University of North Carolina at Greensboro

$$
\text { 10:15-10:35 (257) }
$$

Mapping Visual Brain Activation With Functional MRI and High Density ERP. WALTER SCHNEIDER \& JUDITH SHEDDEN, University of Pittsburgh-Results are reported from noninvasive mapping of brain activation in single individuals attending to visual stimuli. Functional magnetic resonance imaging (MRI) allows noninvasive imaging of neural activation of single subject's cortical gyri to map visual topography. High density (62 channel) evoke response potentials (ERP) measure the time course of activation. Combining these techniques will enable mapping brain activation patterns with high spatial and temporal resolution to interpret visual attentional processing.

$$
\text { 10:40-11:00 (258) }
$$

Anterior and Posterior Cortical Attention Preparations for Location of an Object. DAVID LABERGE, MARC RUSSAK, \& TIMOTHY ZAKHAROV, University of California, Irvine-Subjects were instructed to attend continuously to the location of the first of two dots (cues) flashed serially in 12 possible locations surrounding a fixation cross, and to respond when a circle (target) appeared at either dot location. Response accuracy over increasing cue-target delays remained near $100 \%$ for the first dot but decreased for the second dot. The results suggest a separation of sustained and decaying posterior attentional preparations that depend upon anterior attentional controls.

\section{1:05-11:20 (259)}

Brain Changes in the Acquisition of Literacy. MICHAEL I. POSNER, JEFF KIESNER, LISA THOMAS-THRAPP, BRUCE MCCANDLISS, University of Oregon, THOMAS H. CARR, Michigan State University, \& MARY K. ROTHBART, University of Oregon-Skilled English readers have specific brain areas activated selectively by visual and semantic word features. Signatures of these areas can be recorded noninvasively from scalp electrodes. We are examining the development of these areas in children. Our initial studies show right posterior visual attribute areas are activated both by input and voluntary search prior to literacy. At this age, left hemisphere activation by visual words appears weaker than in skilled readers.

\section{PROBLEM SOLVING \\ St. Louis Ballroom C, Saturday Morning, 9:35-11:30}

Chaired by Catherine G. Penney, Memorial University of Newfoundland

$$
\text { 9:35-9:50 (260) }
$$

Physies Expertise and the Perception of Physics Problems. ROGER W. SCHVANEVELDT, DAVID R. EUSTON, DAVID S. SWARD, \& ALAN VAN HEUVELEN, New Mexico State University-Nine physics problems were created by orthogonally combining three deep principles and three surface features. Naive, introductory physics students, graduate students, and professors judged the similarity of the problem solutions. Several measures derived from the judgments were related to physics expertise. The measures also relate to performance in the introductory course and to the influence of naive physical thinking on qualitative reasoning by graduate students. The orthogonal stimuli provide considerable leverage in assessing physics knowledge.

$$
\text { 9:55-10:10 (261) }
$$

Small Worlds: Their Role in the Development of Medical Expertise. GUY J. GROEN \& VIMLA L. PATEL, McGill University-Recent theoretical developments in medical artificial intelligence related to belief networks have given rise to the "small worlds" hypothesis that experts partition knowledge on the basis of similarities between disease categories. Some formal correspondences between belief networks and the structure of diagnostic explanations in medicine are discussed and used as a basis for models based on the notion that experts have a greater facility in developing suitably small worlds as contexts for explanations. 10:15-10:35 (262)

Acquiring Knowledge Through Practice: What Kind of Knowledge? MITCHELL RABINOWITZ \& NEIL GOLDBERG, Fordham University-Results from three studies will be presented that evaluate the hypothesis that there are two different types of active knowledge structures (procedural and retrieval) that are acquired as a consequence of practice. The knowledge structures vary in terms of representational assumptions and can be experimentally distinguished in terms of acquisition characteristics, performance characteristics, and contexts for transfer.

\section{0:40-11:00 (263)}

Effects of Problem's Content "Cover Story" on Abstraction and Transfer. MIRIAM BASSOK, University of Chicago-Two studies show that the problem's content "cover story" affects analogical transfer because it affects the interpretation of the problem's structure. The first study examines transfer between analogs of problems dealing with constant change in variables that are either discrete (e.g., salary) or continuous (e.g., precipitation). The second study examines transfer between analogs of permutation problems with symmetrical (e.g., flautists and violinists) and asymmetrical (e.g., students and prizes) pairs of variables.

\section{1:05-11:25 (264)}

Diagnostic Reasoning on the Basis of Partial Information. VIMLA L. PATEL, GUY J. GROEN, \& JOSÉ F. AROCHA, McGill UniversityThis paper investigates the effects of problem difficulty and relevance of domain knowledge on expert reasoning, and how these differ as a function of immediate versus sequential problem presentation. The results show that the use of sequential presentation paradigm enhances the diagnostic accuracy. There is an interaction between this phenomenon and relevance of domain knowledge. The experts quickly achieve the correct diagnosis on the basis of partial information. However, this pattern is disrupted with immediate presentation.

\section{ATTENTION II}

St. Louis Ballroom D, Saturday Morning, 9:55-11:30

Chaired by James C. Johnston, NASA-Ames Research Center

9:55-10:10 (265)

Effects of Space and Time on Selection in Partial Report. PETER DIXON, VINCENT DI LOLLO, ALICE LEUNG, \& ROBERT GOR- 
DON, University of Alberta-Existing models of spatial attention are ballistic in the sense that the allocation of attention is assumed to be triggered by the onset of some environmental or cognitive event. Contrary to this assumption, we have found that performance in a bar-probe task is determined by the spatiotemporal characteristics of the probe stimulus. These results suggest that the attentional selection is not ballistic, but rather dynamically related to events in space and time.

$$
\text { 10:15-10:30 (266) }
$$

The Attentional Blink Does Not Require Selection From Among Nontargets. ROBERT WARD, JOHN DUNCAN, Applied Psychology Unit, Cambridge, \& KIMRON SHAPIRO, University of Calgary (read by Kimron Shapiro)-Reduced probe detection in the 100-450 msec interval following identification of a target in an RSVP stream of nontargets reveals the presence of an "attentional blink" (AB) and an even greater "repetition blindness" (RB) when target and probe are identical. Present research findings suggest that removing nontargets from the stream leaves $A B$ intact. The additional difficulty of $\mathrm{RB}$, however, is eliminated.

\section{0:35-10:45 (267)}

Influences of Attentional Cuing and Retinal Location on the Stroop Effect. CHRIS KOCH \& JAMES M. BROWN, University of Georgia (read by James M. Brown)-We have recently shown that the Stroop effect can be eliminated with parafoveal presentation of Stroop stimuli. The present study examined whether or not this finding could be attributed to the distribution of attention across the retina by briefly presenting either a valid or invalid cue in the parafovea before a variable duration target was presented. Only validly cued trials consistently produced Stroop interference suggesting Stroop interference may depend upon allocation of attentional resources.

\section{0:50-11:05 (268)}

Incrementing Interference in the Stroop Color-Word Task. ALAN S. BROWN, CHRISTY A. ENGLE, Southern Methodist University, \& TODD C. JONES, Rice University-In the Stroop color-word task, color-naming latencies increased across items within a single naming session when stimuli were arranged in sheet or continuous strip formats. In contrast, color-naming latencies decreased when stimuli were presented singly on a computer screen. Word-reading latencies consistently showed little change across items. The cause of the incrementing interference is unclear, but suggests that sheet-reading and individualstimulus formats are not comparable.

\section{1:10-11:25 (269)}

Stroop Effect in Cross-Script Homophones. JOSEPH TZELGOV \& RINAT SNEG, Ben Gurion University-In a series of experiments, bilingual Hebrew-English subjects had to report the ink color of English or Hebrew written stimuli that have meaning as color names in Hebrew. Hebrew and English are written in different script. An equal magnitude Stroop effect, for both kinds of stimuli, was found in most experiments. The implications of these results for the automaticity of reading are discussed.

\section{LETTER/WORD PROCESSING III}

Promenade C, Saturday Morning, 9:50-11:30

Chaired by Francis S. Bellezza, Ohio University

\section{9:50-10:05 (270)}

Neighborhood Size and Neighborhood Frequency Effects in Visual Word Recognition. CHRIS SEARS, YASUSHI HINO, ERIC BOURBONNIERE, \& STEPHEN J. LUPKER, University of Western Ontario (read by Stephen J. Lupker)-What role does a word's orthographic neighborhood play in lexical access? According to Grainger et al. (1989), higher frequency neighbors inhibit lexical access. According to Andrews (1989), large neighborhoods facilitate lexical access. Since neighborhood frequency and neighborhood size typically co-vary, these results would seem to be contradictory. To resolve this contradiction, we factorially manipulated these two variables. Our results indicate that both large neighborhoods and higher frequency neighbors facilitate responding in the lexical decision and naming tasks.
10:10-10:25 (271)

The Effect of Scrambled Context on Lexical Access. SUSAN A. DUFFY \& KYLEEN E. CARPENTER, Amherst College-Research on lexical access indicates that sentence contexts that facilitate access do not facilitate when scrambled. This effect of scrambling seems to support a model of access in which the message level representation of the sentence is the source of facilitation. In the current study, we find facilitating effects of scrambled contexts on naming when subjects must remember the context. Results are discussed in terms of the role of the message level in lexical access.

10:30-10:50 (272)

Lexical Effects in Masked Form-Priming. KENNETH I. FORSTER, University of Arizona-The interpretation of form-priming effects alters completely if it can be shown that the phenomena are not restricted to words, but generalize to nonword targets as well. Recent papers have suggested that this is the case for masked form-priming. New evidence will be reported that calls this conclusion into question. 10:55-11:05 (273)

Talking Heads: How to be Ahead of Your Time in a Naming Task. KENNETH R. PAAP, LINDA JOHANSEN, \& DEAN HOOPER, New Mexico State University-Speeded and delayed naming RTs were obtained for 52 heads (e.g., S-, ST-, STR-) followed by the neutral vowel -UH. Delayed naming permits separation of output and measurement factors from those affecting the orthographic to phonological conversion processes. What affects the time it takes to assemble the phonology of the head-head size, manner, voicing, place, single letter frequencies, bigram frequencies, or consistency? Finally, is it possible to form equivalence classes of initial phonemes?

$$
\text { 11:10-11:25 (274) }
$$

Phonological Information in Korean Word Recognition. GREG B. SIMPSON \& HYEWON KANG, University of Kansas-Korean orthography mixes two scripts: an alphabet and a logography. We show that naming times for alphabetic, but not logographic, words are affected by the distributions of the scripts in the stimulus set. We also show a large frequency effect for alphabetic words when embedded in a list consisting mostly of logographic words, but not in a list presenting only alphabetic words. The results suggest a strategic use of phonological information in processing alphabetic Korean.

\section{HUMAN LEARNING/MEMORY III \\ Promenade D, Saturday Morning, 9:50-11:30}

Chaired by Gail McKoon, Northwestern University

9:50-10:05 (275)

Concerning the Nature of Recognition Memory. DAVID L. HORTON \& TIMOTHY J. PAVLICK, University of Maryland-Further evidence will be presented for two kinds of recognition memory that depend on qualitatively different underlying processes. It will be shown that improvements in performance in these two kinds of recognition memory are often inversely related to one another. Some implications of this interpretation will be discussed, particularly as it pertains to the distinction between episodic and semantic memory.

\section{0:10-10:25 (276)}

Short-Term Recognition Memory and LTM Activation. C. ALAN BONEAU \& LARRY Z. DAILY, George Mason University-Activation of primed words may persist over time and should spread to samecategory words. If LTM activation is a source of recognition, false positives should occur on next trial for primed words, and tendency should decrease with further trials. This effect was obtained using a modified Sternberg procedure with target sets of 18 words randomly selected from sets of foods, animals, and unrelated words. Effect was greatest for smallest set and least for unrelated words.

10:30-10:45 (277)

Transfer of Visual Comparison Skills: The Role of Strategies and Response Criteria. STEPHANIE M. DOANE, University of Illinois, JAMES W. PELLEGRINO, Vanderbilt University, DAVID L. ALDERTON, Navy Personnel Research and Development Center, \& AN HSIANG 
LIU, University of Illinois (read by James W. Pellegrino)-Two experiments examined the contribution of task-specific stimulus-response mappings and generalizable discrimination strategies in the acquisition of visual discrimination skills. In Experiment 1 , an initial difficult discrimination context led to the development of a precise comparison strategy that transferred to discriminating among novel stimuli. Experiment 2 shows effects of response criteria on strategy transfer. The results will be discussed in the context of current skill-acquisition theories.

\section{0:50-11:05 (278)}

The Expectation-Violation Effect and the Role of Semantic Relatedness in an Episodic Task. HARRIETT AMSTER, CHRISTOPHER BROOKS, SUZANN LUCAS, \& NILÜFER ÖZYÖRÜK-GEE, University of Texas at Arlington-The expectation-violation effect reported by Hirshman (1988) is a surprising reversal in the free recall of paired associates: Members of weakly associated pairs are recalled better than those from strong pairs. Our attempts to partially replicate the phenom- enon have demonstrated differences in recall of members of weak and strong pairs which depend on the type of test used and on input conditions. An elaborative processing theory is proposed which can account for the new and original results in contrast to the blind-alley search explanation posed by Hirshman.

11:10-11:25 (279)

The Effects of Schema Activation on Explicit and Implicit Retention. PAUL M. BERMAN \& MICHAEL P. TOGLIA, SUNY at Cortland (read by Michael P. Toglia)-Immediately or $24 \mathrm{~h}$ after briefly observing a biology laboratory, subjects either recalled its contents or performed a word fragment completion task. Fragment solutions varied in degree of biology schema relevance. Subjects in the implicit conditions completed more present schema-relevant fragments than other types. In explicit conditions, present high-relevant objects were remembered best, but many absent items were recalled. Surprisingly, retention interval had little influence. Schemata as a form of priming is discussed. 
POSTER SESSION II

St. Louis Ballroom E, Saturday Noon, Noon-1:30

(280)

Content Effects in the Evaluation of Deductive Arguments. SHARON LEE ARMSTRONG \& MARIANNE KAMIEN, Central University of lowa-This research investigated the effect of four types of content on the assessment of an argument's validity for four valid and four invalid argument types. The four types of content were: abstract (using symbols), neutral, helpful, and harmful. The last two contents produced arguments that were in/consistent with real-world experiences that could influence the unwary reasoner. Overall, neutral content produced superior judgments, but a significant sex difference prevailed on other content types.

\section{(281)}

Perceived Necessity Explains the Dissociation Between Logic and Meaning: The Case of "Only If." VALERIE THOMPSON \& JACQUELINE MANN, University of Saskatchewan-The logical implications of sentences of the form " $p$ only if q" often conflict with their semantic interpretation. Two experiments are reported that tested two contrasting explanations of this phenomenon. The results were entirely consistent with an account based on the perceived necessity of the conditional relationship, whereas there was no evidence to indicate that reasoning was mediated by abstract reasoning schemas of the type proposed by Cheng and Holyoak (1985).

(282)

Subjective Definitions of Rape. M. DIANE CLARK, Shippensburg University-Subjective definitions of rape were evaluated by presenting descriptive scenarios. Thirteen scenarios were developed describing situations that started at activities that were clearly not rapes and became progressively more clearly defined as rapes. In the clear nonrape as well as the clear rape scenarios, subjects consistently defined the scenarios correctly. Only one acquaintance rape scenario was not consistently defined as a rape with differences in males' versus females' confidence levels about their decisions.

(283)

The Influence of Problem Representation on Hypothesis Testing. DIANE S. ROHLMAN \& KIRK H. SMITH, Bowling Green State University (presented by Kirk H. Smith)-Subjects were asked to test a hypothesis by generating test cases. The statement of the hypothesis varied in completeness along two dimensions: the principle and the data limits. When given a more complete problem representation, subjects did not test more cases; however, they tested more negative instances. The results appear to support Klayman and Ha's view that people tend to exhibit a positive test strategy which can lead to errors with an incomplete problem representation.

\section{(284)}

Rule Ambiguity and Instructional Effects in the Selection Task. RICHARD D. PLATT \& RICHARD A. GRIGGS, University of Florida (presented by Richard A. Griggs)-Performance on the abstract fourcard selection task using problem statements that explicate the logical relationship of the rule was examined. Explication statements produced the best performance when the standard "If . . then" rule construction was absent. Performance also improved when subjects were required to make and justify selection decisions about each card. It was concluded that much of the selection task difficulty is due to rule ambiguity and the lack of analytic processing.

$$
\text { (285) }
$$

Generating Analogies as a Heuristic for Comprehending Geologic Time. CHRISTOPHER R. WOLFE \& R. HAYS CUMMINS, Miami University-Subjects in three studies generated geologic time analogies. Experiment 1 subjects maintained improvements on a time line task over several months. Experiment 2 compared instructions to generate analogies or study materials. Two analogy categories were discovered, ratio and unit. Study subjects were better at cued recall. Ratio subjects were better on the time line task, inferential reasoning, and asking pro- cess questions. Protocol analysis elucidated analogy generation processes. Results were interpreted in a knowledge representation framework. (286)

Individual Differences in Inferring Motion From Static Diagrams. MARY HEGARTY \& VALERIE K. SIMS, University of California, Santa Barbara-Subjects were presented with static diagrams of mechanical systems and asked to verify sentences describing the motion of system components. Task analyses and verbal protocols indicated that this task involves (1) a sentence-picture verification process and (2) a mental animation process-a process of inferring the motion of system components in a causal order. Spatial ability was highly related to overall performance. This was due to a correlation with only the mental animation process.

Age, Intentionality, and Spaced-Repetition Effects in Free Recall. THOMAS C. TOPPINO \& MELODIE FEARNOW, Villanova University-In two experiments examining the effect of spacing repetitions, preschool and fifth-grade children (Experiment 1) or fifth graders and adults (Experiment 2 ) engaged in free recall of picture lists presented under intentional or incidental learning conditions. Following intentional learning, all subjects recalled spaced repetitions better than massed repetitions. However, only adults exhibited a spacing effect following incidental learning. Results have implications for voluntary- versus involuntary-process explanations of the spacing effect.

(288)

Taking "Flashbulb" Memory by (Desert) Storm. BRIAN J. LYMAN \& PAULA T. HERTEL, Trinity University (presented by Paula T. Hertel)-Within $15 \mathrm{~h}$ of the outbreak of the war with Iraq on January 16,1991 , students were given a questionnaire about their experiences during the outbreak. They were retested at intervals ranging from 1 week to 1.5 years later. Memories were generally accurate, but more forgetting of detail occurred during the first week than from 1 week to 3 months or 1.5 years later, and some reactions were exaggerated in their reconstruction.

Mediation Processes in Memory Retrieval Before and After Extended Retrieval Practice. ROBERT J. CRUTCHER, University of Illinois at Chicago, \& K. ANDERS ERICSSON, University of Colorado at Boulder-Retrieval processes for vocabulary learned using the keyword method were analyzed within a task decomposition paradigm using cued recall, retrieval latencies, and retrospective verbal reports. The results indicate that initial retrieval of the English equivalent requires retrieving the keyword into working memory and using it as an explicit cue to retrieve the English equivalent. However, following extended retrieval practice, the English equivalent is directly retrieved from the Spanish word without any intermediate working memory steps.

\section{(290)}

Hierarchical Organization in Adults' Descriptions of Spatial Location. JODIE M. PLUMERT \& CHRISTOPHER CARSWELL, University of Iowa-Two experiments were conducted to examine the theory that spatial knowledge is represented hierarchically as regions with nested levels of detail. In Experiment 1, the most frequent strategy subjects used to describe object locations was to order information according to size of spatial unit (e.g., "the book is upstairs in my bedroom on the desk"). In Experiment 2, subjects responded significantly faster to hierarchically than to nonhierarchically organized spatial descriptions in a sentence verification task.

The Verbal Overshadowing Effect: Now You See It, Now You Don't. SUZANNE B. LOVETT, MELINDA Y. SMALL, \& SHANE A. ENGSTROM, Bowdoin College-Schooler and Engstler-Schooler (1990) demonstrated that verbally describing a previously seen face can impair subsequent recognition. Three experiments attempted to replicate this finding. In Experiments 1 and 2, verbalizing (either written or oral) or imaging the face did not affect recognition. In Experiment 3, although verbalization alone did not impair recognition, verbalization plus ex- 
plicit instructions to recall and use the verbal description did impair recognition. The generalizability of the verbal overshadowing effect is discussed.

Attention to the Environment and Long-Term Context Effects. MARIA A. ALONSO, Universidad de la Laguna, \& ANGEL FERNANDEZ, Universidad de Salamanca (presented by Angel Fernandez)In one experiment, the environmental context was manipulated by changing rooms between study and test. Furthermore, half the subjects were induced to pay extra attention to the study room. Although the results showed no main effect of context, subjects who paid extra attention to their study environment had significantly better scores than those who did not when they were later tested in a different context. Retention intervals of 1 week and 1 month produced the same results.

$$
\text { (293) }
$$

Dividing and Remembering Surrounding Space. LINDA HENKEL \& NANCY FRANKLIN, SUNY at Stony Brook (presented by Nancy Franklin)-Four experiments demonstrate the primary status of front in horizontal space. For space surrounding oneself, the front region is subjectively larger than right, left, and back and produces the highes recall accuracy for objects' positions. Back produces the lowest accuracy. Comparable experiments on space surrounding a doll replicated the finding for front but not for back, supporting front's privileged status and suggesting perceptual and motor disadvantages as causes for back's low accuracy for egocentric space.

\section{(294)}

Evidence for Mental Model Organizations in Recall and Recognition. GABRIEL A. RADVANSKY \& ROSE T. ZACKS, Michigan State University (presented by Rose T. Zacks)-Free recall, cued recall, recognition, and cued recognition were used to investigate the mental model organization of memorized lists of person-location associations. The organization suggested by free recall markedly differed from that indicated by the other three measures. We interpret these results to indicate that the requirements of the free recall task to retrieve the entire studied list may induce strategies that mask the underlying mental model representation of the materials.

Incongruous Item Generation Effects: A Multiple-Cue Hypothesis. SAL A. SORACI, JR., University of Alabama, JEFFERY J. FRANKS, Vanderbilt University, MICHAEL D. CARR, FRAN A. CONNERS, \& MICHAEL T. CARLIN, University of Alabama-Responses generated by subjects that are incongruous with respect to a question stem (e.g., Is a tree?: car) are recalled at higher levels than are congruous responses (e.g., maple). Explanations have been based on effort (Ayers, 1991; Roenker et al., 1978) or idiosyncratic item selection (Horton, 1987). The present study compares these approaches by testing the hypothesis that multiple cues generated under incongruous encoding rules are responsible for enhanced recall.

(290)

The Generation Effect: Do Test Instructions Influence the Size of the Effect? PATRICIA A. DEWINSTANLEY, Oberlin College, \& WENDY A. HERBERLEIN, University of Kansas -We examined the consequence of different test instructions on the generation effect. Subjects were given instructions consistent with a free-recall test, instructions consistent with a cued-recall test, or general instructions without reference to a specific type of test. Next, subjects either read both a cue and a target (e.g., bird-canary) or read a cue and generated a target (e.g., bird-c-n-ry). Subjects were then tested with either a free-recall or a cued-recall test. The results are consistent with a Resource Allocation theory.

\section{(297)}

Selective Displaced Rehearsal and the Generation Effect. LILLY T. KATSAITI, American College of Greece (sponsored by Norman J. Slamecka)-The generation effect in free recall of mixed lists may be due to selective displaced rehearsal of generated items. Two experiments, carried out to test this hypothesis, controlled subjects' rehearsal activity during input. Outcomes of both experiments lent support to the hypoth- esis, indicating that when selective displaced rehearsal in a within-list manipulation is controlled, there is no generation effect.

(298)

An Investigation of Word Identification Using Word Fragments. RICHARD RINALDO \& RONALD OKADA, York University (presented by Ronald Okada)-Using word recognition tasks, the validity of Weber's (1970) orthographic similarity scale was tested. Word fragments were generated by the deletion of a single interior letter, either a vowel or a consonant, from a word (e.g., cl_b). It was observed that fragments were harder to solve if a consonant was deleted than if a vowel was deleted. Finally, controlling for orthographic similarity using Weber's scale, the dominance of consonant information emerged for pseudohomophone lures.

\section{(299)}

Making High Frequency Words Harder to Read. PATRICK BROWN, University of Western Ontario, LUCIA COLOMBO, University of Padua, \& STEPHEN J. LUPKER, University of Western Ontario-Subjects named or made lexical decisions to five blocks of 100 words (no items were repeated). Frequency effects (FEs) for naming one-syllable words were small and constant across blocks. FEs for naming two-syllable words and lexical decisions to one-syllable words were larger and decreased across blocks. Regularity effects remained constant. Models of FEs based on (1) reduced signal strength due to accumulated residual activations and (2) processes other than lexical access are explored.

\section{(300)}

Attentional Allocation in Visual Word Recognition. LOUISA M. SLOWIACZEK \& JAMES H. NEELY, SUNY at Albany-Pitt and Samuel (1990) reported benefits in phoneme monitoring at attended locations within a spoken stimulus, and costs in performance at unattended locations. These cost/benefit differences were greater at stimulus boundaries than at the middle locations and costs decreased for locations far from the attended location in words. In the present study, subjects monitored for graphemes in visually presented stimuli. Our results revealed (1) pronounced cost/benefit differences in all stimulus locations and (2) an increase, rather than a decrease, in cost for locations farther from the attended location.

\section{(301)}

Ambiguity in Meaning and Phonology: Effects on Naming. PAUL FERA, STEVE JOORDENS, University of Waterloo, DAVID A. BALOTA, \& F. RICHARD FERRARO, Washington University (presented by Richard Ferraro)-Subjects can categorize a letter string as a word faster if it has multiple meanings (e.g., DUCK) than if it has only one meaning (e.g, DUST). In Experiment 1, we demonstrate the semantic ambiguity effect in a naming task. Experiment 2 replicates Experiment 1 and also shows that words with multiple phonologies (e.g., DOVE) are read more slowly than words with only one phonology. Implications of these results for models of reading are discussed.

(302)

Direct and Indirect Measures of Semantic Information Available From Masked Words. STEPHANIE A. BERGER \& DAVID S. GORFEIN, Adelphi University-Most studies of semantic information available from masked words confound the type of task used with the context in which the words are presented. Type of task and context are often confounded in studies of priming by masked words. In a masked-prime word association task, direct measures of semantic information from masked words were consistently more sensitive than were indirect measures. The effect of the context in which masked words were presented was greater in the indirect measures than in the direct measures.

(303)

Lack of Semantic Parafoveal Preview Effect: Evidence From Bilinguals. JEANETTE ALTARRIBA, SUNY at Albany, ALEXANDER POLLATSEK, \& KEITH RAYNER, University of MassachusettsEnglish-Spanish bilinguals viewed a preview word to the right of fixation. When they moved their eyes, the preview was replaced by a target word. The preview was either identical to, a translation of, or different from the target. Naming time of the target word was speeded 
by a translation preview only when it was a cognate, suggesting that preview benefit does not automatically accrue from activation of semantic codes.

\section{(304)}

Single Word Syntactic Primes Afiect Rapid Naming. WILLIAM T. FARRAR, IV \& ALAN H. KAWAMOTO, University of California, Santa Cruz (presented by Alan H. Kawamoto)-Three experiments show an effect of a single word syntactic prime on monosyllabic regular words in naming and lexical decision. Previous research has claimed that this syntactic priming does not affect naming, which is assumed to measure lexical access. The present results suggest an alternative interpretation: Effects of lexical access in naming may be obscured because words are sometimes named without lexical access.

(305)

Erotophobia, Erotophilia, and the Word Superiority Effect. PAUL HAERICH \& HEATHER C. CARMACK, La Sierra UniversitySubjects indicated with a speeded response whether or not a given letter was present in a target letter string. Letter strings included (1) valid English words which were either frankly sexual or affectively neutral in meaning, as well as (2) orthographically irregular nonwords. In addition to the standard word superiority effect, reaction times were faster to sex-related than neutral words for erotophilic subjects. The reverse was observed for erotophobic subjects, with reaction times being faster for neutral than sex-related words.

Coarse Coding and Summation Priming in the Cerebral Hemispheres. MARK BEEMAN, RHONDA B. FRIEDMAN, ENRIQUE PEREZ, SHARI DIAMOND, MIRIAM B. LINDSAY, \& JORDAN GRAFMAN, NINDS/National Institutes of Health-Lexical decision and pronunciation accuracies for near-threshold target words reflected semantic activation resulting from three-word primes. Target accuracy increased when all three primes were weakly related to the target, relative to unrelated triads, especially in the right hemisphere. This asymmetry was not observed for one strongly related prime flanked by two unrelated primes. Automaticity was also examined. These data suggest that, under certain conditions, the right hemisphere coarsely codes semantic information.

\section{(307)}

Metamemory for Texts: Application of the Material Appropriate Hypothesis. DEBORAH S. BRYANT \& CHARLES A. WEAVER, III, Baylor University (presented by Charles A. Weaver, III)-Three experiments were conducted to see if Material Appropriate Processing (MAP) effects extend to metamemory, and to see if text difficulty modulated those effects. Consistent with the MAP predictions, metamemory for narrative texts was better for thematic information, while metamemory for expository texts was better for detailed information. Two other experiments showed that when text difficulty was controlled across the text types, a U-shaped function emerged-metamemory was best for texts of intermediate difficulty.

Individual Differences in Situation-Based Inferencing. DIETER HAENGGI, University of Colorado at Boulder, \& MORTON ANN GERNSBACHER, University of Wisconsin, Madison-Three experiments examined how readers encode implied emotional and spatial text information in their memory representations. Reading times for sentences that either matched or mismatched the information implied by a text suggest that on-line inferencing of implied information is relatively effortless and driven by domain-specific knowledge rather than by empathy, spatial imagery, or reading comprehension ability. In contrast, inferencing measured by a spatial probe task might be more effortful and rely on spatial memory.

\section{(309)}

Memory for Scientific Texts. KEITH MILLIS, SEYMORE SIMON, \& JOAN LUCAS, Northern Illinois University (presented by Seymore Simon)-Subjects read and later recalled scientific texts. Subjects' recall was predicted from conceptual graph structures constructed from the explicit texts. The results indicated that ideas with a causal connection were better recalled than ideas that were not connected via a causal connection. Recall also increased with the number of internode con- nections. These findings were obtained across two delay intervals (immediate vs. 1-week) and rereadings. Overall, the findings replicate past research using narrative texts.

Typographical Cuing Effects on Cued Recall. ROBERT F. LORCH, JR., ELIZABETH PUGZLES LORCH, \& MADELINE A. KLUSEWITZ, University of Kentucky-Two experiments examined effects on cued recall of signaling text information by underlining or capitalization. Infrequent cuing resulted in slower reading and better recall of the signaled information compared to a no-cue control condition; frequent cuing slowed reading but did not affect recall. Typographical signaling effects on memory are not due simply to additional processing time elicited by the cues; rather, how readers process cued information depends upon the informativeness of the cues.

(311)

Recognition of Targets Involved in Necessary and Elaborative Inferences. REBECCA FINCHER-KIEFER, Gettysburg College-In a word recognition paradigm, responses to referents of anaphors are facilitated. However, in Experiment 1, responses to targets involved in inferences required to maintain text coherence were inhibited. This inhibition may be the result of encoding targets as both explicit text and as part of an inference. In Experiment 2, responses to targets involved in predictive inferences were also inhibited. These results suggest that elaborative inferences, as well as necessary inferences, occur during reading.

\section{(312)}

Updating a Mental Model: Maintaining Both Local and Global Coherence. JASON E. ALBRECHT, CHRISTOPHER M. HAKALA, \& EDWARD J. O'BRIEN, University of New Hampshire (presented by Edward J. O'Brien)-Subjects read passages containing target sentences that were consistent, inconsistent, or unrelated to a previously backgrounded description of the protagonist. All target sentences maintained local coherence, but inconsistent target sentences violated global coherence. Reading times were longest when the target sentence was inconsistent with the description. Recall of the elaborated description was greatest when the target sentence was inconsistent. These results suggest that readers attempt to maintain global coherence even when local coherence is present.

\section{(313)}

A Verb's Causal Bias Can Facilitate Pronoun Resolution. STEVEN GREENE, Princeton University, GAIL McKOON, \& ROGER RATCLIFF, Northwestern University-Coherent discourse typically provides cues that assist in identification of referents for anaphors. One such cue is provided by the "causal bias" of the main verb of a sentence, which may create an expectation that a subordinate clause will refer to either the subject or the object of that verb. This expectation facilitated pronoun resolution within a causal subordinate clause, but not across a sentence boundary.

\section{(314)}

Effects of Practice on Speed of Information Processing in Children and Adults. SANDRA HALE \& ASTRID F. FRY, Washington University-Children and adults performed four information-processing tasks. Consistent with the global trend hypothesis, linear relations were observed between child and adult latencies with slopes predicted by Kail's (1991) growth function. The linear relation did not change with practice, implying practice has equivalent effects on corresponding processing steps in children and adults. An age-invariant linear relation between dispersion and central tendency was observed, indicating that children's greater within-subject variability is entirely due to their slower speed. (315)

What Do Young and Old Adults Learn in Consistent Category Search Tasks? WENDY A. ROGERS \& D. KRISTEN GILBERT, Memphis State University-Extensive consistent practice on a semantic category visual search task was provided to 36 young (age 21) and 36 old adults (age 72). Research questions focused on whether or not old and young adults learn general search skills as well as task consistencies necessary to automatize the task. In addition, we assessed whether both young and old adults learn at the category level on these tasks. Age-related differences are discussed in terms of learning mechanisms. 
Acquisition of Arithmetic Skills in Chinese and American Children. DAVID C. GEARY, C. CHRISTINE BOW-THOMAS, University of Missouri-Columbia, LIU FAN, Chinese Institute for Educational Science, JENNIFER MUELLER, \& ANTHONY TURK, University of Missouri-Columbia-The performance of 103 Chinese and American kindergarten and first-grade children was compared for a numerical ability measure, numerical memory span, and problem-solving strategies and solution times used to solve addition problems, at the beginning and the end of the academic year. Academic instruction in mathematics was also tracked throughout the academic year. Academic year changes in problem-solving strategies and solution times as related to numerical memory span and mathematics instruction are presented.

Aging and the Semantic Processing of Visual Objects. CHANDAN J. VAIDYA \& WILLIAM J. HOYER, Syracuse University (presented by William J. Hoyer)-Semantic priming of picture naming and object decision was examined by age and SOA $(350,550 \mathrm{msec})$. In picture naming, young adults showed priming at both SOAs, and older adults showed priming only at the longer SOA. In object decision, no priming was found for young adults at either SOA, but older adults showed robust priming at the longer SOA. Results suggested that aging is characterized by an increased reliance on the semantic system for the processing of visual objects.

Comprehension Monitoring and Memory in Adults: On-Line and Whole-Text Methodologies. KAREN ZABRUCKY, Georgia State University, DEWAYNE MOORE, Clemson University, \& DIXIE McGINTY, Georgia State University-We examined younger and older adults' comprehension monitoring and memory of texts containing inconsistencies using on-line and whole-text methodologies. On-line data revealed that both younger and older adults slowed down while reading inconsistent information. Adults were also more able to verbally report inconsistencies in on-line conditions. Adults' rereadings of inconsistent information and memory for inconsistent information will be assessed. The effects of individual difference measures on comprehension monitoring and memory will be discussed.

Aviation Expertise and Age Differences in Memory. DANIEL MORROW, VON LEIRER, PATSY ALTIERI, \& COLLEEN FITZ SIMMONS, Decision Systems, Los Altos-Aviation expertise may compensate age declines in capacity by reducing task demands, thus reducing age differences in performance. Two experiments investigated age differences in how accurately pilots and nonpilots read back, or repeat, commands in air traffic control messages presented by voice or computer. Expertise improved and aging impaired performance, and expertise reduced age differences for some but not all command types. The results help identify when knowledge compensates age declines in capacity.

Belief and Desire in the Development of Theory of Mind. KIMBERLY CASSIDY \& MICHAEL KELLY, University of Pennsylvania (presented by Michael Kelly)-The present study finds that children who fail the false-belief task incorrectly attribute a true belief to the deceived actor. Further, these children attribute to the deceived actor knowledge of the events that would lead to the true belief. These findings are consistent with Fodor's (1992) claims that these children assume that all beliefs are true unless shown to be otherwise. A second study supports Fodor's premise that desire takes precedence over belief in predicting behavior.

\section{(321)}

Contributions of Form and Motion to Young Children's Perceptions of Animacy. DIANE S. BERRY \& KEN SPRINGER, Southern Methodist University-This research examined whether form or motion is more central to young children's perceptions of animacy. Preschoolers described either Heider and Simmel's animated film, or an edited version in which form or motion was disrupted. Although children were less likely than adults to produce animistic descriptions, motion was more influential than form for both age groups in producing the perception of animacy.
(322)

Transformational Knowledge and Categorization. DONALD HOMA \& SAFA ZAKI, Arizona State University-Transformational knowledge, in which patterns progressed from initial to final form, was explored in a category task. Subjects were assigned to one of five conditions, including two nontransformational controls, with learning followed by a classification/recognition task immediately and 1 week later. Transformational learning produced tighter concepts that were more resistant to decay than control conditions. The relevance of these results to prototype, exemplar, and feature models is discussed.

\section{(323)}

Knowledge and Linear Separability: Object Versus Social Categorization. WILLIAM D. WATTENMAKER \& STEPHANIE J. SCHWERTZ, University of Pittsburgh-The degree to which linear separability constrains categorization was investigated in object and social domains. Linearly separable structures were found to be easier to learn with social materials, whereas nonlinearly separable structures were easier to learn with object materials. It was concluded that the structure of knowledge varies with domain, and consequently it will be difficult to formulate domain-general constraints in terms of abstract structural properties such as linear separability.

(324)

Context Effects on Category Membership and Typicality Judgments. LESLIE J. CAPLAN, National Institute of Mental Health, \& ROBIN A. BARR, National Institute on Aging-Two experiments examined the effects of retrieval context on natural language category membership and typicality judgments. In one, contexts were varied experimentally. In the other, subjects were assumed to differ in retrieval strategies, thereby creating natural context differences. In both, context effects were greater for typicality than for membership judgments. Also, results of both experiments supported the hypothesis that categories represented by extrinsic features yield larger context effects than those represented by intrinsic features.

Instance Comparisons During Category Learning. THOMAS L. SPALDING \& BRIAN H. ROSS, University of Illinois (presented by Brian H. Ross)-To categorize a new instance, or make other judgments about it, people may compare the new instance to previous instances. Our research investigates instance comparisons during category learning and what might be learned from these comparisons. Two experiments vary which instances are compared during learning. The results suggest that the particular instance comparisons affect what is learned about the category and how this knowledge is used.

(326)

Modeling the Effects of Prior Knowledge on Memory and Categorization. EVAN HEIT, University of Michigan-Expectations have consistent effects on memory and categorization, and this pattern of results helps distinguish between memory models. Three theories of how expectations affect memory were implemented as mathematical models. The predictions of the integration, weighting, and distortion models were compared with the results of a meta-analysis on experiments on expectation effects (Strangor \& McMillan, Psychological Bulletin, 1992). Only the integration model, derived from exemplar theory of categorization and information integration theory, correctly predicted human performance.

\section{(327)}

A Complex Mapping From Concepts to Classification and Word Use. BARBARA C. MALT, Lehigh University-Classification is generally assumed to result from comparison of a concept to entities in the world. Similarly, most theories of word meaning take the intension of a word to directly determine its extension. However, these mappings, and the mapping from classification to word use, may not be so simple. A study of these mappings for two artifact terms reveals complex relationships between conceptual content and measures of classification and naming.

\section{(328)}

The Development of Infant Attention to the Form and Function of Object Parts. KELLY L. MADOLE \& LESLIE B. COHEN, University of Texas at Austin (presented by Leslie B. Cohen)-Two studies explored whether part structure mediates infants' recognition of form- 
function correlations. Fourteen- and 18-month-old infants attended to form-function correlations within separate parts of objects. However, when form and function were correlated in a nonintuitive way (the form of one part was correlated with the function of another part), only 14month-olds attended to this relationship, suggesting that attention to formfunction correlations develops from atheoretical to theoretical.

(329)

Dimensional Relevance Shifts During Category Learning. JOHN K KRUSCHKE, Indiana University-Humans learned binary classifications of stimuli with three binary-valued dimensions. In initial training, two of the three dimensions were relevant (XOR). Then the structure was shifted to either (1) a reversal of categories on the same two relevant dimensions, (2) a single, previously relevant dimension, (3) a single, previously irrelevant dimension, or (4) an XOR on one previously relevant and one previously irrelevant dimension. The results pose a challenge to a wide variety of incremental learning models, for example, connectionist models.

\section{(330)}

Effect of Stimulus Duration and Number of Sound Sources on Auditory Apparent Motion. THOMAS Z. STRYBEL \& NASRIN ZAMIRI, California State University, Long Beach-Auditory apparent motion was produced with both two sound sources (located at $\pm 40^{\circ}$ azimuth) and three sound sources (located at $-40^{\circ}, 0^{\circ}$, and $40^{\circ}$ azimuth). The stimulus onset asynchrony (SOA) range which produced continuous motion depended on both stimulus duration and number of sound sources. These results will be discussed with respect to a minimumintegration-time requirement for auditory motion perception.

\section{(331)}

The Perception of Target and Nontarget Stimuli Presented to the Forearm. PAUL M. EVANS \& LAURA K. FLORL, Willamette University-Subjects have difficulty in focusing their attention on one finger and ignoring a stimulus presented to another finger. The amount of interference is independent of whether the target and nontarget stimuli are presented to adjacent or nonadjacent fingers. The present study expanded upon these findings by presenting stimuli to the forearm. Results indicate that the initial findings are generalizable to less sensitive areas of skin and to stimuli defined by temporal, not spatial, characteristics.

Crossmodal and Intramodal Matching: Effects of Stimulus Order SLATER E. NEWMAN, BERRIN BOZOGLU, \& DAVID T. HAHN, North Carolina State University-Subjects $(N=128)$ examined a standard stimulus visually or haptically and each of four comparison stimuli visually or haptically. For half the subjects in each condition, the standard stimulus appeared first in the set of five; for the remaining subjects, it appeared last. All stimuli were braille symbols with 3, 4, or 5 dots. Analysis of variance for number correct indicated that all three main effects and three of the interactions were significant.

\section{(333)}

Modality-Specific and Amodal Aspects of Object Perception in Infancy. E. S. SPELKE, Cornell University, A. STRERI, Université de Paris V, G. A. VAN DE WALLE, Cornell University, E. RAMEIX, Université de Paris $V$, \& J. KAUFMAN, Cornell University-Experiments investigated 4.5-month-old infants' perception of the unity and boundaries of objects explored bimanually without vision. Infants perceived a single object if they explored two handles that moved rigidly together. They perceived two distinct objects if each handle underwent either a relative vertical or horizontal motion. Perception was indeterminate if the handles were nonrigidly connected. These findings accord with the findings of studies of visual object perception and suggest that object perception depends on amodal processes.

$$
\text { (334) }
$$

Imagery Induced Interference in the Third Dimension. MARTHA E. ARTERBERRY \& CATHERINE CRAVER-LEMLEY, Gettysburg College-Imagery-induced interference (the "Perky Effect") was investigated under conditions in which a vertical-line image and an acuity target were in either the same or different depth planes. Imagery reduced accuracy for the target when the image was "in front", of the target or when the image and target were in the same depth plane. Imagery had no effect on acuity when the image was evoked "behind" the target.

Mental Models 'Midst the Optical Flow. JEREMY M. A. BEER, USAF Armstrong Laboratory-Motion pictures can display selected characteristics of real-world optical flow, and "cuts" can test mental transformations separating successive views. Here, simulated lateral selfmotion revealed, over time, scenes wider than the screen. Viewers successfully anticipated the moment at which off-screen landmarks reappeared, revealing the ability to use mentally rescaled spatial information remembered from prior panoramic views. Data are compared with models of this ability.

Imagining Projective Transformations in Drawing and ShadowCasting. JOHN R. PANI, JOHN A. JEFFRES, \& GORDON SHIPPEY, Emory University-Visualization of projective transformations was studied in two experiments. Subjects indicated the contours of a simple object that would be traced from alternative viewpoints or they indicated the shadows that would be cast by various light beams. Subjects were quite good at these tasks if, and only if, the object was aligned with the direction of projection. The orientation of the object or the direction of projection in the environment had little independent effect.

A New Twist on the Rotating Trapezoid: Neural Fatigue Effects. GERALD M. LONG, THOMAS C. TOPPINO, \& SHARON E. APPLING, Villanova University-Before viewing a 3-D rotating trapezoid for a 30-sec test period, observers adapted for $2 \mathrm{~min}$ to either a blank field or an unambiguous rotating rectangle. More illusory oscillations of the trapezoid were reported when the adapting figure rotated in the same direction as the trapezoid than when either no adaptation or adaptation in the opposite direction occurred. Results are discussed in terms of the likely role of neural fatigue effects on this famous transactionalist illusion.

\section{(338)}

Judging Dynamic and Kinematic Aspects of Rotational Motions. HEIKO HECHT, Max-Planck Institute for Psychological ResearchObservers' abilities to judge different aspects of rotational motions were investigated. Spontaneous judgments about the dynamics of wheels rolling down an inclined plane were erroneous. Observers were not able to make quantitative judgments about the effect of gravity or the coupling between rotation and translation. However, it is demonstrated that observers can attentively extract the critical information. Expert skills like playing billiards could be based on attunement to such kinematic information about rotation.

\section{(339)}

Valence Effects in Information Processing: Evaluating Descriptive Characteristics. SANDRA L. SCHNEIDER, JOHN M. BUNCH, \& SHARON M. KERUTIS, University of South Florida-Two studies were conducted using priming, response time, memory, and other measures to assess processing differences in the evaluation of positive versus negative descriptors (e.g., lively, sloppy). Results include a positive response bias and shorter response latencies for positive descriptors, as well as asymmetries in self-reference ratings and extremeness ratings. We discuss the contribution of our findings relative to the growing evidence for valence effects in a wide variety of contexts.

\section{(340)}

The Cognitive Representation of Action: Evidence From Effects of Correspondence Between Irrelevant Stimulus Information and Conditioned Action Effects. BERNHARD HOMMEL, Max-Planck Institute for Psychological Research-It is assumed that actions are cognitively represented by codes (anticipations) of their environmental effects. A paradigm is presented that combines a simple conditioning procedure (presentation of letters as contingent effects of keypressing actions) with double stimulation (target letter flanked by irrelevant letters used as action effects of correct or alternative response). It is shown that response facilitation and interference occur depending on the relation between irrelevant stimulus and conditioned action effect. 
(341)

Are Both Nonsemantic and Semantic Information Processed From an Icon? CURTIS W. McINTYRE, CHRISTINE P. GANCARZ, Southern Methodist University, CHRISTINE J. PTACEK, University of Iowa, \& LORI A. NIX, Southern Methodist University-The processing of semantic (letters) and nonsemantic (meaningless characters) information was examined by combining a forced-choice span of apprehension (SOA) task with backward masking. SOAs were obtained from both the target and the mask on the same trials under various conditions of target/mask similarity. The interstimulus intervals were varied from 50 to $500 \mathrm{msec}$. Target/mask similarity did not influence the amount of information being processed from either the target or the mask. Evidently, both types of information are processed similarly.

Dynamic Reallocation of Visual Attention Within an Experimental Trial. VINCENT BROWN, University of Texas at ArlingtonLaBerge \& Brown (1986) reported when attention was sharply focused, RT to probes presented away from that focus depended on their relative position but was independent of the physical range over which they appeared. Neither a spotlight nor a resource model could account for the result. It is shown here that if time is allowed after the focusing stimulus, the "range effect" disappears; RT becomes a function of distance, independent of the range over which the probes appear.

\section{(343)}

Reflexive and Voluntary Orienting in Detection and Discrimination Tasks. ROBERT EGLY, ROBERT D. RAFAL, University of California, Davis, \& AVISHAI HENIK, Ben Gurion University (presented by Robert Rafal)-Three types of cues were compared for detection and discrimination: Informative central cues (C80), uninformative peripheral cues (P50), and informative peripheral cues (P80). For detection, peripheral cues produced early facilitation followed by inhibition of return; no IOR was evident for discrimination. For P80, IOR was manifest at an attended location. For discrimination, peripheral cues produced more rapid orienting, and larger cuing effects were observed with P80 than with P50, indicating both a reflexive and endogenous component.

\section{(344)}

Mapping the Allocation of Spatial Attention. KYLE R. CAVE, Vanderbilt University-The allocation of spatial attention to a visual display was mapped by timing responses to a probe stimulus that appeared at various locations following the display. The results conflict with any "spotlight" account of attention. Responses were slowest at the location occupied by a distractor object, and were generally faster at the target location and blank locations. In this task, spatial attention appears to be blocking distractors rather than selecting targets.

$$
\text { (345) }
$$

Temporal Tradeofis Among Central Arrow, Peripheral Arrow and Abrupt Onset Cues. JAMES F. JUOLA, HIDEYA KOSHINO, \& C. BRUCE WARNER, University of Kansas-The detection of a target character among noise characters was differentially affected by central arrow, peripheral arrow, and abrupt onset cues. In order to compare the time courses of their different effects, SOAs of each type of cue were varied independently. The results showed that abrupt onset of a potential target dominated the attentional effects of both central and peripheral arrows unless the arrow cue led the onset cue and had a greater expected validity.

\section{(346)}

Attention Shifts to a Subtle Physical Change During Selective Listening. NOELLE WOOD \& NELSON COWAN, University of Mis- souri, Columbia (presented by Nelson Cowan)-It is commonly believed that subtle changes in unattended stimuli go unnoticed. We reevaluated Cherry's (1953) claim that a change in the unattended channel in selective listening to backward speech is not noticed, using modern techniques for stimulus control and on-line response measurement. Many subjects did notice the change. However, there was no evidence of covert attention shifts in the absence of later verbal confirmation. The temporal course of attention shifts was especially informative.

(347)

Task-Dependent Visuospatial Precuing Effects. LYNN ZIMBA \& DONALD J. TELLINGHUISEN, University of Iowa-Visuospatial peripheral precuing effects were investigated in terms of identification latencies to targets presented at attended versus unattended locations as a function of SOA (50-250 msec or 1,000-2,000 msec). Observers made 2AFC decisions about linear integrity or lexical nature of targets. Precuing effects were found for all stimuli presented at the $1,000-2,000$ msec SOA, but only for linear stimuli at the $50-250-\mathrm{msec}$ SOA. Results suggest attentional resource allocation may be altered by characteristics of the imperative stimulus.

(348)

Separate Target Features are Processed in Parallel, But Only When Parts of a Single Object. HOWARD EGETH, Johns Hopkins University, \& J. TOBY MORDKOFF, University of California, San Diego (presented by J. Toby Mordkoff)-In a both task, subjects respond when two features (e.g., green and the letter $\mathrm{X}$ ) are present in a display regardless of whether they are at the same location (or are parts of the same object). RT data from such a task indicated that performance is better when critical features are parts of the same object. Further analysis indicated that features are processed in parallel when in the same object and serially when in different objects.

(349)

Covert Shifts of Attention in Three-Dimensional Space. A. RASTELLI, A. PERU, SALVATORE AGLIOTI, \& G. BERLUCCHI, Istituto Fisiologia Umana, Verona (presented by Salvatore Aglioti) (sponsored by Melvin A. Goodale)-Simple reaction times to the second of two successive light stimuli randomly presented along the midsagittal plane were longer when both stimuli fell before or beyond the fixation point than when they occurred on opposite sides of fixation. This and other comparable effects found with similar stimulations of the right and left or upper and lower visual hemifields are all attributable to a single mechanism for covert orienting in different dimensions of visual space.

\section{(350)}

The Power Law of Attention Capture. DAVID L. STRAYER, University of Utah-Race models of visual search make several predictions concerning the capture of attention. First, both mean RT and the RT standard deviation must decrease as a power function of the number of independent stimulus dimensions specifying a target location. Second, the rate parameter for these two power functions must be equivalent. Two studies will be presented that support these predictions.

(351)

Inferences From Stimuli About Stimulus Sets. ALBERT F. SMITH, SUNY at Binghamton-Dimensions and features have been distinguished as having different consequences for cognition. Of special interest is what a single stimulus implies about a larger set. Subjects saw one, two, or three stimuli from a set generated either by crossing two dimensions or by adding subsets of two features to a stem. Subjects inferred the nonpresented members. Differences in inferred sets as a function of presented-set size and type of attribute will be discussed. 
ANIMAL LEARNING III

Rose Garden, Saturday Afternoon, 1:30-3:25

Chaired by W. Scott Terry, University of North Carolina at Charlotte

1:30-1:50 (352)

The Behavioral Theory of Timing (BeT): Transition Analysis. J. GREGOR FETTERMAN, Indiana University-Purdue University at Indianapolis, \& PETER R. KILLEEN, Arizona State University-We show that BeT provides a very good, parameter-free account of correlational patterns in peak time data (Gibbon \& Church, 1990), and of previously unpublished data from our laboratory with a new timing technique, the "peak choice" procedure. We describe an augmented (oneparameter) version of $\mathrm{BeT}$, which posits a lag between receipt of pulses from the pacemaker and movement into the next behavioral state. The augmentation significantly improves the correspondence between the theory and the data.

$$
\text { 1:55-2:15 (353) }
$$

Use of Time-Course Measurements for Functional Analysis. STEVEN DERBY \& SETH ROBERTS, University of Califormia, Berkeley (read by Seth Roberts)-Two peak-procedure experiments with rats asked how seven performance measures were influenced by (1) time within the 6-h session and (2) the presence or absence of food on preceding trials. The number of different time courses observed suggest that the underlying mechanism can be divided into at least six separately changeable parts-including a part that generates the initial responses that are increased by reward ("curiosity"), and a part responsible for increased effort after nonreward ("frustration").

$$
\text { 2:20-2:35 (354) }
$$

Temporal Learning in Pigeons: The Effects of Transitional Variations in Interfood Interval Duration. JENNIFER J. HIGA, Duke University-Recent developments revealed that animals can rapidly learn about intervals of time. I will discuss the results from experiments aimed at unraveling this process and show (1) the time course of learning during an unpredictable, step-like, transition in interfood interval (IFI) duration and (2) how temporal control, during a cyclic sequence of IFIs, changes with training - it is clear during the first few sessions of exposure and deteriorates with further training.

$$
\text { 2:40-3:00 (355) }
$$

Temporal Organization of Behavior on Periodic Food Schedules. ALLISTON K. REID, Eastern Oregon State College-Various theories of temporal control and schedule induction imply that periodic schedules temporally modulate an organism's motivational states within IRIs. However, in three series of experiments, obtained multimodal activity distributions created by averaging across IRIs were not representative of the transitions occurring within individual IRIs, so the averaged distributions do not represent transitions in motivational states. Sequential patterns of drinking and running on periodic schedules do not result from temporal modulation of motivational states.

$$
\text { 3:05-3:20 (356) }
$$

Conditioned Reinforcing Value of Informative Stimuli in Pigeons and People. MICHAEL PERONE, KAREN COURTNEY, West Virginia University, DAVID STAFFORD, University of Florida, \& BARBARA J. KAMINSKI, Johns Hopkins University-According to Pavlovian accounts of conditioned reinforcement, neutral stimuli acquire reinforcing functions if positively correlated with an established reinforcer and aversive functions if negatively correlated, but remain neutral if uncorrelated. In simultaneous choice tests, subjects could respond to observe stimuli either negatively correlated or uncorrelated with operant reinforcement. Consistent with Pavlovian accounts, pigeons' observing behavior extinguished. College students, however, observed the negative stimulus in preference to the uncorrelated one, suggesting susceptibility to reinforcement by information.

\section{3-D/MOVEMENT PERCEPTION II}

St. Louis Ballroom B, Saturday Afternoon, 1:30-3:35

Chaired by Lynn A. Cooper, Columbia University

1:30-1:45 (357)

Spatiotemporal Boundary Formation: Evidence for a Local Integration Process. THOMAS F. SHIPLEY, University of Georgia, \& PHILIP J. KELLMAN, Swarthmore College-Moving objects may appear to have continuous boundaries despite being specified by information sparsely distributed in space and time (e.g., perception of occluding surfaces in sparse accretion-deletion displays). Two kinds of studies reveal the information integration process to be relatively local. Varying the information rate indicates that integration occurs within a temporal window of about $150 \mathrm{msec}$. Varying the global motion path indicates that integration does not depend on path uniformity or smoothness.

\section{1:50-2:05 (358)}

Perception of Target Motion by Passively Moving Observers. MARY K. KAISER, NASA-Ames Research Center, PHILIP J. KELLMAN, Swarthmore College, MARTIN S. BANKS, University of California, Berkeley, \& WILLIAM H. AIKEN, University of California, Santa Cruz-For moving observers, the motion of a target on a parallel trajectory is indeterminate unless the distance to the target is specified. We are examining what distance information is sufficient to clarify target motion. Our first experiment removed all environmental and target structure, and examined performance with monocular and binocular viewing over a range of target motion velocities and durations. The data indicate above chance performance only at higher velocities, and suggest observers overestimate target distance.

\section{2:10-2:25 (359)}

How Does the Visual System Combine Motion Signals Having Different Degrees of Ambiguity? MAGGIE SHIFFRAR \& XIAOJUN LI, Rutgers University-To interpret the projected image of a moving object, the visual system must integrate motion signals across different image regions. Research in this area has traditionally focused on the integration of equally ambiguous motion signals. How does the visual system combine ambiguous and unambiguous motion signals together? To address this question, coherence of ambiguously moving contours and unambiguously moving random dot patterns was studied. Conditions under which unambiguous motion signals dominate image interpretation are discussed.

$$
\text { 2:30-2:50 (360) }
$$

Imagined Motion is Influenced by Adaptation. DAVID L. GILDEN, RANDOLPH BLAKE, \& GEOFFRY HURST, Vanderbilt UniversityWe have examined the neural basis of the imagination by assessing imagined speed in states of motion adaptation. Dot motions were initiated in unadapted retina and then were continued imaginally through adapted retina in a time-to-contact paradigm. Imagined time-to-contact was overestimated in the direction of adaptation, underestimated in the opposite direction, and was unaffected in orthogonal directions. These results suggest that adapted neurons are used in the execution of this task.

$$
\text { 2:55-3:10 (361) }
$$

Creature Motion. JENNIFER J. FREYD, University of Oregon, \& GEOFFREY F. MILLER, Stanford University-We showed subjects a line-drawn creature moving on a computer screen. Suddenly the creature stopped and subjects' memory for position was tested, revealing large forward memory shifts. Representational momentum was reduced when the creature moved tail-first instead of head-first, corresponding to a subjective experience of watching an impaired or sick animal. An "inanimate" icon condition produced no directionality effect. We discuss the significance of dynamics, directionality, and animacy in event and object perception. 


\section{3:15-3:30 (362)}

Pathways of Perceptual Consequence. JULIAN HOCHBERG, Columbia University-Beer (1992) just showed imagined distances are commensurate with those revealed by optic flow. More generally, disparate information sources (whether "direct" or "indirect") normally conjoin in the construal of changing environments. Even when commensurate, however, we now show that different kinds of tokens of identity, location, or distance have very different parameters for the same perceptual consequences, and the same tokens may have different parameters for different consequences, suggesting different underlying pathways of processing.

\section{PSYCHOLINGUISTICS II}

\section{St. Louis Ballroom C, Saturday Afternoon, 1:30-3:00}

\section{Chaired by Lynne E. Bernstein, Gallaudet University}

1:30-1:45 (363)

Conceptual Matching Afiects Syntactic Interpretation. MORTON ANN GERNSBACHER, University of Wisconsin-Madison-Grammaticality judgments to a second sentence are harder when it mismatches a first sentence in number (Whining students are often a drag. Visiting in-laws is often a drag, too), even when the verb in the first sentence is unmarked (Washing clothes can be a drag. Visiting in-laws are often a drag, too). Mismatches are even harder, although matches are unaffected, when the second sentence is syntactically dependent (Whining students are a drag. Visiting in-laws is, too).

\section{1:50-2:05 (364)}

Imagining What Might Have Been: Replotting and Ease of Verification. RICHARD J. GERRIG \& DAVID W. ALLBRITTON, Yale University-Our experiments consider some consequences of peoples' imagining alternatives to past events-"replotting"-on their ability to verify those events. Subjects were required to list reasons why famous real-world events (e.g., Lindbergh crossing the Atlantic or the Titanic sinking) might have failed to occur. Although subjects had to consider the events at length to undo them (an activity that we demonstrate in a control experiment facilitated verification), replotting itself impaired performance.

\section{2:10-2:20 (365)}

Common Processes Underlie Phonological and Morphological Analysis. LAURIE B. FELDMAN, SUNY at Albany and Haskins Laboratories, DARINKA ANDJELKOVIĆ, University of Belgrade, \& ANNE FOWLER, Bryn Mawr College and Haskins LaboratoriesThe relation between morphological and phonological awareness in beginning readers of Serbo-Croation was examined. The morphological task consisted of a source word ("to cook") that required morphological affixes (inflectional/derivational) in order to fit with a sentence frame (This restaurant has good___ ). The phonological task entailed deleting a phoneme. Inflectional adjustments were easier than derivational adjustments. Controlling for verbal and nonverbal IQ, performance on the morphological and phonological tasks was significantly associated.

\section{2:25-2:35 (366)}

In Reading Chinese, There Is No Semantics Without Phonology. CHARLES A. PERFETTI \& SULAN ZHANG, University of Pittsburgh-Chinese character identification is sometimes discussed as if it were a "semantics-only" process. Following earlier work in which we showed phonological effects in Chinese word naming (Perfetti \& Zhang, 1991), we report results from brief-exposure nonnaming semantic and phonological tasks. The experiments provide new evidence for automatic and very early activation of character names. The time course of semantic and phonological activation is summarized as "no semantics without phonology."

$$
\text { 2:40-2:55 (367) }
$$

Multiple Constraints on Lexical Category Ambiguity Resolution. MARYELLEN C. MACDONALD, University of Southern CaliforniaTwo experiments examined comprehension of sentences containing lexical category ambiguities (e.g., "fires" is a noun or verb). Ambiguity effects appeared in self-paced reading following only misleading, not helpful, contexts. Experiment 2 investigated three subcomponents of these contexts: noun versus verb biases of ambiguous words, head versus modifier usage of biasing words, and combinatorial semantic information across several words. Only the latter two factors predicted ambiguity effects. Implications for ambiguity resolution models are discussed.

\section{SYMPOSIUM II: REASONING AND DECISION MAKING}

St. Louis Ballroom D, Saturday Afternoon, 1:30-3:35

Chaired by Eldar Shafir, Princeton University

\section{1:30-1:50 (368)}

The Elusive Wishful Thinking Effect. MAYA BAR-HILLEL, Hebrew University, \& DAVID V. BUDESCU, University of Haifa-Subjects read short stories, each story describing two contestants competing for some desirable outcome (e.g., firms competing for a contract). Some judged the probability that A would win, others judged the desirability that A would win. Factors enhancing a contestant's desirability had no normative bearing on its winning probability. The "wishful thinking" hypothesis predicts that, ceteris paribus, the favored contestant would be judged more likely to win. No such effect was found.

\section{1:55-2:15 (369)}

Focusing in Reasoning and Decision Making. P. N. JOHNSONLAIRD, Princeton University-Human decision makers reason to make decisions, and their reasoning depends on the construction of mental models of the options. Reasoning and decision making should therefore give rise to similar phenomena. One such phenomenon is referred to as "focusing": Individuals are likely to restrict their thoughts to what is explicitly represented in their models. Focusing occurs in three domains. (1) Individuals fail to draw inferences in the modus tollens form (if $p$ then $q$, not- $q$, therefore not-p) because they focus on their initial models of the conditional, which make explicit only the case in which the antecedent and consequent occur. (2) In Wason's selection task, they similarly tend to select only those cards that are explicitly represented in their initial models of the conditional rule. (3) Their requests for information to enable them to decide whether or not to carry out a certain action are focused on the action to the exclusion of alternatives to it. In each case, the focusing bias can be reduced by certain experimental manipulations.

$$
\text { 2:20-2:40 (370) }
$$

Judging the Utility of Past Episodes. DANIEL KAHNEMAN, University of California, Berkeley-The evaluation of the overall hedonic quality of past episodes plays a significant role in determining choices for the future. Temporal integration of momentary affect is a plausible normative rule for such evaluations, but retrospective evaluations generally violate this rule. Except when it is singled out as the major dimension ("hours of labor"), the duration of experiences is largely neglected in their evaluation. Because trend is important and duration is not, it is sometimes possible to improve the evaluation of an unpleasant episode by adding diminishing pain to it. Decisions that maximize the anticipated quality of memories do not necessarily maximize the quality of experience.

\section{2:45-3:05 (371)}

Reflective Choice: Reasons in Decision Making. ELDAR SHAFIR, Princeton University, \& AMOS TVERSKY, Stanford UniversityPreferences are often constructed, not merely revealed, during the making of decisions. The construction of preferences is partially guided by an attempt to formulate coherent reasons for choosing one option rather than another. We explore the role of reasons and arguments in decision making. In particular, we investigate the ability of a qualitative analysis based on reasons to explain decisions that are puzzling from the perspective of a quantitative analysis based on value.

\section{3:10-3:30 (372)}

Category Based Judgment of Probability. EDWARD E. SMITH, University of Michigan, ELDAR SHAFIR, Princeton University, \& DANIEL OSHERSON, IDIAP - In a category-based argument, the premises and conclusion are of the form All members of $C$ have property $P$, in which $C$ is a natural category. An example is Collies have 
sesamoid bones. Therefore German Shepherds have sesamoid bones. In this example, the property is unfamiliar or "blank," and in making probability judgments about such arguments, people rely heavily on similarity relations between the categories. In contrast, when the property is more familiar (e.g., Collies can bite through wire), people rely heavily on the relation between property and category information.

\section{HUMAN LEARNING/MEMORY IV}

Promenade C, Saturday Afternoon, 1:30-3:25

Chaired by Henry L. Roediger III, Rice University

\section{1:30-1:50 (373)}

Compound Cue versus Spreading Activation Theories of Priming. GAIL MCKOON \& ROGER RATCLIFF, Northwestern UniversityMcNamara (1992) has claimed that compound cue theories cannot account for mediated priming effects or for the sequential effects of items preceding a target on responses to the target. With new data and simulations of SAM (Gillund \& Shiffrin, 1984), we show that compound cue theories can explain these effects. We also show that priming effects in lexical decision cannot be predicted from free association production probabilities.

\section{1:55-2:15 (374)}

The Effects of External and Internal Repetition on Memory. MOSHE NAVEH-BENJAMIN, Ben-Gurion University of the NegevMemory researchers generally believe that repetition (external presentation) is a better mechanism than rehearsal (internal repetition), in the formation of enduring memory traces. This belief is based mostly on cross-experimental comparisons. In a series of studies, we directly compared the effects of repetition and rehearsal on memory. Results indicate that the performance relationships between the two depend on the level of processing employed and the type of memory test used.

$$
\text { 2:20-2:40 (375) }
$$

Learning, Performance, and Individual Differences in an Associative Memory Task. PHILLIP L. ACKERMAN, University of Minnesota, \& DAN J. WOLTZ, University of Utah-Several consistent and varied versions of an associative memory/perceptual scanning task are used to examine the nature of individual differences under conditions designed to elicit learning and/or performance. Manipulations of task difficulty, explicit memory testing, self-focus, and goal setting illuminate the interplay of individual differences and general learning factors. In addition, ability-performance relations demonstrate how interindividual difference measures may be used to triangulate the locus of information processing constraints.

$$
\text { 2:45-3:00 (376) }
$$

Narrowing of Attention and the Recognition of Emotionally Arousing Scenes. SVEN-ȦKE CHRISTIANSON, University of Stockholm, MARTIN SAFER, M. W. AUTRY, Catholic University of America, \& KARIN ÖSTERLUND, University of Stockholm-Subjects attend more to central than to peripheral details in emotionally arousing scenes (Christianson, Loftus, Hoffman, \& Loftus, 1991). We demonstrate further that this narrowed attention affects recognition. In one experiment, using a four-choice recognition test, 10 of 14 subjects incorrectly selected pictures with a more narrowed focus than the original emotional picture. In a second recognition experiment, in which camera distances were rigorously controlled, subjects were more likely to select close-up versions for emotion-arousing pictures than for neutral pictures.

$$
\text { 3:05-3:20 (377) }
$$

Memory and Other Psychological Processes. DOUGLAS HERRMANN, National Center for Health Statistics, ALAN SEARLEMAN, St. Lawrence University, \& PAUL MULLIN, Bureau of Labor Statistics-A full understanding of memory requires consideration of several different aspects of human functioning. Because behavior can be influenced by many psychological processes (e.g., perceptual, motivational, emotional, social, physiological), we argue that memory performance typically reflects the operation of a variety of processes. This paper examines the impact that other psychological processes can have on memory performance and memory modeling.

\section{ATTENTION III}

Promenade D, Saturday Afternoon, 1:30-3:20

Chaired by Anne-Marie Bonnel, University of California, Berkeley

1:30-1:45 (378)

Segregation of Moving and Stationary Items in Visual Search. ARTHUR F. KRAMER, KENNETH BRADY, MING-PO THAM, JOHN LARISH, University of Illinois, \& YEI-YU YEH, University of Wisconsin-The hypothesis that humans can selectively attend to moving items and ignore physically interspersed stationary items was examined. Subjects performed same/different matching tasks with moving stimuli while attempting to ignore response compatible and incompatible stationary distractors. The most important finding was a large and robust interaction between target response and distractor type. The data argue for a number of constraints on our ability to selectively attend to moving items and ignore stationary distractors.

\section{1:50-2:10 (379)}

Attention Control in Dichoptic Vision. DANIEL GOPHER, EHUD TIROSH, RUTH KIMCHI, \& ARTHUR GRUNWALD, TechnionIsrael Institute of Technology-Two experiments investigated the interplay between attention control and visual field characteristics, employing dichoptic viewing tasks. One experiment required flying a simulated flight path under 2-D or 3-D instructions. In a second experiment, subjects were required to detect lateral or looming motions of objects presented to one eye at threshold levels, while being passively exposed or actively responding to high contrast rich information presented to the other eye. Subjects were capable of selectively adopting a "frame of mind" when interacting with a complex display. Attention and display characteristics were equally potent determinants of eye field dominance. Directed attention washed out a preattentive advantage of detecting looming motion.

$$
\text { 2:15-2:30 (380) }
$$

Perception of On- and Off-Screen Self-Motion Heading. RIK WARREN \& JEREMY M. A. BEER, USAF Armstrong Laboratory-Warren (1976) investigated perceived direction of simulated rectilinear travel over a flat plane using a "shoot from the hip" pointing technique. Both on-screen and off-screen headings were included. Recently, forced-choice methods have found small errors for on-screen headings. We here assess both on- and off-screen headings using both forced choice and direct pointing. Additional variables include speed, duration, texture type, texture density, and disturbances. Implications for perceiving off-screen events are stressed.

\section{2:35-2:50 (381)}

Parallel and Serial Operations in Character Identification. TERESA PANTZER \& SAUL STERNBERG, University of Pennsylvania (read by Saul Sternberg)-Degrading one or more numerals in an array produces dramatically different timing patterns in speeded ordered whole report, depending on type of degradation. These timing patterns show that superimposition of a grid on a numeral influences primarily a parallel component of the encoding process, whereas disorientation of a numeral influences primarily a serial component; ordering of the serial components corresponds to the order of report. Encoding for identification is thus both serial and parallel.

$$
\text { 2:55-3:15 (382) }
$$

Distributional Tests of Serial, Parallel, and Coactivation Models Using the Double Factorial Paradigm. JAMES T. TOWNSEND, Indiana University, \& GEORGE NOZAWA, Dartmouth College-The Double Factorial Paradigm was demonstrated in earlier Psychonomic Society talks (1) to test parallel versus serial processing in exhaustive tasks, by Townsend and Piotrowski, 1981, and (2) to test parallel versus serial processing and assess capacity in minimum time contexts, by Townsend and Nozawa, 1988. In this study, further data are gathered and a number of new distributional methods are presented that test among parallel race and coactivation models. The tests are distribution and parameter free. 
ANIMAL LEARNING IV

Rose Garden, Saturday Afternoon, 3:35-5:00

Chaired by Russell M. Church, Brown University

$$
\text { 3:35-3:50 (383) }
$$

Short-Term and Long-Term Effects of Reinforcers on Choice. LEONARD GREEN, RANDY L. BUCKNER, \& JOEL MYERSON, Washington University-Short-term and long-term effects of reinforcers on choice were studied in pigeons on concurrent schedules. Time ratios matched reinforcement ratios, and preference was unchanged during interleaved reinforcer-free periods and extinction. Reinforcers increased the duration of those stays during which they were delivered but not immediately following stays. This short-term effect was necessarily absent from the interleaved reinforcer-free periods and extinction, and thus cannot account for long-term matching.

$$
\text { 3:55-4:10 (384) }
$$

Behavior Regulation on Simple Variable Interval Schedules. JAMES D. DOUGAN, Illinois Wesleyan University-Two experiments examined the evidence for within-session regulatory effects on simple $\mathrm{VI}$ schedules. In Experiment 1, the function relating response rate to reinforcement rate was different for 10-min sessions than for the first $10 \mathrm{~min}$ of 30-min sessions. In Experiment 2, animals were able to discriminate session length on the basis of reinforcer flavor. When flavor signaled short sessions, the animal responded significantly faster at the start of the session than over comparable time periods for long sessions. Both experiments show that session length affects responding early in the session, which is consistent with both economic and regulatory models.

$$
\text { 4:15-4:35 (385) }
$$

Does Reward Increase or Decrease Human Creativity? ROBERT EISENBERGER \& MICHAEL SELBST, University of Delaware-Based upon what would appear to be overwhelming empirical evidence, textbooks in animal learning, cognition, social and industrial psychology, and animal learning frequently warn of the debilitating effects of reward on human creativity. In contrast, general behavior theory assumes that creativity, as other response classes, can be strengthened by reward. The learned industriousness model successfully predicts the conditions under which reward increases, as well as decreases, the learning and generalization of children's creative behavior.

$$
\text { 4:40-4:55 (386) }
$$

Choice and Transitions of Reinforcement. D. ALAN STUBBS, DAVID M. BOYNTON, LAURENCE D. SMITH, University of Maine, LEON R. DREYFUS, Vassar College, \& J. GREGOR FETTERMAN, Indiana University-Purdue University at Indianapolis-Pigeons, trained on concurrent variable-interval choice schedules, were given weekly or daily transitions in relative reinforcement rates. Weekly transitions revealed spontaneous recovery effects, with reversion to prior choice pattern. Conditions with daily transitions from low to high relative reinforcement rate anywhere during a session showed rapid changes in behavior within 10-20 reinforcers following a change. Addition of absolute reinforcement rate changes to relative reinforcement changes at the transition enhanced the rate of change.

\section{3-D/MOVEMENT PERCEPTION III}

\section{St. Louis Ballroom B, Saturday Afternoon, 3:45-5:00}

\section{Chaired by Julian Hochberg, Columbia University}

\section{3:45-3:55 (387)}

Steering Need Not Require the Correct Perception of Heading. JACK M. LOOMIS, University of Califormia, Santa Barbara-Consider an observer who is steering a straight path in the presence of lateral perturbing forces. When performed with solid lane markers, only optical rotation of the markers is available; when performed with broken (dashed) lane markers, radial outflow is also available. The latter permits correct perception of heading, but the former does not because the optical rotation depends only upon the lateral component of motion. Steering can be performed effectively in both cases.

\section{4:00-4:15 (388)}

Visual Information During Locomotion for Avoiding Stationary and Moving Objects. JAMES E. CUTTING \& PAUL A. BRAREN, Cornell University - Two sources of information are isolated for a moving observer, one about heading and avoiding stationary objects, and the other about avoiding moving objects. Stationary objects may be avoided through use of retinal flow information under pursuit fixation of a stationary object, information that is useless when the fixated object moves. Moving objects may be avoided through use of retinal flow information under a constant gaze-movement angle. The latter's relation to kinetic depth will be discussed.

\section{4:20-4:35 (389)}

Anisotropy in Visual Control of Posture During Walking. WILLIAM H. WARREN, BRUCE A. KAY, \& EMRE H. YILMAZ, Brown University-Large-screen displays simulating translation down a hallway were presented during treadmill walking, with a superimposed optical oscillation in the anterior-posterior (A-P) or lateral direction. With translation plus oscillation, A-P sway amplitude was only $40 \%$ of lateral; with oscillation alone, it was $66 \%$; but with an oscillating wall, it was $91 \%$. The asymmetry is thus perceptual, not biomechanical, and suggests that vision is primarily used to control lateral balance during normal walking. 4:40-4:55 (390)

3-D Structure From Motion: A New Method and New Phenomena. JOSEPH S. LAPPIN \& WARREN D. CRAFT, Vanderbilt UniversityThe projected image of a smooth surface can be locally described by a linear coordinate transformation which specifies the mapping of spatial relations between the surface patch and its image. Using this principle, we have transformed the image coordinates of computer displays of 2-D moving shapes. The resulting percepts are of 2-D shapes moving over slanted planes and curved surfaces in 3-D space. In certain cases, the metric shapes can be very accurately perceived.

\section{PSYCHOLINGUISTICS III \\ St. Louis Ballroom C, Saturday Afternoon, 3:10-5:00}

Chaired by Charles A. Perfetti, University of Pittsburgh

3:10-3:30 (391)

Lexical Short-Term Memory, Semantic Integration, and Sentence Comprehension. RANDI C. MARTIN \& CRISTINA ROMANI, Rice University-On-line sentence comprehension was investigated for a brain damaged patient who appears to have a selective deficit to the lexical component of short-term memory. The patient showed increasingly poor comprehension of sentences as the number of lexical items increased, but the effect was greatly exaggerated for sentences that did not allow immediate semantic integration. The results imply an overlap between the lexical memory resources tapped by span tasks and those involved in sentence comprehension.

$$
\text { 3:35-3:50 (392) }
$$

What Can We Learn From "That"? CORNELL JULIANO, JOHN C. TRUESWELL, \& MICHAEL K. TANENHAUS, University of Rochester (read by Michael K. Tanenhaus)-In written English, "that" is typically ambiguous between a determiner (e.g., "that hotel") and a complementizer (e.g., "that hotels"), but the relative frequency of the two changes with syntactic environment. We demonstrate that readers resolve local ambiguities with "that" consistent with the statistical patterns in the language. We also use "that" to show that some apparent paradoxes about what information is used when in parsing are resolved when statistical co-occurrence information is taken into account. 3:55-4:15 (393)

Words Block Children's Attention to the Functions of Complex Artifacts. LINDA B. SMITH, SUSAN S. JONES, Indiana University, \& BARBARA LANDAU, University of Califormia, Irvine-Five experiments examined the effects of naming and demonstrated functions on 3-yearolds' attention to object properties. In non-naming tasks, children attended to the properties critical to the demonstrated function. In the naming tasks, demonstrated functions had no effect on children's formed lexical categories. The mechanism that directs attention in novel word interpretation 
appears to depend on previously learned long-term memory connections that take precedence over more transient forces on attention.

$$
\text { 4:20-4:35 (394) }
$$

Promoting Native-Like Acquisition of a Second Language in Adults. BARBARA PITTS COCHRAN \& JANET L. McDONALD, Louisiana State University (read by Janet L. McDonald)-Newport's (1988, 1990) "less is more" hypothesis states that general cognitive limitations of young children may work in favor of language acquisition. This hypothesis was tested by training adult English speakers in a new language (American Sign Language) under two conditions: (1) control or (2) limited cognitive resources-subjects performed a simultaneous tone counting task. At test, the resource-limited subjects made significantly fewer errors on ASL directional verbs in novel sentences, supporting Newport's hypothesis.

$$
\text { 4:40-4:55 (395) }
$$

Overtensing, Regularity, and the Unreality of Rules. JOSEPH PAUL STEMBERGER, University of Minnesota-In adult and child speech, errors occur where tensed verbs replace infinitives (I didn't broke it). The fact that irregular verbs are involved more than regular verbs has been used to argue that regular verbs are produced via rules but irregular verbs are stored in the lexicon. An experimental task shows that this effect is not due to a confound between regularity and frequency, but may be due to phonological confounds. Rules are not implicated.

\section{JUDGMENT/DECISION MAKING I}

\section{St. Louis Ballroom D, Saturday Afternoon, 3:45-4:50}

\section{Chaired by Valerie F. Reyna, University of Arizona}

\section{3:45-4:05 (396)}

What Do Experts Think About Expert Decision Makers? JAMES SHANTEAU, Kansas State University, \& MOHAMMAD J. ABDOLMOHAMMADI, Bentley College-Little is known about how experts view expert decision makers. Three groups of auditors, varying in professional status, were asked first to list all attributes they considered important in an expert auditor and second to evaluate the importance of 20 prespecified attributes. Unexpectedly, the results for the three groups were similar: cognitive/knowledge attributes were considered most important, followed by self-presentation/image and strategic/decision-making attributes, with personal appearance/style characteristics considered least important.

$$
\text { 4:10-4:25 (397) }
$$

Expert-Novice Confidence on Judgment Under Uncertainty. M. J. GONZALEZ LABRA, I. ARTIETA PINEDO, \& A. J. GARRIGA TRILLO, Universidad Nacional de Educación a Distancia-Research on experts and novices has shown that experts exhibit more confidence on their judgments than novices. This study analyzed whether expert and novice midwives maintain this pattern across two different tasks: (1) clinical cases in which symptoms had to be weighted and a diagnosis was required, and (2) problems based on obstetric cases that might induce biases in reasoning. Results indicate different confidence patterns depending on type of clinical case and bias.

$$
\text { 4:30-4:45 (398) }
$$

Efficient Use of Working Memory Capacity Contributes to Expert Performance. ROBERT M. HAMM, University of Oklahoma Health Sciences Center, \& CHARLES ABERNATHY, University of Colorado Health Sciences Center- "Mental capacity" can account for experts' greater abilities, on several levels. First, experts' larger chunks and ability to use LTM to extend working memory allow the "same" representation to take up less capacity. Second, differences in spare capacity due to expert knowledge can contribute to expert-novice performance differences, just as preexisting capacity differences account for differences in good versus bad readers' performance (Just \& Carpenter, 1992, Psychological Review, Vol. 99). Expert and novice surgeons provide examples.

\section{MOTOR CONTROL}

Promenade C, Saturday Afternoon, 3:35-5:10

\section{Chaired by Jasper Brener, SUNY at Stony Brook}

\section{3:35-3:50 (399)}

Constraints on Perceptual-Motor Exploration. PAUL V. MCDONALD \& KARL M. NEWELL, University of Illinois at Urbana-
Champaign (read by Karl M. Newell)-To examine the impact of task and biomechanical constraints on exploratory behavior in a perceptualmotor coordination task, four experiments varied gain and symmetry in an action-information mapping and examined between limb, within limb, and within joint biomechanical combinations. On the basis of identifying one consistent search strategy supported by biomechanical combination specific action modes, we conclude that a perceived task equivalence emerged at the level of interaction between information states and action modes.

$$
\text { 3:55-4:10 (400) }
$$

Effects of Movement Duration on Adaptive Spatial Alignment of Eye and Hand. GORDON M. REDDING, Illinois State University, \& BENJAMIN WALLACE, Cleveland State University-Subjects engaged in reciprocal, sagittal target-pointing while viewing a prismatically displaced field. Pointing was paced at one complete out-and-back movement every 1,3 , or $6 \mathrm{sec}$, producing movement durations on the order of .5 , 1.5 , or $3.0 \mathrm{sec}$. Aftereffects showed spatial realignment localized in the hand-head system with the shortest movement, but locus shifted to the eye-head system for longer movements, especially with visual feedback delayed until terminal end of movement.

$$
\text { 4:15-4:30 (401) }
$$

Selecting a Grip for Manipulation: Order of Information Presentation. JONATHAN VAUGHAN, Hamilton College, DAVID ROSENBAUM, University of Massachusetts, ERIC JOACHIM, MICHELLE PULEIO, \& DAVID GROFF, Hamilton College-Selecting a grip to manipulate an object depends on anticipated comfort at the beginning and end of the movement, and on the part of the object to which instructions have directed attention. In this study, signals about starting and ending positions of an object to be moved were presented simultaneously or sequentially, with starting information presented before or after ending information. Grip choices and the timing of performance revealed how planning and execution were controlled.

$$
\text { 4:35-4:45 (402) }
$$

Dynamics of Phase Attraction During Bimanual Coordination. CHARLES B. WALTER \& HONGYAN PAN, University of Illinois at Chicago-Bimanual oscillations have been used by a number of investigators to examine the intrinsic dynamics of interlimb coordination. The velocity of the phase difference between movements oscillating at different frequencies was used to observe these dynamics. Frequency and laterality effects were examined. Intermittent coordination was evident as the tendency for relative phase velocity to diminish at in-phase and/or antiphase relationships, although clear individual differences were present among subjects. Laterality effects were observed as well.

$$
\text { 4:50-5:05 (403) }
$$

What Gets Synchronized With What in Sensorimotor Synchronization? WOLFGANG PRINZ \& GISA ASCHERSLEBEN, Max-Planck Institute, Munich-In periodic synchronization tasks the subject is required to tap in synchrony with a periodic signal (e.g., a sequence of clicks). Our experiments address the issue of what exactly gets synchronized with what in these tasks. Results suggest that movement-related afferent codes (feedback from taps) get superimposed on stimulus-induced afferent codes (arising from pacing signals). Some constraints for a model of the operations underlying synchronization are discussed.

\section{ATTENTION IV}

Promenade D, Saturday Afternoon, 3:30-5:10

\section{Chaired by Joel S. Warm, University of Cincinnati}

\section{3:30-3:50 (404)}

What Makes it Difficult to Process Multiple Targets in Rapid Serial Visual Presentation? KRISTA LYNN HORLITZ, JAMES C. JOHNSTON, \& ROGER W. REMINGTON, NASA-Ames Research Center (read by James $C$. Johnston)-Attentional limitations not attributable to spatial selection are revealed by impaired performance on the second of two sequential targets in RSVP streams. Three single-cause hypotheses-that the interference is due to filter-switching costs, task-switching costs, or overload of particular classification processes-are experimentally disconfirmed. The amount of interference is influenced by the difficulty of both selecting and classifying the first target. Implications of these results for attention models will be discussed. 


\section{3:55-4:15 (405)}

Dissociative Effects of Two Different Attentional Manipulations: Evidence for Two Attentional Bottlenecks. ROBERT S. MCCANN, Sterling Software, JAMES C. JOHNSTON, \& ROGER W. REMINGTON, NASA-Ames Research Center-Two different attention manipulations produced qualitatively different effects on the same task (identifying forms as " $A$ " or " $\mathrm{H}$," with normal or distorted characters). Spatial cuing had effects that were additive with distortion effects, but performing another task concurrently had effects that were strongly underadditive with distortion effects. The dissociation supports an architecture with two attentional bottlenecks; an early stimulus-selection bottleneck before character identification and a central decision-making bottleneck.

\section{4:20-4:40 (406)}

Dimensional Constraints in Response Selection: Evidence From the Flanker Task. ASHER COHEN \& RACHEL E. SHOUP, Indiana University-Subjects made one response to either a color or an orientation and made a second response to either another color or another orientation. RT was slow even after extensive training when target of one di- mension was flanked by the other dimension's stimuli regardless of the flanker's identity. This inference was not observed within orientation, within color, or between nondimensional categories (e.g., digits and letters). Subsequent experiments explore the boundary conditions of this dimensional interference.

\section{4:45-5:05 (407)}

The PRP Effect: Central Bottleneck, Perceptual-Motor Limitations, or Task Strategies? DAVID E. MEYER \& DAVID E. KIERAS, University of Michigan-When two choice-reaction tasks are temporally adjacent, second-task response latencies typically increase. Some theorists have attributed this psychological refractory period (PRP) effect to a central response-selection "bottleneck." However, detailed computational modeling of some past dual-task experiments suggests that the PRP effect actually stems instead from subjects' task strategies and limitations on peripheral perceptual-motor resources. According to our simulations, central processing mechanisms may have more capacity than sometimes previously claimed. 
POSTER SESSION III

St. Louis Ballroom E, Saturday Evening, 5:45-7:15

(408)

Categorical Attributes Determine Visual Similarity Even When Recognition Requires Scrutiny. JOHN E. HUMMEL \& BRIAN J. STANKIEWICZ, UCLA-Some researchers have suggested that difficult recognition tasks (e.g., recognizing a particular piece of bent wire) are performed by matching an image to a pictorial description stored in memory. We trained subjects to recognize unfamiliar shapes that are difficult to discriminate. Subsequent similarity judgments with systematically distorted versions of those shapes were better predicted by an account based on matching categorical properties than by either of two accounts based on matching pictorial descriptions.

(409)

Naming Familiar Faces Rotated in Two and Three Dimensions. PATRICIA A. MCMULLEN, Dalhousie University-Naming latencies have supported mental representations of objects in 3/4 view. Yet, cells in the monkey temporal gyrus respond preferentially to frontal and profile views of faces. Are objects and faces represented in fundamentally different ways? Frontal, 3/4, and profile views of familiar faces were named. Like objects, upright faces in 3/4 view were named fastest. However, rotations in the picture-plane had equivalent effects on latencies for $3 / 4$ and frontal views and much greater effects for profile views.

(410)

Orientation Perception: Categorical or Continuous? PAUL C. QUINN, Washington \& Jefferson College-This study examined whether orientation information is perceived categorically. In separate experiments, adult subjects sorted oriented line stimuli into broad oblique and narrow vertical or horizontal categories. Subsequent experiments showed that categorical discrimination of orientation occurred only near the vertical-oblique boundary. These results suggest that there may be (1) categorical perception near vertical and continuous perception near horizontal and (2) differences in the functional significance of orientation information near the two main axes.

(411)

Degree of Figural Symmetry Specifies Orientation of Interpreted Objects. MICHAEL K. McBEATH, NASA-Ames Research Center, \& DIANE J. SCHIANO, SunSofi, Inc. and Stanford University (presented by Diane J. Schiano)-Subjects viewed random polygons varying in degree of vertical symmetry. After describing "what the figure looks like," they rated figural orientation as straight-on, oblique, or directside. A robust linear trend was found between degree of symmetry and rated orientation: Symmetric figures were generally interpreted as objects viewed straight-on, more asymmetric figures as increasingly oblique or side views. These data provide further evidence that the assumption of 3-D bilateral symmetry is a commonly used pattern-recognition heuristic.

\section{(412)}

Viewpoint-Dependent Image Features in Human Object Representation. MICHAEL J. TARR \& DAVID J. KRIEGMAN, Yale University - What image features are used to judge an object's orientation and shape? By rotating an object in depth, sensitivities for detecting changes in the image structure of smoothly curved objects were measured using either line drawings or shaded images. As catastrophe theory predicts (e.g., Koenderink), increases in sensitivity were found at the same orientations as the visual events that delineate topologically distinct views. This has implications for the kinds of image features used in object representations.

Cross-Modal Negative Priming. PENNY L. YEE \& HUGH SNYDER, Hamilton College-Negative priming effects were replicated in a cross-modal study in which subjects ignored an auditory word and attended to it visually in a subsequent trial. Positive priming effects were also observed in certain conditions and suggest that the manner in which subjects process relevant events is an important factor in the accessibility of irrelevant events.
(414)

Response Number and Targeted Percentile Schedules: Manipulating Target Run Length. GREGORY GALBICKA, MARY KAUTZ, \& TRACI JAGERS, Department of Medical Neurosciences, WRAIRA targeted percentile schedule presented rats food if the run of left-lever responses on the current trial was closer to $N$ than a specified percentage of recent runs, thereby holding reinforcement probability constant throughout acquisition/maintenance under different values of $N$. Mean run length increased as a power function of $N$ with slope $<1.0$, but with an intercept close to zero than generally obtained under more traditional differentiation procedures (e.g., fixed-consecutive-number).

(415)

What Is Learned During Conditional Discrimination Training? ROBERT GISINER, NCCOSC RDT\&E Division, Hawaii-A bottlenose dolphin was trained in a two-choice conditional discrimination task. Tests with novel stimulus pairs showed that the dolphin had learned only one of the original two pairings and paired any other two stimuli by exclusion. These results are consistent with a similar experiment with sea lions (Schusterman et al., in press). In both experiments, discriminations based on set relationships (familiar vs. novel) preceded learning of specific stimulus pairs.

Nonassociative Sensitization of Associative Fear Conditioning Following US Preexposure. JOSEPH P. DECOLA \& MICHAEL S. FANSELOW, $U C L A$-Inflated conditional responding is obtained when a more intense US is presented prior or subsequent to CS-US pairing. The present experiments demonstrate enhanced one-trial contextual conditioning following a series of same intensity USs presented in a different context. This enhancement is not obtained when conditioning precedes US exposure. This effect is not due to generalization between the two contexts since it is observed independent of the current fear level in the preexposure context.

\section{(417)}

Effects of Nonreward in a Serial-Maze Task. W. SCOTT TERRY, University of North Carolina at Charlotte-In a serial-alternation task, rats received exposures to one arm of three T-mazes, and were then rewarded for choosing the opposite arm in each. Nonreward in a single maze enhanced retention of the maze (1) nonrewarded in the first, but not second, serial position, (2) nonrewarded later in the daily sequence of trials, and (3) following the nonrewarded maze. These findings are relevant to both rehearsal and proactive interference accounts of serial memory.

\section{(418)}

Effect of Sample-Comparison Mapping Arrangement on Pigeons' Coding of Temporal Samples. DOUGLAS S. GRANT \& MARCIA L. SPETCH, University of Alberta (presented by Marcia L. Spetch)-In choice-matching tasks with temporal samples, pigeons tend to choose the comparison associated with the shorter sample as delay increases (choose-short effect). This effect was eliminated with a many-to-one (MTO) mapping arrangement in which two sets of samples were associated with a single set of comparisons. We conclude that the chooseshort effect occurs when temporal samples are coded analogically, and that MTO procedures can produce nonanalogical coding of temporal samples.

Evidence for Common Coding of Temporal and Nontemporal Samples in Pigeons. DOUGLAS S. GRANT \& MARCIA L. SPETCH, University of Alberta-Temporal samples (two durations of houselight) and nontemporal samples (two line orientations) were followed by either the same (many-to-one group) or different (one-to-one group) sets of comparisons. One pair of samples was subsequently associated with a new set of comparisons. Only the many-to-one group demonstrated transfer when the alternate pair of samples was tested with the new set of comparisons, revealing common coding of the temporal and nontemporal samples.

(420)

Stimulus Intensity Effects on Perception and Memory for Event Duration. PHILIPP J. KRAEMER \& CHRISTOPHER K. RANDALL, 
University of Kentucky-The influence of stimulus intensity on temporal perception and memory was tested in pigeons. Birds were trained to discriminate short and long durations of two stimuli of different intensities. The point of subjective equality lengthened, and forgetting of a long duration was more rapid and more severe with the less intense stimulus. Implications of these findings for timing, temporal perception, and duration memory will be discussed.

$$
\text { (421) }
$$

Effects of Quality of Motivation and Task Difficulty on Persistence. KENNETH B. MELVIN \& LAURA N. BAYNHAM, University of Alabama-In Martin's Quality of Motivation Questionnaire (QMQ), a key variable is the net difference (ND) score, which assesses the balance of positive and negative motivation. Martin asserts that persons with high positive ND scores will show superior performance on demanding tasks. Using the top and bottom one-third ND scores, 109 subjects were randomly assigned to 4-, 5-, and 6-letter anagram groups. Relatively more high-ND subjects stayed to finish the most difficult task. (422)

Relationship Between Gender and Knowledge of State Names and Locations. HOLLY R. STRAUB \& BRENT E. SEATON, University of South Dakota-Gender differences in college students' knowledge of U.S. state names and locations were assessed in two experiments. In Experiment 1, males correctly identified more state outlines on a blank map than females did. In Experiment 2, no gender differences were found in ability to recall state names. It is suggested that superior male use of visuospatial cues is largely responsible for gender differences in geographical knowledge. Implications of geographical knowledge deficits are also discussed.

(423)

External Source Monitoring and Reality Monitoring in LearningDisabled Children. TOM LORSBACH \& ROSEANNE EWING, University of Nebraska at Omaha-Lorsbach, Melendez, and Caroll-Maher (1991) found that LD children were deficient on tasks measuring internal source monitoring (Say-Think condition) and reality monitoring (Say-Listen condition). The present investigation further studies the source monitoring abilities of LD children by examining external source monitoring (Listen-Listen condition) and another form of reality monitoring (Think-Listen condition). LD children were deficient in both forms of source monitoring. These results suggest LD children possess a general deficit in source monitoring ability.

$$
\text { (424) }
$$

ANXiety/FAVorability Longitudinally Assessed Via the Adjective Generation Technique (AGT). BEM P. ALLEN, Western Illinois University-Anxiety (ANX) and favorability (FAV) (self-esteem) of unlikely college attenders (UCAs) and college freshmen (CFs) were assessed via the AGT. Words generated weekly for six weeks were scored from the FAV/ANX list of 2,200 values. Although the UCA program emphasized self-esteem, UCAs showed a linear decline in FAV relative to fluctuating FAV for the CFs. The CFs displayed a greater elevation of ANX than UCAs when they faced finals and the UCAs faced a talent show.

\section{(425)}

Accuracy and Bias in Judgments of Others' Opinions. SUSAN R. FUSSELL, Princeton University-Previous studies found accuracy and bias in people's estimates of others' knowledge. In this experiment, subjects estimated the distributions of undergraduates' opinions about public figures. As a group, subjects were rather accurate at estimating the means and shapes of the distributions; however, individual subjects' judgments were biased toward their own opinions. The results suggest that assessing attitudinal aspects of others' perspectives may be as problematic as assessing their information content. Implications for communication are discussed.

Children's Inferences About Ambiguous Events: The Effects of Foregrounding and Multiple Clues. MARK A. CASTEEL, Pennsylvania State University, York Campus-Both second- and fourth-graders read neutral, near-, or far-biasing stories. Each story contained two clues that suggested alternative causes of an ambiguous event. One clue sup- ported the contextual information while the other was neutral, and clue order was manipulated. While previous research has found few effects based on text structure variables, both the type of foregrounding context and the clue position were shown to be important. Implications of the results are discussed.

(427)

The Effect of Injury Description Explicitness on Perception of Wife-Battering. RICHARD JACKSON HARRIS \& MAUREEN C. PIERCE, Kansas State University - In a social cognition study, subjects read one of eight versions of a newspaper report of a wife-battering incident and completed a series of ratings about the two protagonists and the incident. A more explicit description of injuries ("bleeding profusely") led subjects to evaluate the incident more seriously. This factor also interacted with race of the assailant and whether the woman had provoked the man. Effects on memory representations of media reports of crimes were considered.

(428)

Conversational Hand Gestures: Perceived Gestural Meaning and Gestural Velocity. PALMER MORREL-SAMUELS, EDS Cenier for Advanced Research, \& ROBERT KRAUSS, Columbia UniversityPrevious work suggests conversational gestures are poorly remembered and convey little novel content. This study shows that ratings of gestural meaning (GM) are reliable; GM is more related to tone-of-voice (TOV) than semantic content (SC); low-velocity gestures convey sadness; and GM is predicted by velocity, duration, and ratings of TOV, SC, and the narrator's general topic. Results suggest GM is not entirely redundant with SC, and that perceptions of GM derive from diverse sources during conversation.

Semantic Priming During Language Processing: Several Failures to Replicate. ELLEN R. STOLTZFUS, LYNN HASHER, Duke University, \& ROSE T. ZACKS, Michigan State University (presented by Lynn Hasher)-Several studies are reported, all of which use procedures and materials from highly cited studies which measure priming for semantic associates or word properties during sentence processing. Each study failed to replicate data reported in the literature. The results are discussed in terms of possible factors which may influence "automatic" activation during language processing tasks.

(430)

Effects of Verb Type on Production of Passive Sentences. FERNANDA FERREIRA, Michigan State University-In three experiments, I examined the circumstances under which speakers produce a passive sentence. Subjects formulated a sentence using a verb and two nouns presented on a computer screen. Passives occurred about a third of the time with theme-experiencer verbs such as "frighten" and only about $5 \%$ of the time with experiencer-theme verbs such as "resent." I argue that speakers attempt to place entities high on a thematic hierarchy (Grimshaw, 1990) early in their sentences.

(431)

Syntactic Guidance in Sentence Processing. BEVERLY COLWELL ADAMS, CHARLES E. CLIFTON, JR., University of Massachusetts, \& DON C. MITCHELL, University of Exeter-Eye movements were monitored in sentences that contained a transitive or intransitive verb followed by a noun phrase (e.g., After the dog struggled/scratched (,) the kindly old veterinarian took off the muzzle). Previous results suggested that the noun phrase was taken as the object of both transitive and intransitive verbs when a comma was absent. The present study explored this effect further, examining the consequence of the position of the head noun within the noun phrase.

(432)

Verb-Usage Knowledge in Sentence Comprehension. SUSAN M. GARNSEY \& MELANIE LOTOCKY, University of Illinois at UrbanaChampaign-When a sentence is ambiguous, knowledge about how particular words occurring in the sentence are most typically used can help constrain interpretation. Typical-usage information for a set of verbs was obtained from a norming study, and usage preferences were then manipulated for sentences in an eye-tracking study. The results show that typical-usage information is used immediately by readers to limit 
their initial interpretation of sentences containing temporary attachment ambiguities.

Are Form-Relatives of Semantic Associates Activated? PADRAIG G. O'SEAGHDHA \& JOSEPH W. MARIN, Lehigh University-We examine a specific pattern of mediated activation-from sheep through goat to goal in naming experiments. Semantic priming ("sheep"-"goat") is facilitatory. Form-related priming ("goat"-"goal") tends to be inhibitory unless the prime is masked. We find little evidence of mediated semantic-phonological priming ("sheep"-"goal") whether "sheep" is masked or not. We discuss implications for interactive activation and other models of lexical governance in comprehension and production.

\section{(434)}

Do Alternate Words Block Retrieval in Tip-of-the-Tongue States? NUSHA ASKARI, University of San Francisco, \& DEBORAH BURKE, Pomona College -In two experiments, subjects were asked to produce a low-frequency word corresponding to a definition. On some trials, the definition was followed by an alternate word semantically related, phonologically related, or unrelated to the target. Phonologically related alternate words reduced the frequency of tip-of-the-tongue (TOT) states and increased correct responses. These results are consistent with deficits in transmission of priming causing TOTs, but not with blocking accounts of TOTs.

Does Language Figure in Numerical Fact Retrieval? JYOTSNA VAID, Texas A\&M University, CHERYL FRENCK-MESTRE, Université de Provence, \& STEVE BALFOUR, Texas A\&M University-Two experiments with fluent bilingual adults compared verification latencies to true solutions versus associatively related (e.g., $2 \times 5=7 ; 2+5=$ 10) or unrelated solutions for problems presented in digit format, or in $\mathrm{L} 1$ or L2. The results reveal a first language advantage for verification of true solutions and larger associate confusion effects for $\mathrm{L} 1$ than for $\mathrm{L} 2$ words. The findings suggest that automatic activation of arithmetic facts is tied to the language in which they were acquired and predominantly used.

\section{(436)}

The Influence of Prosodic Structure on Processing Temporary Syntactic Ambiguity. SHARI R. SPEER \& MARGARET KJELGAARD BERNSTEIN, Northeastern University-Subjects listened to sentences with early closure [NP V NP] [NP VP] and late closure [NP V] [NP VP] syntactic structures in three prosodic conditions: cooperating prosody, conflicting prosody, and baseline prosody (established by pretesting). Speeded acceptability judgments show a processing advantage for late closure syntax in the conflicting and baseline conditions, but no differences in the cooperating condition. We argue that prosodic information can prevent the syntactic "garden-pathing" that produces increased processing difficulty for early closure sentences during reading.

$$
\text { (437) }
$$

Syllable Priming in Auditory Word Recognition. MARTHA W. BURTON, Pennsylvania State University-This study investigated auditory priming for pairs of words and nonword stimuli in which initial or final syllable information overlapped. The results for both word and nonword conditions showed significant priming for pairs with overlap of final syllables, but no significant priming for pairs with overlap of initial syllables. The implications of these findings for models of auditory word recognition will be discussed.

A Model for Conceptual Processing of Naturalistic Scenes. AURA HANNA, NASA-Ames Research Center, \& GEOFFREY LOFTUS, University of Washington-Is processing fundamentally different for lists of pictures versus lists of words? To answer this question, we measured scene recognition as a function of scene serial position. Serial position curves were basically flat, in contrast to U-shaped verbal curves, suggesting qualitatively different visual versus linguistic processing. The findings can be accounted for by a serial processing model whose main parameter is the probability that the subject switches attention from one scene to the next.

The Structure of the Other Race Effect. ALICE J. O'TOOLE, University of Texas at Dallas, KENNETH A. DEFFENBACHER, Univer- sity of Nebraska at Omaha, DOMINIQUE VALENTIN, \& HERVÉ ABDI, University of Texas at Dallas-Caucasian observers contributed scores on four recognition performance and six facial characteristic variables for 80 Caucasian and 80 Japanese faces. A principal components analysis (PCA) on the variables showed a similar qualitative pattern for same- and other-race faces. The PCA showed separate performance and rating subspaces. A measure of distinctiveness extracted from an autoassociative memory trained with pictorially coded faces was more strongly related to performance for Caucasian faces than were any of the facial ratings.

Role of Attention in Face Encoding. MARK TIPPENS REINITZ, JOE MORRISSEY, \& JON DEMB, Boston University-Subjects studied faces in a full or a divided attention condition, and then received a recognition test which included previously studied faces ("old faces") and new faces constructed by recombining features from previously studied faces ("conjunction faces"). The divided attention group made many fewer hits for old faces than did full-attention subjects; however, the groups made equal false alarms for conjunction faces. This indicates that features, but not associations between features, are automatically encoded.

\section{(441)}

Features or Rules? Replicating and Extending Visual Stimulus Set Generalization. J. TERRELL TUTEN, Culver-Stockton College, JAMES J. JENKINS, University of South Florida, \& TERRI FIESELMAN, Culver-Stockton College-Concept attainment/categorical perception theories may be divided into two broad approaches: feature-based and rule-based. Palmer (personal communication) suggested an empirical contrast between the predictions derived from "feature-theoretico models" and mathematical group theory. A $4 \times 4$ permutation group of pictures (cf. Shaw, Wilson, \& Wellman, 1986) and incidental yes-no recognition were used. Patterns of false positive responding to target and belonging pictures were compared. Results failed to support featurebased predictions, yet supported rule-based predictions.

$$
\text { (442) }
$$

Holistic Face Recognition and Experience. JAMES TANAKA, ELIZA GRINNELL, JOSHUA KAY, \& BRENT STANSFIELD, Oberlin College - Tanaka and Farah (1991) found that faces were recognized as whole objects (i.e., holistically) whereas other stimuli were recognized as constituent parts. What role does experience play in the development of holistic face recognition? This question was addressed in two studies by testing holistic face recognition in children and crossracial recognition in adults. Results from both studies suggest that holistic recognition is a fundamental aspect of face recognition processes, independent of experience.

\section{(443)}

Repetition Priming in Dual Lexical Decision and Categorization. VINZENZ MORGER, University of Chicago (sponsored by Howard Nusbaum)-Repetition priming was investigated with dual lexical decision and categorization tasks. Some word pairs were presented under either task at both study and test. Other word pairs were seen only at test. Lexical decision times at test were equally primed by both study tasks. Categorization times at test were primed strongly by prior categorization, but only low production frequency category exemplars were primed by prior lexical decision. These results support procedural rather than activational accounts.

\section{(444)}

Repetition Effects With Categorizable Stimulus and Response Sets. KATHRYN C. CAMPBELL \& ROBERT W. PROCTOR, Purdue University-Five experiments are reported that examine the contribution of both stimulus and response factors in producing the repetition effect. Experiment 1 determined that categorizable stimuli were necessary to obtain a response repetition effect. In the remaining experiments, it was determined that responses on trial $n-1$ and trial $n$ must share relative spatial location, effector, or both for any repetition effect to be obtained. The results are interpreted as consistent with a salient-features coding principle.

(445)

The Role of Meaning and Word Form in Repetition Priming. J. VIVIEN BAINBRIDGE, University of Oklahoma-Previous studies 
have shown that when a word is placed in context, meaning becomes an important aspect of repetition priming. These studies do not specify the relative importance of repetition of meaning versus repetition of lexical form. Two experiments, using synonyms and hyponyms, show that the repetition of meaning alone is insufficient to produce priming; a third, using derivatives, where both meaning and form are similar, not only fails to show priming, but in fact shows inhibition.

Between-Language Phonological Priming in Bilinguals. LYNNE BOILY \& JAMES M. CLARK, University of Winnipeg (presented by James M. Clark)-Between-language phonological priming of fragment completion was studied using 72 similar-sounding English-French word pairs. During initial translation, subjects generated 24 French words that were subsequent fragments and 24 English words that sounded like subsequent French fragments. Relative to unprimed fragments, completion performance improved for direct French primes but not for English phonological primes. Other measures confirmed subjects' fluency in both languages and word pair similarity. Conditions that produce delayed phonological priming within languages are considered.

(447)

Mechanisms Mediating Repetition Priming in Picture Naming. CAROLYN BACKER CAVE, Vanderbilt University-Although previous results in picture naming were interpreted as reflecting both "visual" and "nonvisual" priming, two experiments suggest that this priming may be mediated by one "visual" mechanism. Experiment 1 demonstrated priming for pictures that were different examples of items named originally (previously termed nonvisual priming), but no priming for names of originally pictured items (nonvisual repetition). Experiment 2 revealed equivalent priming for identical pictures and different pictures across several delays ( 3 min-1 week).

$$
\text { (448) }
$$

Orientation Specificity in Explicit and Implicit Memory. KAVITHA SRINIVAS, Boston College-Rotation of familiar objects in depth produced similar effects on recognition memory and priming (measured on an object/nonobject decision task). On both tasks, latencies to respond to objects presented in different views at study and test were longer than latencies to objects presented in identical views. These results suggest that even in familiar objects, the representations mediating priming and recognition memory are viewpoint-dependent when the views engender changes in the visible parts.

\section{(449)}

Implicit and Explicit Repetition Effects in Picture Naming. TODD C JONES, Rice University, ALAN S. BROWN, \& DAVID B. MTTCHELL, Southern Methodist University (presented by David B. Mitchell)-An effect of multiple repetitions was observed for both implicit and explicit memory using a picture naming paradigm with an on-line recognition task. The RTs for naming multiply presented pictures decreased systematically across tests, whereas RTs for once-repeated and new items did not change. Priming was significantly greater for items repeated three times versus items repeated once. Corrected recognition scores yielded results similar to the implicit measure with respect to multiple repetitions.

Cross-Language Conceptual Priming in English-Spanish Bilinguals. WENDY S. FRANCIS \& ROBERT A. BJORK, UCLA (presented by Robert A. Bjork)-English-Spanish bilinguals were tested using the category-association priming paradigm both within and across languages. Conceptual priming across languages was significant but not as strong as priming within languages. These results support neither the separate-concept model of bilingual language representation nor a strict version of the shared-concept model. Instead, they suggest a multicomponent representation of word meanings, some shared by translation equivalents and some not.

\section{(451)}

Forced Choice Associative Recognition. STEVEN E. CLARK, ALDEN HORI, University of California, Riverside, \& DANIEL E. CALLAN, University of Wisconsin-Global memory models make a clear prediction for forced-choice associative recognition: SAM, MINERVA 2 , and the matrix model predict that recognition performance will be better when intact and rearranged test pairs contain overlapping words (OLAP) than when they do not contain overlapping words (NOLAP). TODAM can produce an OLAP advantage or no difference. Contrary to all of these models, three experiments showed a consistent NOLAP advantage. Mechanisms underlying the NOLAP advantage are explored.

(452)

Contextual Dependencies During Motor Skill Acquisition: Gone but Not Forgotten! DAVID L. WRIGHT, CHARLES H. SHEA, YUHUA LI, \& CHAD WHITACRE, Texas A\&M University-The occurrence of contextual dependencies during motor skill acquisition has recently been attributed to the inclusion of contextual information within the extant task representation. This being true, a dependency would be predicted for both delayed as well as immediate tests. Data indicated that the influence of a contextual shift was reduced as the retention interval increased. However, brief reexposure to the original acquisition context before a delayed test led to a reappearance of the contextual dependency.

Developmental Differences in Source Monitoring and Eyewitness Suggestibility. JENNIFER ACKIL \& MARIA S. ZARAGOZA, Kent State University (presented by Maria S. Zaragoza)-Adult subjects who are exposed to misleading suggestions about an event they have witnessed sometimes come to believe they remember seeing items that were merely suggested to them, an error we refer to as source misattributions. The present study included first-, third-, and fifth-grade participants (and adults) to assess potential age differences in the tendency to commit source misattributions. Although yes/no recognition did not vary with age, source misattribution errors were age related.

(454)

Who, What, When, and Where? Memory Organization of Event Descriptions. HOLLY A. TAYLOR, Texas Christian University, \& BARBARA TVERSKY, Stanford University (presented by Barbara Tversky)-In the first study, subjects read descriptions of events involving several characters at several times, organized either by character or by time. The dependent measures, study time, test statement responses, and diagram organization indicated that memory was organized by character. In the second study, events were grouped meaningfully, and memory organization followed the grouping organization, character or time. In a third study pitting character against place as organizers, subjects organized around place.

The Influence of Study Context (Verbal vs. Pictorial) on Source Attribution Biases. HUNTER HOFFMAN, McMaster University (sponsored by Elizabeth Loftus)-In Experiment 1, subjects studied "read" and "self-generated" words. At test, when they falsely recognized a new item, they showed a bias to respond "read" (i.e., external source). In Experiment 2, subjects saw photos of some objects and generated mental images of others. At test, for false recognitions they showed a strong bias to respond "self-generated" (i.e., internal source). The context (verbal vs. pictorial study list) in which the false memory was embedded largely determined which bias subjects displayed.

\section{(456)}

Retroactive Interference in Matching Recognition: The Role of Accessible Competitors. C. C. CHANDLER, Washington State University - When is memory for an event impaired by related events? Names were presented and followed by related names (experimental items) or by unrelated names (control items). The original first and last names were then provided for matching. Accuracy for control items exceeded that for experimental items at short retention intervals. At longer intervals, no interference occurred unless the related names appeared just before the test. Interference may occur only when related events are highly accessible.

Video Violence Affects Recall of Imaginally and Verbally Encoded Stimuli. G. A. SHAW, Georgetown College, D. A. BEKERIAN, MRC Applied Psychology Unit, \& J. A. McCUBBIN, University of KentuckyTo determine whether emotional arousal differentially affects memory for imaginally and verbally encoded stimuli (concrete and abstract words), violent (high-arousal) and bird-nest-building (low-arousal) videos were 
interpolated at five different points in memory experiments. In all conditions, concrete words were recalled at twice the rate of abstract words. Specific placement of violence enhanced second trial recall of imagery information in some conditions and depressed recall of abstract information in most conditions.

\section{(458)}

Is a Suffixed Auditory List Equivalent to a Visual List? DIANE WILLIAMS, Naval Health Research Center-The PAS interpretation of the suffix and modality effects assumes that performance on an auditorily presented list followed by a suffix is the same as performance on a visually presented list. This assumption was tested in a serial digit recall experiment. The results show that performance on the lists is significantly different. This finding suggests that the suffix and modality effects are less related than was assumed by the PAS interpretation of these effects.

\section{(459)}

Artificial Grammars: Can Learning Be Consciously Controlled? DENNY C. LECOMPTE, Louisiana State University-Four experiments explore the extent to which subjects can consciously control the learning of artificial grammars. All four experiments demonstrate that subjects have at least some ability to ignore ungrammatical information when it is interspersed among the letter strings generated by an artificial grammar; however, the evidence from each of these four experiments also indicates that subjects' ability to ignore ungrammatical information is substantially limited. Implications for theories of artificial grammar learning are discussed.

\section{(460)}

Mouthed Recency as a Function of Working Memory Capacity. MARILYN L. TURNER \& F. MARIE SAWYER, Wichita State University-We propose that mouthed recency found in immediate serial recall reflects central rather than peripheral processing. To support this theory, we review results of three experiments in which mouthed (but not auditory) recency and working memory span scores were related. Further, mouthed, but not auditory, recency was dependent on vocabulary size and word relatedness. Conversely, acoustic similarity affected auditory but not mouthed recency, suggesting auditory recency reflects peripheral rather than central processing.

\section{(461)}

The Influence of Circadian Variations on Cognitive Performance. MARILYN LIVOSKY, KAREN J. MITCHELL, Pennsylvania State University, Erie, \& JUDITH A. SUGAR, Colorado State UniversityThe influence of circadian variations on long-term memory was examined. College students were randomly assigned to either a morning or evening testing time and were given a free- and cued-recall test. Subjects then completed a new morningness questionnaire (Smith, Reilly, \& Midkiff, 1989) to assess time-of-day preference. The measurement of circadian preferences in different populations and the effects of such preferences on simple and more complex cognitive tasks are discussed. (462)

Alphabetic Letters and U.S. Presidents: Chunk-Position Effects in Linear Orders. DANIEL B. BERCH \& ANGELA BIRKHEADFLIGHT, University of Cincinnati-Subjects judged either which of two alphabetic letters is closer to " $A$ " (Experiment 1) or which of two named U.S. presidents held office earlier (Experiment 2). Pairs were constructed from 16 items comprising four "chunks." Both errors and RTs were analyzed in order to (1) compare between- and within-chunk pairs, and (2) assess the contribution of chunk position to the distance effect. Implications for positional discriminability and dual-process models will be discussed.

\section{(463)}

Can Bizarre Images Enhance Individual Item Access? VIRGINIA A LANG \& ANTHONY SHIBLOM, Wichita State University-Bizarre image formation has long been advocated as a means of improving access to increasing numbers of individual items, when in fact only relational processing has been improved (e.g., McDaniel \& Einstein, 1986). This set of experiments test whether there are conditions that can increase access to items in bizarre images-namely, the incorporation of subject generated, rather than experimenter generated, stimuli sentences. Preliminary results indicate that bizarre images cannot enhance individual item processing and subsequent free recall.
(464)

To Forget or Not to Forget: The Effect of an Ambiguous Cue on Directed Forgetting. JONATHAN M. GOLDING, KAREN L. ROPER, \& JERRY HAUSELT, University of Kentucky-Two experiments investigated directed forgetting using FORGET, REMEMBER, and AMBIGUOUS (50\% chance of a word appearing on a subsequent memory test) cues. The results found that AMBIGUOUS cues led to intermediate rehearsal and recall (FORGET < AMBIGUOUS < REMEMBER). Also, relative to control groups (no AMBIGUOUS cues), the presence of AMBIGUOUS cues was coupled with decreased memory of the REMEMBER words. Thus, the continued processing of AMBIGUOUs words can attenuate certain aspects of directed forgetting.

(465)

Decision Making Under Uncertainty: Numerical Versus Experiential Presentation of Outcome Probability. IN JAE MYUNG, Ohio State University - In previous studies, probabilistic information has been presented numerically rather than experientially. The present study, using a gambling decision task, included three conditions in which subjects made a choice over two gambles: (1) with explicitly given outcome probabilities, (2) after learning outcome probabilities by observing random events, and (3) while actually playing gambles repeatedly with feedback. Results showed striking differences in choice behavior among conditions, challenging the static decision theoretic explanation.

$$
\text { (466) }
$$

Relevant Dimensional Information Facilitates the Utilization of Configural Information II. STEPHEN E. EDGELL, University of Louisville-Two previously presented experiments, using the paradigm of nonmetric multiple-cue probability learning, found greater utilization for configural information when the relevant pattern contained a relevant dimension than when the relevant dimension was outside the pattern. It was found, in two new experiments, that two relevant dimensions contained in the relevant pattern could be even more facilitating to the utilization of the pattern than only one relevant dimension.

$$
\text { (467) }
$$

Some Cognitive Causes of Framing Effects in Decision Making. JERWEN JOU, Georgia Southern University, JAMES SHANTEAU, \& RICHARD JACKSON HARRIS, Kansas State University-Several experiments adopting the paradigm of the disease problem as used in Tversky and Kahneman's "The framing of decisions and the psychology of choice" (Science, 1981) found that the framing effect could be eliminated by providing some evidential causal link between the gains and the losses resulting from a decision. In addition, subjects tended to be consistently risk-seeking in decisions concerning human life, but risk-averse concerning property.

\section{(468)}

The Effects of Possible Error and Multiple Hypotheses on Scientific Induction. ERIC G. FREEDMAN, Michigan Technological University-The effects of possible error on testing multiple hypotheses was investigated with Wason's 2-4-6 task. Two variables were manipulated: whether or not subjects were informed up to $20 \%$ of the feedback could be erroneous, and whether subjects tested a single or a pair of hypotheses. Possible error impaired induction only when subjects tested a single hypothesis. Error may not impair the evaluation of multiple hypotheses because these subjects generated more experiments and more disconfirmation.

\section{(469)}

Cognitive Aspects of Death Certification. DAVID J. MINGAY, NORC, University of Chicago, ALBERT F. SMITH, SUNY at Binghamton, JAMES A. WEED, \& JARED B. JOBE, National Center for Health Statistics-When completing a death certificate, the physician is required to report the sequence of diseases that caused the patient's death, and other conditions that contributed to it. The task is frequently complex, and the information available to the certifier may be inadequate and/or conflicting. We describe death certification, and discuss whether it is better conceptualized as a classification task or as a problem-solving/ decision-making task.

\section{(470)}

The Effects of Feature Distribution on Estimation. ROBERT GOLDSTONE, Indiana University-Subjects estimated the percentage of items that had a particular feature. Features were either randomly 
distributed, or were spatially clustered such that features of the same type tended to be close. Subjects systematically overestimated the prevalence of features in clustered displays. The pattern of results is best explained by a regional salience bias: Features tend to be more salient if they belong to regions that have a high concentration of instructionmentioned features.

\section{(471)}

Hemispheric Lateralization of Negative Priming in Monolinguals and Bilinguals. MICHAEL S. McCLOSKEY, Villanova University, AMY C. FELIO, SUSAN C. ROSSER, \& EWALD NEUMANN, Middlebury College (presented by Ewald Neumann)-We investigated hemisphere-specific processes in negative priming. Subjects responded to lowercase target words and ignored uppercase distractor words in a prime display followed by a probe display. Slowed lexical decisions to target probe words resulted when they were the previously ignored word. This suppression effect varied over visual fields. A follow-up experiment investigated this hemispheric difference in negative priming using Spanish target probe words in an English-Spanish bilingual population.

Shifting Attention Across the Field Before Making a Directed Reach. ULRIC NEISSER \& M. J. WRAGA, Emory University-To touch a target defined by a fixed offset to one side of a given cue, a subject must shift attention from the cue to the target location. Using a display in which the cue was optically superimposed on one response key and the target was another key to the right (or left) of it, we measured the speed of this shift. With finger travel distance controlled, RT was a linear function of offset distance.

$$
\text { (473) }
$$

Patterns of Activation in Attended and Unattended Objects. WILLIAM P. BANKS, DAN T. KOUWABUNPAT, \& MICHAEL A. CIRANNI, Pomona College-This research used a probe technique to determine the relative degree of allocation of attention to different regions of objects in an array containing line drawings of several simple objects. In attended drawings, probes were detected fastest in areas with highest information content. We tested activation in objects and in background, in unattended objects, and as a function of time after presentation. Implications for attention in picture perception and for the Tipper paradigm are discussed.

On the Nature of Learning in Consistent Search-Detection Tasks. ARTHUR D. FISK, GREGORY M. CORSO, \& KEVIN A. HODGE, Georgia Institute of Technology -We evaluated the extent to which automatic attention attraction and stimulus-set categorization occurred in purememory and pure-visual search. Subjects were trained in either memory or visual search and then transferred to the other search condition (or were not transferred). Subjects trained in pure visual search perfectly transferred to memory search; the opposite was not the case. The implications for generality of strength- and nonstrength-based theories of automaticity are discussed.

Attention and Consciousness. STEVE JOORDENS \& PHILIP M. MERIKLE, University of Waterloo (presented by Philip M. Merikle)Comparable variations in attention and awareness can lead to parallel results. In one study, we found that short and long duration primes led to different patterns of facilitation and interference in a Stroop priming task. In a second study, we obtained similar results when clearly visible stimuli were presented under conditions of focused versus divided attention. These findings suggest that the perception of attended and unattended information is equivalent to perception with and without awareness.

Can Focusing Attention Eliminate Parafoveal Identification Asymmetry? GARVIN CHASTAIN, CHRISTINE CLINE, MICHELLE RUMOLD, \& GREGG BURGESS, Boise State University-In the absence of a precue, identification of a parafoveally appearing target character is more accurate if a nontarget character appears to its foveal rather than peripheral side. In our experiment, the characters followed a targetarea precue after varying delays. The identification asymmetry apparent with 0 -msec delay disappeared with 50-msec delay, although the absence of a significant interaction with target-to-nontarget distance complicates an interpretation involving a narrowing spatial focus of attention.

(477)

Apparent Motion, Attentional Capture, and Inhibitory Attentional Control Settings. CHARLES L. FOLK, Villanova University, \& ROGER W. REMINGTON, NASA-Ames Research Center-In a modified spatial cuing task, apparent motion cues and targets were crossed with color cues and targets (Experiment 1), as well as with abrupt-onset cues and targets (Experiment 2). Attention capture by all cues was found to be contingent on the defining target property, although the effect was asymmetric when motion was paired with onset. The results support the existence of alterable attentional control settings manifested through inhibition of irrelevant properties.

(478)

Interference in Detecting Multiple RSVP Targets: Effects of Similarity. MYUNGWOO M. CHUN \& MARY C. POTTER, MIT (presented by Mary C. Potter)-Detection of a target among distractors in RSVP (rapid serial visual presentation) produces a brief (200-500 $\mathrm{msec}$ ) deficit for reporting a second target when the targets and distractors are similar (letters among digits), but not when they are dissimilar (letters among symbols). Target order is less accurate in the high similarity condition. An additive deficit is obtained for identical targets (repetition blindness). Temporal characteristics of attentional selection and token formation may account for these deficits.

\section{(479)}

The Suppression of Identity and Spatial Location. S. LISA CONNELLY, LYNN HASHER, \& GREGORY A. KIMBLE, Duke University (presented by Gregory A. Kimble)-Younger adults selected and named a target letter on the basis of its color. The target occupied one of four locations on the screen, and a distractor letter occupied one of the other locations. Critical trials were constructed so that identity suppression, location suppression, and a combination of location and identity suppression could be assessed. Younger adults showed a significant suppression effect for both identity and location, and an additive effect of combining location and identity suppression.

(480)

Research Support from the National Science Foundation. JOSEPH YOUNG, FRED STOLLNITZ, \& N. JOHN CASTELLAN, JR., National Science Foundation.

\section{(481)}

Research Support from the Air Force Office of Scientific Research. JOHN F. TANGNEY, Air Force Office of Scientific Research. 
ANIMAL COGNITION II

Rose Garden, Sunday Morning, 8:00-10:10

Chaired by Sara J. Shettleworth, University of Toronto

8:00-8:20 (482)

Single-Trial Analysis of Timing in Pigeons. KEN CHENG, RICHARD WESTWOOD, \& JONATHON D. CRYSTAL, University of Toronto-On single trials, pigeons' response rate on the peak procedure showed a high-rate run phase bracketed by low-rate break phases, and sometimes also a yet higher-rate super-run phase within the run phase. Negative correlations between starts and durations of runs suggest threshold variance, while positive correlations between starts and ends of runs suggest variance in clock speed, switch, or criterion time. Further manipulations found definite positive evidence for variance in criterion time. 8:25-8:40 (483)

Cross Modal Transfer Between Grouping Cue Modalities in Rat Serial Learning. STEVEN J. HAGGBLOOM, Arkansas State University-Rats use grouping cues, for example, a change in the temporal distribution of trials or runway brightness, to partition a long series of reinforcement events into smaller units. In three experiments, rats trained with a grouping cue in one modality were tested with grouping cues in untrained modalities. Correct responding survived cross modal changes in grouping cues indicating that for rats, like humans, grouping cues functional independently of the items they serve to organize.

\section{8:45-9:05 (484)}

Are Differential Outcome Effects Mediated by Differential Sample Behaviors? PETER J. URCUIOLI \& THOMAS DEMARSE, Purdue University-We examined whether or not sample stimuli associated with food versus no-food outcomes in pigeons' matching-to-sample would be interchangeable with other stimuli generating peck versus no-peck response patterns similar to those seen to the samples. Transfer of matching across stimuli (i.e., interchangeability) was observed in two experiments. These results indicate that differential sample behaviors may mediate some differential outcome effects.

\section{9:10-9:25 (485)}

Factors Influencing Object Investigation in Rats: A Cumulative Analysis. MICHAEL J. RENNER, West Chester University, DOUGLAS B. MATTHEWS, Miami University, \& PETER J. PIERRE, Memphis State University-A large database (704 sessions from 354 LongEvans rats) was studied to discover the factors that control object investigation. Objects varied on multiple dimensions. Object characteristics accounted for only moderate amounts of variance: In the best case, multiple regression on Intensity Index yielded $r^{2}=.449$ using object mass, stability and familiarity, and subject age. Object familiarity was correlated with number of bouts and total contact time, but not bout length or number of different behaviors employed in investigation. Implications for studying spontaneous learning are discussed.

$$
\text { 9:30-9:45 (486) }
$$

Nonreward and Reward in Nonverbal Transitive Inference. CLIVE D. L. WYNNE, Duke University-On a nonverbal transitive inference task, five stimuli are presented in four overlapping pairs $(A+B-, B+C-$, $\mathrm{C}+\mathrm{D}-$, and $\mathrm{D}+\mathrm{E}-$, where + signifies reward and - nonreward). Choice of B on BD tests shows transitivity. Successful performance by animals and humans can be modeled by assuming that stimuli have distinct values, which are incremented by reward and decremented by nonreward. Tests of the model on different training series will be presented. 9:50-10:05 (487)

Same/Different Discrimination Learning in Pigeons. ROBERT G. COOK, KIMBERLY FULBRIGHT, \& BRIAN R. CAVOTO, Tufts University-Using a new variation of a $2 \mathrm{AFC}$ conditional discrimination task, six pigeons learned to simultaneously discriminate the presence and absence of color or shape differences in computer-presented textured stimuli. They subsequently showed positive transfer to both intra- and extradimensional novel test displays. Further tests indicated that attention to dimensional, global, and local differences in the displays influenced this perceptual same/different discrimination. Implications for avian and primate pattern recognition will be discussed.

\section{LANGUAGE/DISCOURSE PROCESSING I}

St. Louis Ballroom B, Sunday Morning, 8:00-10:25

\author{
Chaired by Richard Jackson Harris, Kansas State University
}

\section{8:00-8:15 (488)}

Task Effects on the Activation and Incorporation of Elaborative Inferences. PAUL WHITNEY, DOUGLAS A. WARING, \& DESIREÉ HEWITT, Washington State University-We used a priming procedure to test whether a reader's comprehension task, such as factual or inferential questions, affects the activation of dispositional inferences and instantiations. We compared these results with data obtained from recognition and reading time paradigms. We found variations in inference activation by task, and dissociations between priming results and the incorporation measures. The data support a multi-stage view of elaboration in social and nonsocial cognition.

\section{8:20-8:35 (489)}

Causal and Associative Constraints in the Generation of Bridging Inferences. PAUL VAN DEN BROEK, KIRSTEN RISDEN, \& ELISABETH HUSEBYE, University of Minnesota-In two experiments, we investigated the role of causal and associative constraints in the generation of "bridging" inferences during reading. The generation of target inferences in a completion task depended on causal but not associative constraints. Availability of inferences in a lexical decision task immediately after reading $(500 \mathrm{msec})$ was determined by both constraint types. Thus, causal factors influence inference generation both after a delay and during initial stages of activation. Associative factors only affect early activation.

\section{8:40-8:55 (490)}

Integration of Inference-Validating Knowledge and Text Representation. MICHAEL HALLDORSON \& MURRAY SINGER, University of Manitoba (read by Murray Singer)-According to the validation model, inferential bridging of the sentences Al stepped on the banana peel, He fell down requires that the bridge be validated against world knowledge. This study assessed whether the validating knowledge is integrated with the text representation. Consistent with this hypothesis, text outcomes, such as Al fell down, primed the validating fact, Banana peels are slippery, after people read causal sequences but not after control temporal sequences.

\section{9:00-9:15 (491)}

Metaphoric Comparisons are Fundamentally Directional. DEANNA MANFREDI, SAM GLUCKSBERG, \& MATTHEW S. MCGLONE, Princeton University (read by Sam Glucksberg)-Feature-matching models of metaphor comprehension fail to capture the fundamental asymmetry of metaphors. Observed asymmetries of metaphors have been attributed to simple order preferences. We show that while order preferences may account for asymmetries in literal comparisons, the asymmetry of metaphorical comparisons is substantive. Reversed metaphors are either anomalous, or they evoke entirely new interpretations. These results support a property attribution rather than a feature-matching model of metaphor comprehension.

\section{9:20-9:35 (492)}

The Interference Between Literal Meanings and Figurative Referents. CRISTINA CACCIARI, University of Bologna, \& SAM GLUCKSBERG, Princeton University-Gibbs and O'Brien (1990) claimed that people associate conventional images to idioms on the basis of underlying conceptual metaphors. Problem: Can people inhibit or ignore the concrete action denoted by most idiomatic strings while producing a mental image of a string's idiomatic meaning? The potential interference between these two levels of meaning of an idiomatic stringliteral-concrete and idiomatic-abstract-was investigated in two experiments using a mental-image production task and a sentence verification task.

\section{9:40-10:00 (493)}

Working Memory Constraints on the Maintenance of Multiple Interpretations of Lexical Ambiguities. AKIRA MIYAKE, MARCEL ADAM JUST, \& PATRICIA A. CARPENTER, Carnegie-Mellon University (read by Marcel Adam Just)-We present a model of how working 
memory capacity constrains the process of resolving lexical ambiguities in the absence of preceding contextual cues. The results from two reading time experiments showed that (1) readers with a larger working memory capacity can maintain the multiple interpretations of a homograph longer than lower-capacity readers and that (2) a longer neutral phrase intervening between the homograph and the disambiguation selectively interfered with the maintenance of subordinate interpretations. 10:05-10:20 (494)

Gross Improvements in Texts' Memory Representation With Minimal Misconception-Driven Revisions. BRUCE K. BRITTON, University of Georgia, \& PAMELA TIDWELL, Mercer University-Adding a single phrase to a 1,000-word textbook passage significantly changed $3 \%$ to $25 \%$ of the text's mental representation of the average Air Force recruit in three experiments with three different phrases. Adding the phrase to a more coherent version of the text had twice the effect on the mental representation of adding the same phrase to the original (less coherent) version of the text. Revision effects spread locally and remotely, along interesting lines of force.

\section{VISION}

St. Louis Ballroom C, Sunday Morning, 8:00-10:25

Chaired by Arnold E. Stoper, California State University, Hayward

\section{8:00-8:15 (495)}

The McCollough Effect Reveals Orientation Discrimination in a Case of Cortical Blindness. MELVYN A. GOODALE, University of Western Ontario, SALVATORE AGLIOTI, University of Verona, G. KEITH HUMPHREY, University of Western Ontario, \& RICK GURNSEY, Concordia University-We describe a patient with profound damage to cortical visual pathways who cannot discriminate even simple differences in orientation using grating stimuli. After McCollough adaptation, however, the patient experiences the orientation-contingent color aftereffect with these same gratings. These results, together with our earlier report of a similar case (Psychological Science, 1991, Vol. 2, pp. 331-335), will be discussed in relation to the possible brain mechanisms mediating the McCollough effect.

\section{8:20-8:30 (496)}

Word Contingency in the Motion Aftereffect. GLENN E. MEYER \& SHERRON M. STONECYPHER, Lewis and Clark College-The level of stimulus selectivity in visual phenomena such as the McCollough and other contingent aftereffects is controversial. Motion, orientation, color, and spatial frequency effects are known. Recently, wordspecific McCollough effects have been reported. We have attempted to apply the same contingency to the motion aftereffect. Directions of motion were paired with several words. Care was taken to avoid confounds of retinal or spatial specificity. Unfortunately, little evidence was found for word-contingent motion aftereffects.

$$
\text { 8:35-8:50 (497) }
$$

The Anchoring Rule for Minimal Conditions of Lightness Perception. ALAN L. GILCHRIST \& FREDERICK BONATO, Rutgers University, Newark Campus-For disk/annulus stimuli (Wallach, 1948) specific lightness percepts require an anchoring rule as well as the ratio principle. The annulus always appears white (when brighter than the disk), but is this based on its intensity (photometric rule) or on its surroundingness (geometric rule)? Perception of disks surrounded by less intense annuli and ganzfelds shows that (1) the geometric rule governs and (2) the disk/ganzfeld configuration is more fundamental than the disk/annulus.

\section{8:55-9:05 (498)}

Accommodation and the Blind Spot. DENNIS H. HOLDING \& JEFFREY H. SCHMIDT, University of Louisville-In accordance with the zoom-lens explanation for the moon illusion and micropsia, there is evidence that the projected size of the blind spot may be inversely related to depth of accommodation. Because this would contravene the standard optical model, it was tested by presenting acuity demands to 6 practiced observers at 3,6, and $12 \mathrm{~m}$ and mapping the blind spot. As predicted, both size and locus were negatively correlated with optometric focal distances.

\section{9:10-9:20 (499)}

Simultaneous Selection of Multiple Locations: Further Evidence for FINST Theory. JACQUELYN A. BURKELL \& ZENON PYLYSHYN, University of Western Ontario (read by Zenon Pylyshyn)-FINST theory (Pylyshyn, 1989) suggests that observers can simultaneously index a number of visual features, maintaining those indices in parallel over time and over movement of the features. The current research investigates the processing that can be performed selectively over indexed locations in a display. Results from a conjunction search task and a numerosity judgment task suggest that, after an initial cost associated with selecting relevant items (or inhibiting irrelevant items), observers treat the indexed items as if they were the only items in the display.

\section{9:25-9:40 (500)}

Global Precedence in the Spatial Frequency Domain. HOWARD C HUGHES, GEORGE NOZAWA, Dartmouth College, FRED KITTERLE, University of Toledo, \& PATRICIA A. REUTER-LORENZ, University of Michigan-Global configurations often dominate the processing of local details. Similarly, low spatial frequencies often appear to dominate the processing of high-frequency cues. We extend these observations by examining the dissipation of low-frequency dominance over time (via manipulations of SOA) and by exploring the time course for the availability of high- and low-frequency information in a redundant target paradigm. The results are compared with simulations of inhibitory interactions between transient and sustained detectors.

\section{9:45-10:00 (501)}

Does Transsaccadic Information Integration Involve Object Files? JOHN M. HENDERSON, Michigan State University-Pollatsek, Rayner, and Henderson (1990) found that transsaccadic preview benefits were not dependent on maintaining spatial location or object frame from preview to target. More recently, Kahneman, Treisman, and Gibbs (1992) found that preview benefits were observed primarily when targets remained tied to their review location and/or object frame. New research examining transsaccadic integration will be reported, providing further evidence that robust preview benefits are observed across saccades despite changes in location and object frame.

\section{0:05-10:20 (502)}

Inhibition of Return: Effects of Attentional Cueing on Eye Movement Latencies. RICHARD S. DOBKIN \& RICHARD A. ABRAMS, Washington University (read by Richard A. Abrams)-Inhibition of return refers to a bias against attending to visual stimuli at recently attended locations. In several experiments, we studied the effects of this phenomenon on the latency to initiate saccadic eye movements. Antisaccades (saccades in the direction opposite to a signal) were less affected by the attentional manipulation than were prosaccades. We also compared saccades to recently attended or unattended locations that were signaled by either central or peripheral stimuli.

\section{JUDGMENT/DECISION MAKING II} St. Louis Ballroom D, Sunday Morning, 8:00-10:30

\section{Chaired by James Shanteau, Kansas State University}

\section{8:00-8:15 (503)}

Varieties of Subjective Probability. ROBERT S. LOCKHART, University of Toronto-Two distinctions are used to identify different forms of subjective probability. The first distinguishes subjective probabilities that are acquired through repeated exposure to outcomes from those acquired as facts or derived rationally. The former type of subjective probability might be termed procedural or implicit, the latter declarative or explicit. The second distinction is between subjective probabilities construed as propensities versus relative frequencies. Experimental results are described that document the value of these distinctions. 8:20-8:35 (504)

Aggregate Judgment Under Uncertainty: Weighting by Graininess and Discounting of Opinions. ILAN YANIV, University of Chicago-People often poll the opinions of knowledgeable individuals before making major decisions (e.g., surgery, investment). Opinions are frequently uncertain and/or incompatible. Our studies and computer simulations suggest that (1) in forming aggregate opinions, people weight 
judgments by their graininess (interval width) and discount outlying opinions and (2) a weighting and trimming scheme is relatively accurate. These results are related to the view that judgment under uncertainty involves a tradeoff between accuracy and informativeness.

\section{8:40-9:00 (505)}

A Conflict Model of Confidence. ELKE WEBER, University of Chicago, \& ULF BÖCKENHOLT, University of Illinois at UrbanaChampaign-Confidence by physicians that a list of hypotheses generated about a clinical case contained the correct diagnosis was a function of the degree of conflict between alternative hypotheses. Confidence was highest when doctors strongly believed in only one hypothesis and lowest when they entertained two strong competing hypotheses. Availability of a diagnosis (by having previously diagnosed a similar case) did not increase confidence. Overall confidence first increased and then decreased with years of clinical practice.

$$
\text { 9:05-9:20 (506) }
$$

Defining and Teaching Objectively Accurate Confidence Judgments. GEORGE SPERLING \& HAI-JUNG WU, New York University-High confidence is equivalent to being willing to accept risky bets with high stakes; low confidence is equivalent to accepting only conservative bets with low stakes. Betting principles can be applied to define arbitrary confidence intervals. We trained subjects to make objectively accurate confidence judgments (using experimenter-defined intervals) by giving the subjects feedback about outcomes. Recommendation: Experiments that record confidence judgments should incorporate this feedback procedure to assess and insure the fidelity of the judgments.

$$
\text { 9:25-9:45 (507) }
$$

Cross-National Variation in Probability Judgment. J. FRANK YATES, University of Michigan, JU-WHEI LEE, Chung Yuan Christian University, Taiwan, \& HIROMI SHINOTSUKA, Hokkaido University, Japan-People's probability judgments that they have correctly answered general knowledge questions are typically too high. Such apparent overconfidence is almost always stronger in some countries than in others, for example, in China as compared with the U.S. The present research evaluated the hypothesis that such differences are due to crossnational variation in dominant cognitive strategies, such as spontaneously considering both the pros and cons of the available options.

\section{9:50-10:05 (508)}

Group Decision Making: Analysis of the Ideal Group. ROBERT D. SORKIN \& HUANPING DAI, University of Florida-Group decision making was modeled using multichannel signal detection theory. The optimum decision statistic is $\sum_{i=1}^{m} a_{i} x_{i}$, where $m$ is the group size, $x_{i}$ is the member's observation, and $a_{i}$ is a decision weight dependent on the member's detectability, $d^{\prime}{ }_{i}$. Group $d^{\prime}$ depends on $m, d^{\prime}{ }_{i}$, and the correlation between members' observation. Inaccurate knowledge of $d^{\prime}$ can yield nonoptimal weights. Juries and other groups may acquire information about $x_{i}$ and $d^{\prime}{ }_{i}$ through deliberation.

$$
\text { 10:10-10:25 (509) }
$$

Judgments of Film Quality Based on Critics' Comments and Personal Viewing Experience. IRWIN P. LEVIN, GARY J. GAETH, CHIFEI JUANG, \& S. V. BALACHANDER, University of Iowa-Subjects viewed a sample film clip and/or read critics' comments about a movie. Although self-reports indicated that a sample clip was more important than critics' comments, evaluations were more heavily influenced by critics' comments than by the film clip. An averaging model with greater weight for the more recent information described how film clip and critics' comments were combined. Outside sources appear to have directive influence on the way we reevaluate ambiguous information.

\section{COGNITION I}

Promenade C, Sunday Morning, 8:00-11:10

\section{Chaired by Lyie E. Bourne, Jr., University of Colorado}

8:00-8:15 (510)

An Experimental Assessment of the Fluid/Crystallized Intelligence Distinction. BJÖRN B. LEVIDOW \& EARL HUNT, University of Washington (read by Earl Hunt)-Horn and Cattell have proposed that intelligence has two varieties: fluid intelligence (Gf), related to learning ability, and crystallized intelligence $(\mathrm{Gc})$, related to what a person has learned. Previous evidence has been based on correlational analyses of test performance. We report a field experiment. High school physics students were administered Gf and Gc tests. Different portions of their postinstruction performance were predictable from the $\mathrm{Gf}$ and Gc measures.

\section{8:20-8:40 (511)}

A Cognitive Approach to Creativity. STEVEN M. SMITH, THOMAS B. WARD, \& RONALD A. FINKE, Texas A\&M University-Creative thinking can be understood by studying underlying $\operatorname{cog}$ nitive processes, such as memory, attention, mental imagery, conceptualization, transfer and mapping of prior knowledge, rule-based thinking, and metacognition. The goal of this creative cognition approach is not necessarily to describe a determined path to successful creativity, but to understand what patterns of thinking are likely to produce creative ideas, discoveries, and products. Some new research paradigms we have developed to study creative cognition will be discussed.

\section{8:45-9:00 (512)}

Time-Accuracy Functions: A Psychophysics Approach to Cognition. REINHOLD KLIEGL, ULRICH MAYR, \& RALF TH. KRAMPE, MPI for Human Development and Education, Berlin (sponsored by Richard K. Olson)-With a paradigm yielding complete (presentation-) time-accuracy functions for individuals (i.e., psychometric functions), differences in processing time needed for equal accuracy were determined for experimental manipulations of episodic and working memory in young and old adults. Data of each individual were fit to negative exponentials. Criterion-referenced presentation times increased with task complexity; age differences increased stronger than predicted by models of general slowing. Relations to speed-accuracy tradeoff and performance-resource functions are discussed.

\section{9:05-9:20 (513)}

Creativity in the Eyes of the Creator and the Beholder. RITA E. ANDERSON, Memorial University of Newfoundland, LISA M. DILLON, University of British Columbia, \& TORE HELSTRUP, University of Bergen-After mentally generating a novel pattern from three simple shapes with or without external support, subjects briefly described and then drew the pattern. After several trials, subjects rated the correspondence between each pattern and its description and made a creativity judgment, as did three external condition-blind judges. Discussion focuses on the implications of the patterns of agreement between the creators and the beholders for research on creative discovery.

\section{9:25-9:40 (514)}

Time Estimation and Expectancies. MARILYN BOLTZ, Haverford College-Effects of expectancies upon time estimation behavior were examined by manipulating subjects' expected amount of activity in an experimental task. All subjects engaged in a musical perception task that occurred over a series of trials. After receiving one block of 36 trials, subjects were told that they were either (1) one half, (2) one third, or (3) two thirds of the way through the experiment. They were then presented with a second block of 36 trials which therefore either confirmed $(1)$ or violated $(2,3)$ their expected amount of activity. Retrospective time judgments revealed that expectancy confirmation led to accurate duration estimates. However, those subjects receiving more (fewer) trials than expected not only judged the second block of trials to be relatively longer (shorter) than the first, but also over/underestimated the total duration of the experimental session. Results are discussed in terms of an expectancy/contrast model of judged duration.

$$
\text { 9:45-10:00 (515) }
$$

Where Does "Off the Top of Your Head" Come From? BRADLEY D. MCDOWELL \& GREGG C. ODEN, University of Iowa (read by Gregg C. Oden)-Ratings can provide a rich source of information about perceptual objects and events. Nevertheless, some (e.g., McClelland, 1991) have wondered whether the access we have to the contents of our minds might somehow be unconnected from the underlying cognitive processes of interest. Previous work on this issue has been reassuring, but has left room for the determined skeptic. We have tried to reduce this room by devising an even more strenuous test. 


\section{0:05-10:25 (516)}

Verbal Overshadowing: The Disruptive Effects of Verbalization on Non-Verbal Thought. JONATHAN W. SCHOOLER, University of Pittsburgh-Although language may often provide a critical scaffolding for human thought, recent findings suggest that verbalization can interfere with nonverbal cognition. This paper will review the disruptive effects of verbalization in a variety of domains, including memory, decision making, and problem solving. It is suggested that verbalization may overemphasize reportable processes and may thereby overshadow critical nonverbal processes associated with perceptual memory, automaticity, and spreading activation.

\section{0:30-10:40 (517)}

Frames of Reference Used in Accessing Spatial Knowledge. M. JEANNE SHOLL, Boston College-Previous research has shown that people typically access knowledge of their spatial environments by imaging themselves within the space and locating landmarks within a body-centered frame of reference (Sholl, JEP:LMC, 1987). In this experiment, people were asked to imagine an environment from an external, aerial perspective and to locate landmarks using an object-centered reference frame. The results suggest body-centered access characterizes the retrieval of spatial information from representations of navigated environments.

10:45-11:05 (518)

Measures of Object Location Knowledge in the Blind. LYN HABER \& RALPH NORMAN HABER, University of Illinois at Chicago-The location of an object could be indicated by recognition (you would know it when you got there), egocentrically, by relation to other objects, or by external coordinates independent of the observer's position. Blind subjects used all four levels of indicators when describing object locations. These indicators must differ in their underlying representation, because choice of indicator correlated with performance in knowing the locations of objects, and with travel skill, spatial knowledge, and familiarity with the scene.

\section{ATTENTION $v$}

Promenade D, Sunday Morning, 8:00-10:50

Chaired by Michael Perone, West Virginia University

8:00-8:15 (519)

Dividing Attention Among Multiple Attributes of a Single Object. JOHN PALMER \& BRITT ANDERSON, University of WashingtonMany refined measurements have been made of divided attention across objects. These measurements usually have involved a single attribute of multiple objects. In the current experiments, similar measurements were made of divided attention across multiple attributes of a single object. These measurements were made for both memory and search tasks. The results were similar to those for dividing attention across objects, which disconfirmed the predictions of purely object-based and locationbased theories of attention.

8:20-8:35 (520)

Stimulus-Driven Attentional Capture. STEVEN YANTIS \& ANNE P. HILLSTROM, Johns Hopkins University-It is commonly but incorrectly assumed that a featural singleton (e.g., a red element among multiple green elements) will capture attention automatically. Accumulated evidence suggests instead that featural singletons rarely capture attention unless the target of search is defined as a singleton. We argue that purely stimulus-driven attentional capture occurs only when a new perceptual object appears. New evidence from apparent motion corroborates this claim and helps define "perceptual object." 8:40-9:00 (521)

Divided Attention to Visual and Auditory Stimuli. ERVIN R. HAFTER \& ANNE-MARIE BONNEL, University of California, Berkeley (read by Anne-Marie Bonnel) (sponsored by Ervin R. Hafter)Studies of simultaneous attention to pairs of visual stimuli show that detection of a change in luminance is governed by "automatic" processing while identification of the direction of change is "highly controlled." This is done by using instructions to direct attention unevenly to the two stimuli. The importance of central processing in the "simul- taneous task" was tested here by using one auditory and one visual stimulus. The results are much the same, with identification requiring more attention than detection.

\section{9:05-9:20 (522)}

Perceived Workload in Cognitive Vigilance Tasks. JOEL $S$. WARM, WILLIAM N. DEMBER, W. TODD NELSON, PAULA L. GRUBB, University of Cincinnati, \& D. ROY DAVIES, University of Aston-Consistent with earlier results, performance on a cognitive vigilance task declined over time when simple discriminations were involved while it remained stable at a high level of efficiency when more complex discriminations were required. The perceived overall workload (NASA Task Load Index) of the two types of tasks was similar, but subjects found the simple task to be more frustrating. The results support an account of task differences in terms of intrinsic motivation. 9:25-9:45 (523)

Attention to Form and Surface Properties of Objects: Semantic Interference on Form Information. M. BOUCART, Université Paris V, \& G. HUMPHREYS, University of Birmingham (sponsored by $G$. Humphreys)-A series of experiments is reported testing whether either physical properties of form (shape, size, orientation) or of surface (color, luminance, texture) of objects can be attended without object identification taking place. Object identification was inferred if effects of semantic relations were observed on form- or surface-based matching. Semantic effects on performance were found when subjects attended to form, but not when they attended to surface information. The results are discussed in terms of the separate processing of form and surface information, based on physiological, experimental, and neuropsychological data.

\section{9:50-10:05 (524)}

Semantic Priming Can Lead to Selective Attention. VERONICA J. DARK \& KARL G. VOCHATZER, Iowa State University-Pairs of masked 100-msec targets were preceded at 1,000- and 250-msec SOAs by consonant strings, primes unrelated to either target, or primes related to just one of the targets. Subjects successfully reported both targets on less than $10 \%$ of the trials, most often following related primes. At both SOAs, correct report of single targets occurred most often for targets related to the preceding prime, suggesting that selective attention was the result of semantic priming.

\section{0:10-10:25 (525)}

Guided Search 2.0: A Revised Model of Visual Search. JEREMY M. WOLFE, Harvard Medical School-The guided search model shows how serial deployment of attention can be guided by top-down and bottom-up parallel processing of features such as color, orientation, and so forth. The original version (Wolfe et al., 1989) was silent or incorrect about blank trials, search asymmetries, RT variances, and so forth. Guided Search 2.0 is an upgrade dealing with these issues. With fixed parameters, the revised model simulates a wide range of search behavior (e.g., conjunction, feature, and odd-man-out searches.)

\section{0:30-10:45 (526)}

Overlapping Mental Operations in Serial Performance With Preview. HAROLD PASHLER, University of Califormia, San DiegoDual-task studies have revealed stubborn attentional limitations preventing parallel response selection. More common outside the laboratory, however, is serial performance, in which people do the same task over and over. In five serial-RT experiments, various task difficulty factors were manipulated along with stimulus preview. The results indicate that the response-selection bottleneck limits serial performance (just as it limits dual-task performance). One implication is that the bottleneck is not caused by the need to switch task set.

\section{ANIMAL COGNITION III}

Rose Garden, Sunday Morning, 10:20-12:55

\section{Chaired by Stewart H. Hulse, Johns Hopkins University}

10:20-10:40 (527)

Do Food-Storing Birds Remember Different Things From NonStorers? DAVID R. BRODBECK \& SARA J. SHETTLEWORTH, University of Toronto (read by Sara J. Shettleworth)-In delayed matching 
with trial-unique spatial and local cues to food location in an aviary, black-capped chickadees (food-storers) relied primarily on spatial cues but also remembered local cues. Dark-eyed juncos (nonstorers) used spatial and local cues equally. Possible reasons for this species difference in use of redundant relevant cues were tested using (1) reference memory for food locations in an aviary and (2) delayed matching in an operant touch-screen analogue of the aviary task.

\section{0:45-11:05 (528)}

Performance of Seed-Caching Corvids During Color Nonmatching. ALAN C. KAMIL, DEBORAH J. OLSON, University of Nebraska, \& RUSSELL P. BALDA, Northern Arizona University-Clark's nutcrackers perform better than scrub jays on three spatial memory tasks: cache recovery, radial maze and spatial nonmatching-to-sample. In this experiment, nutcrackers, scrub jays, pinyon jays, and gray-breasted jays were tested in color nonmatching-to-sample by titration of delay. The species did not differ during the first 1,000 trials (data collection is continuing), implying that seed-caching-correlated species differences in memory among corvids are limited to spatial memory.

$$
\text { 11:10-11:30 (529) }
$$

"Chunking" vs. "Blueprinting" by Rats in the Radial Arm Maze. J. S. COHEN, University of Windsor, \& M. ESKRITT, Queen's University -The present experiment determined whether rats would learn to "chunk" a 16-arm maze on the basis of four different visual and tactual arm cues, each associated with a different type of food. Rats either had each type of arm paired with each food type in a constant or random configuration (two separate groups) or experienced food types unpaired with arm cues also presented in a constant or random configuration (two separate groups).

$$
\text { 11:35-11:50 (530) }
$$

A Comparison of Working and Reference Memory Performance in the Radial-Arm Maze. MICHAEL F. BROWN \& PATRICIA A. RISH, Villanova University-In a procedure introduced by Olton and Pappas (1979), rats were trained in a 12-arm radial maze in which only 8 maze arms were baited prior to each trial. Because the identity of the unbaited arms remained constant over trials, the task required both reference memory and working memory. Detailed measures of choice behavior were used to compare the extent to which choices were guided to baited arms by spatially organized representations in working and reference memory.

\section{1:55-12:05 (531)}

Preliminary Studies of Spatial Memory in Captive African Elephants. ROBERT H. I. DALE, Butler University, DAVID A. HAGAN, Indianapolis Zoo, \& MELISSA R. SHYAN, Butler University-Five female African elephants were tested on spatial memory tasks. Initial tests involved two unbaited pots, two initially baited pots with food replacement between choices, then two baited pots without food replacement. Later tests involved four baited pots without food replacement. On the two-pot tests, there were wide variations in performance. With four pots, the subjects exceeded "chance" choice accuracy by the second block of five trials. Error and response patterns were assessed.

$$
\text { 12:10-12:30 (532) }
$$

Dead Reckoning and the Cognitive Map: Vestibular Inputs to Spatial Navigation. NANCY L. DALLAL \& WARREN H. MECK, Columbia University (read by Warren H. Meck)-Radial-arm maze experiments with vestibularly lesioned rats provide choice selection data consistent with dead reckoning theories of spatial mapping. In particular, the hypothesis that disruption of egocentric orientation by vestibular damage should interfere with the rat's ability to form and/or use an abstract representation of space is supported. Functional recovery of normal navigational strategies and spatial memory efficacy based on the multisensory nature of egocentric orientation can be demonstrated only if lesions are produced in early development prior to eye opening.

$$
\text { 12:35-12:50 (533) }
$$

Periodic Searching in a Temporally Random Environment. HILARY A. BROADBENT \& RUSSELL M. CHURCH, Brown University (read by Russell M. Church)-Animals' tendency to search periodically in random environments was studied by presenting rats with RI 60 and RI 120 schedules. Response-time power spectra revealed a 30 -sec periodicity for all animals regardless of condition. Overall re- sponse rates, however, were doubled in the denser schedule. A model is proposed in which search periodicity is driven by an internal oscillator with a limited range of entrainment, and search duration depends on a threshold controlled by reinforcement density.

\section{LANGUAGE/DISCOURSE PROCESSING II}

St. Louis Ballroom B, Sunday Morning, 10:35-12:55

\section{Chaired by Randi C. Martin, Rice University}

\section{0:35-10:55 (534)}

Explanatory Inferences During Comprehension: Encoding Effects on Story Recall. TOM TRABASSO, SOYOUNG SUH, PAULA PAYTON, \& RACHNA JAIN, University of Chicago-Subjects talked aloud while reading story sentences one at a time. Protocol analysis revealed four working memory operations: maintaining, explaining, retrieving, or elaborating. Maintenance, retrieval, and explanation co-occurred and were negatively correlated with elaboration and predicted recall by college students and 9-year-olds. Individual differences in explanation across stories accounted for recall. Implications of using talk-aloud methods for studying mental operations, encoding and retrieval effects, and individual differences in working memory are discussed.

11:00-11:15 (535)

A Model for the Serial Recall of Verse. DAVID C. RUBIN, Duke University - In recalling oral traditions, poetry, and songs, people start at the beginning of a piece cued by a general knowledge of the theme, rhyme/alliterative scheme, and metrical structure. The specific metrical structure is the same for all verses and is available from the start. Specific themes and rhymes, however, must be reached to cue remaining words, so meaning and rhyme function locally, making summaries and nonserial recalls difficult. Empirical support is provided.

\section{1:20-11:35 (536)}

Topic Knowledge and Verbal Knowledge in Writing. RONALD T. KELLOGG, University of Missouri, Rolla-The ability of a writer to plan, compose, and edit a text presumably depends at least in part on verbal knowledge and domain-specific topic knowledge. The present research examined measures of text quality as a function of these two forms of knowledge as indexed by scores on the ACT English subtest and Voss, Vesonder, and Spilich's (1980) baseball knowledge quiz. Narrative and persuasive writing assignments on the topic of baseball yielded different functional relationships.

11:40-11:55 (537)

Pronominalization and Discourse Coherence, Discourse Structure, and Pronoun Interpretation. PETER C. GORDON, Harvard University-Results from reading time experiments are reported showing that pronominalization interacts with the structural relations between utterances to promote local discourse coherence. However, pronominalization also reduces the linguistic form of a referring expression in a way that lessens the information available for identifying an expression's referent. Discourse structure appears to guide the initial interpretation of syntactically ambiguous pronouns, though their final interpretation is determined by what is semantically sensible.

12:00-12:10 (538)

Memory for the Far Side. STEPHEN R. SCHMIDT \& ALAN R. WILLIAMS, Middle Tennessee State University-To separate the effects of incongruity and humor on memory, three versions of Far Side cartoons were created: original cartoons (incongruous-humorous), bizarre cartoons (incongruous-not humorous), and literal translations (not incongruous-not humorous). In incidental memory, original versions were remembered better than bizarre versions, which were remembered better than literal versions. Incongruity did enhance memory, but resolving the incongruity in a cartoon led to the perception of humor and further improvement in memory.

12:15-12:30 (539)

Frames of Reference in Vision and Language: Where is Above? LAURA A. CARLSON RADVANSKY \& DAVID E. IRWIN, University of Illinois (read by David E. Irwin)-Spatial terms must be interpreted with respect to some reference frame. Perceptual cues for verticality were varied to investigate whether "above" is based on a viewer- 
centered, an environment-centered, or an object-centered reference frame. An environment-centered frame dominated use of "above," but object-centered frames contributed as well. The meaning of "above" appears not to specify a particular reference frame; rather, selection of a reference frame during spatial assignment determines its use.

$$
\text { 12:35-12:50 (540) }
$$

Differences in Comprehension as a Function of Text and Feedback. PHILIP LANGER, VERNE KEENAN, \& JASON BERGMAN, University of Colorado-Subjects were presented sentence by sentence a spatial or linear route description of the town. As was provided by either (1) limited access to a map, (2) limited opportunities to review previously scanned sentences, or (3) presentation of the entire text after completion. Subjects then reread the sentences without assistance. In terms of levels of memorial representation there were no differences in number of propositions recalled or distinguishing original sentences from paraphrases. However, feedback differentially affected inferential reasoning.

\section{HUMAN LEARNING/MEMORY $V$}

St. Louis Ballroom C, Sunday Morning, 10:35-1:05

\section{Chaired by James J. Jenkins, University of South Florida}

\section{0:35-10:50 (541)}

Time Course Studies of Reality Monitoring and Recognition. MAR CIA K. JOHNSON, Princeton University, JOHN KOUNIOS, Tufts University, \& JOHN A. REEDER, Princeton University-Subjects judged whether probe words corresponded to pictures that previously had been seen, had been imagined, or were new. We used a speed-accuracy tradeoff (SAT) technique to assess accuracy at different delays after test probes were presented. Differences in SAT functions for old-new recognition and for discriminating perceived from imagined events (reality monitoring) are discussed in terms of differences in the information implicated in such source attributions.

$$
\text { 10:55-11:10 (542) }
$$

Effects of Confabulation on Later Recall. HENRY L. ROEDIGER, III, Rice University, BRADFORD H. CHALLIS, University of Toronto, \& MARK A. WHEELER, Rice University-Subjects were forced to guess during recall of a studied set of pictures. Relative to a free recall group, guessing did not aid recall on an immediate test and impaired recall on a delayed test. On the delayed test, these forced-recall subjects often generated list words but failed to recognize them. Also, they often believed their previously generated guesses to be members of the list. Subjects' own erroneous responses constitute a potent source of interference.

\section{1:15-11:30 (543)}

Delayed Judgments of Learning: When They Do/Don't Increase the Accuracy of Metacognitive Monitoring and Evidence of Their Importance for Learning. THOMAS O. NELSON \& JOHN DUNLOSKY, University of Washington-A delayed judgment of learning can yield greater accuracy for predicting eventual recall than can a judgment made immediately after studying the item. Evidence is presented to show how this delayed-JOL effect is critically modulated by the cue used for the judgment (namely, stimulus-alone cue versus stimulusresponse cue). Additional data demonstrate that the utilization of delayed JOLs in allocating subsequent study time can affect both the efficiency of learning and the level of learning attained.

$$
\text { 11:35-11:50 (544) }
$$

The Relation Between Consistency and Accuracy of Eyewitness Testimony. RONALD P. FISHER \& BRIAN L. CUTLER, Florida International University-The conventional legal belief is that inconsistency of an eyewitness's report is an indicator of inaccuracy. The present study examined empirically this intuitively reasonable, but as yet untested, belief. Following a staged theft, eyewitnesses described the "thief' on two occasions and also tried to identify him in a lineup. Consistency of report was a surprisingly weak predictor of both report accuracy and identification accuracy. Implications for juror instructions and psychological research are discussed.

11:55-12:10 (545)

The Associative Nature of Serial Order Memory. JAMES S. NAIRNE \& MATT SERRA, Purdue University-Most attempts to dem- onstrate the associative nature of serial order memory have employed transfer designs, without much success. In our experiments, subjects reconstructed the order of short lists and were either cued or not with a subset of item-position information. In contrast to position accounts, or the part-set cuing literature, item-position cuing had a substantial positive effect on overall order retention. These results support the role of item-to-item associations in serial order memory.

$$
\text { 12:15-12:35 (546) }
$$

Free Recall Latency and Search-Based Models of Retrieval. JOHN T. WIXTED \& DOUG ROHRER, University of California, San DiegoAlthough free recall is not an instantaneous process, relatively few investigations of its time course have ever been performed. Of those, none have examined how average latency to free recall is affected by standard variables (e.g., list length) or how this measure relates to the vastly more popular dependent variable, probability of recall. Our research suggests that dynamic, time-based measures offer a unique and largely unexplored window into the nature of retrieval.

$$
\text { 12:40-1:00 (547) }
$$

Hypermnesia as Determined by Initial Recall Levels and Encoding Conditions. DAVID G. PAYNE, JEFFREY S. ANASTASI, MICHAEL J. WENGER, \& BRIAN BURRELL, SUNY at Binghamton-Data from numerous published and unpublished hypermnesia experiments employing a variety of study materials and encoding conditions were analyzed to determine whether the magnitude of the hypermnesic effect is related to initial performance levels as Madigan and O'Hara (1992, Journal of Experimental Psychology: Leaming, Memory, \& Cognition) suggested. Results were analyzed at the level of both individual subjects and treatment groups. Results will be discussed in terms of their implications for theoretical accounts of hypermnesia and memory dynamics in general.

\section{JUDGMENT/DECISION MAKING III St. Louis Ballroom D, Sunday Morning, 10:40-12:55}

\section{Chaired by Elke Weber, University of Chicago}

\section{0:40-11:00 (548)}

Is Choice the Correct Primitive? R. DUNCAN LUCE, University of California, Irvine, BARBARA A. MELLERS, \& SHI-JIE CHANG, University of California, Berkeley-Choices among gambles are treated as derived from certainty equivalents (CE). Assume CEs are described by Luce's (1992) rank- and sign-dependent theory; a theory of reference levels (RL) is axiomatized; and each gamble in a choice set is recast in terms of deviations from the RL and reevaluated. The choice is based on these CEs. The model admits well-known anomalies, and is applied with some success to data of Mellers, Chang, Birnbaum, and Ordóñez (1992).

\section{1:05-11:25 (549)}

Selective Processing Effects and Theories of Choice. VALERIE F. REYNA, University of Arizona-Theories generally assume that choices depend on the psychophysics of quantities (e.g., sums of money), an assumption that is violated by selective processing effects. When subjects selectively processed relevant quantities, the usual phenomena of choice (e.g., reflection effects) disappeared. However, when the zerooutcome complement of gambles was selectively processed, choice phenomena were augmented. Results ruled out ambiguity, and favored an intuitive account of choice.

$$
\text { 11:30-11:50 (550) }
$$

The "Position Effect" in Resource Dilemmas. DAVID V. BUDESCU, University of Haifa, AMNON RAPOPORT, University of Arizona, \& RAMZI SULEIMAN, University of Haifa-We report results of several resource dilemma experiments combining features of the simultaneous and the sequential protocols. Play is conducted sequentially, but players are not given information regarding the previous requests. Strategically, this protocol is equivalent to a simultaneous one, yet empirical results indicate the existence of the "position" effect characterizing sequential games: Players' requests correlate with their positions. The effect is replicated with $n=2,3,5$ players and when the resource size varies randomly 
11:55-12:10 (551)

Effects of Information and Instructions to Disconfirm on Hypothesis Testing. HUGH GARAVAN \& MICHAEL E. DOHERTY, Bowling Green State University (read by Michael E. Doherty)-Science students attempted to discover the laws of a computer-based "artificial universe" in which moving particles are deflected by invisible boundaries surrounding geometric figures. Instructions (disconfirm vs. test hypotheses) and stage of knowledge (early vs. advanced, manipulated by providing subjects in the advanced group with the results of prior observations) were crossed in a $2 \times 2$ design. Unexpectedly, disconfirmation instructions hindered performance, while knowledge had no impact. The expected interaction did not materialize.

\section{2:15-12:30 (552)}

Human Contingency Judgments: Reanalysis. LORRAINE ALLAN, McMaster University-Normative models view humans as intuitive statisticians who base contingency judgments on a rule integrating information from the $2 \times 2$ matrix. Allan and Jenkins (1983) conducted an extensive rule analysis of their data. It will be shown that associative models, developed to describe animal conditioning, can account for the data reported by Allan and Jenkins. This reanalysis is consistent with recent studies indicating that human contingency judgments can be explained using associative learning principles.

$$
\text { 12:35-12:50 (553) }
$$

Probability Matching in Probabilistic Mental Models. NIGEL HARVEY \& RICHARD RAWLES, University College, London-People answered almanac questions, judged confidence in their answers, and estimated difficulty of questions for peers. An item's difficulty is the proportion of subjects answering it correctly. Simulations showed the distribution of item difficulties (and other aspects of the results) could not be explained by Gigerenzer et al.'s probabilistic mental model theory without the following modification: The alternative with the higher cue validity must be selected-not always, but with a probability equaling its validity.

\section{PSYCHOPHYSICS}

Promenade C, Sunday Morning, 11:20-12:50

\section{Chaired by Marilyn Boltz, Haverford College}

\section{1:20-11:30 (554)}

Early Vision: Dichotomous or Continuous? JOCHEN BRAUN, California Institute of Technology, \& BELA JULESZ, Rutgers University (read by Bela Julesz)-We studied texture segregation at various orientation differences $\left(\Delta \phi=15-90^{\circ}\right)$ and presentation times (SOA $=$ $270-36 \mathrm{msec}$ ). Discriminability was held to $0.4<\mathrm{d}^{\prime}<2.5$. For $\Delta \phi=90^{\circ}$, discriminability is reportedly the same with focal attention free and encumbered (Braun \& Sagi, 1990). Using a concurrent letter search, which we know engages attention, we extended this result down to $\Delta \phi=15^{\circ}$. Thus, texture segregation appears not to require focal attention, strengthening dichotomous models of early vision.

$$
\text { 11:35-11:55 (555) }
$$

Fechner's Ideal Observer Theory. STEPHEN LINK, McMaster University-Fechner's 1860 extension of the Gaussian theory of error to the process of mental comparison became the basis for much experimental psychology during the 19th and 20th centuries. Somehow, the theory was forgotten by psychologists but redeveloped by engineers in 1950 as ideal observer theory. This paper presents Fechner's original theory, recognized long ago as the basis for scientific psychology, and the extension of Fechner's ideas to wave theory.

$$
\text { 12:00-12:20 (556) }
$$

Efficiency and Observer Noise for Discriminations in Noisy Image Backgrounds. RICHARD G. SWENSSON, PHILIP F. JUDY, \& RICHARD NAWFEL, Brigham and Women's Hospital and Harvard Medical School-Observers performed forced-choice, confidence-rating tasks to discriminate differences in contrast between disks superimposed on gray-scale backgrounds of uncorrelated noise. Discrimination efficiency (relative to an ideal observer) decreased (from $60 \%$ to $5 \%$ ) as the disk size increased. The fraction of random, nonreproducible decision variability (intra-observer "noise"), estimated from replicated judgments of identical image-noise stimuli, increased only from $25 \%$ to $50 \%$ with disk size. Substantial inefficiencies were attributable to systematic observer "miscalculations" of the image information.

$$
\text { 12:25-12:45 (557) }
$$

A Random Sampling Model of Visual Information Acquisition. GEOFFREY LOFTUS, THOMAS BUSEY, University of Washington, \& JOHN SENDERS, University of Maine-When observers must remember briefly presented four-digit arrays, proportion correct is a perfect exponential function of array exposure duration. A simple randomsampling model describes both this result and data from a more complex task in which arrays are presented twice with an intervening 250 msec gap. Two aspects of visual perception (phenomenological appearance and information extraction) are shown to be determined by corresponding aspects (shape and area under) of a single hypothetical function.

\section{COGNITION II}

Promenade D, Sunday Morning, 11:00-1:05

Chaired by Joseph Young, National Science Foundation

11:00-11:20 (558)

Language and the Origin of Mathematical Abilities: U.S./China Comparisons. KEVIN F. MILLER, University of Illinois-When children learn to count, they must figure out the rules of a particular system of number names at the same time that they develop basic mathematical concepts. A model of the effects of language on early mathematical development will be described and used to explain the nature and timing of differences in the mathematical competence of preschoolers in China and the U.S.

\section{1:25-11:35 (559)}

Interference Effects of Mixing Arithmetic Operations is Not Due to Uncertainty. JAMIE CAMPBELL \& ALAN MAJER, University of Saskatchewan-When simple addition and multiplication problems are mixed within a block of trials retrieval performance is reduced relative to pure blocks of addition or multiplication. To determine if this effect is due to uncertainty of operation in mixed blocks, the pure-block vs. mixed-block manipulation was crossed factorially with operationcued vs. operation-not-cued. RTs and cross-operation errors were higher in mixed blocks and cuing the operation did not eliminate these effects. 11:40-11:55 (560)

"A-Half" and "One-Have": Not the Same Meaning. ROCHEL GELMAN, UCLA-Since beginning school-aged children think that numbers are "what you get when you count things," they should misinterpret the representations of fractions they encounter in school. Our prediction that subjects in kindergarten through grades 2 or 3 would treat these representations as opportunities to apply their whole number theory was supported in several studies. Training efforts offer clues about the move toward a mathematical understanding of fractions, in particular, and a theory change, in general.

\section{2:00-12:20 (561)}

Cross-Operation Transfer of Mental Arithmetic Skill. TIMOTHY C. RICKARD \& LYLE E. BOURNE, JR., University of Colorado (read by Lyle E. Bourne, Jr.)-The results of two acquisition/transfer experiments indicate that practice on simple mental multiplication and division problems strengthens problem representations corresponding to three unique realizations of each practiced number relation (e.g., 6, 9, 54) within the multiplication/division domain. Data are not entirely consistent with representational formats assumed within either McCloskey's Abstract-Modular theory (MATHnet) or Campbell's Encoding-Complex (network-interference) approach. Implications for alternative connectionist models are presented.

$$
\text { 12:25-12:40 (562) }
$$

Component Skills and Problem Solving: Acquisition Context and Transfer Demands. RICHARD A. CARLSON \& JACQUELINE C. YOON, Pennsylvania State University-Fluent routine problem solving involves coordinating sequences of component skills arranged in hierarchical goal structures. In these experiments, subjects practiced Boolean algebra operations, then applied them in problem-solving transfer tasks. Stepwise trace of problem-solving latency showed that acquisition conditions interacted with transfer task demands in several ways. 
Results suggest that individuals achieve problem-solving fluency by coordinating initiation of controlled but ballistic memory retrievals to allow temporal overlap of cascaded problem-solving steps.

\section{2:45-1:00 (563)}

Why Can't My Students Understand Conditional Probability? CATHERINE G. PENNEY, Memorial University of Newfoundland-
University students were given three pieces of information in a conditional probability problem involving a two-by-two classification. The given information was either the probabilities of three intersections, or two conditional probabilities and a marginal probability. Subjects were asked to provide the remaining intersection probabilities, conditional probabilities, and marginal probabilities. The results elucidate some of the difficulties students have in understanding conditional probability. 